$$
\text { DR. 22.37 }
$$

\title{
THE MEASUREMENT AND MODELLING OF POSTIRRADIATION FISSION PRODUCT RELEASE FROM HTGR FUEL PARTICLES UNDER ACCIDENT CONDITIONS
}

by

B. F. MYERS and R. E. MORRISSEY

Prepared under

Contract EY-76-C-03-0167

Project Agreement No. 65

for the San Francisco Operations Office

Department of Energy

\section{GENERAL ATOMIC COMPANY}




\section{NOTICE}

This report was prepared as an account of work sponsored by the United States Government. Neither the United States nor the Department of Energy, nor any of their employees, nor any of their contractors, subcontractors, or their employees, makes any warranty, express or implied, or assumes any legal liability or responsibility for the accuracy, completeness or usefulness of any information, apparatus, product or process disclosed, or represents that its use would not infringe privately owned rights.

Printed in the United States of America Available from

National Technical Information Service

U. S. Department of Commerce 5285 Port Royal Road

Springfield, Virginia 22161

Price: Printed Copy $\$ 8.00$; Microfiche $\$ 3.00$ 


\section{DISCLAIMER}

This report was prepared as an account of work sponsored by an agency of the United States Government. Neither the United States Government nor any agency Thereof, nor any of their employees, makes any warranty, express or implied, or assumes any legal liability or responsibility for the accuracy, completeness, or usefulness of any information, apparatus, product, or process disclosed, or represents that its use would not infringe privately owned rights. Reference herein to any specific commercial product, process, or service by trade name, trademark, manufacturer, or otherwise does not necessarily constitute or imply its endorsement, recommendation, or favoring by the United States Government or any agency thereof. The views and opinions of authors expressed herein do not necessarily state or reflect those of the United States Government or any agency thereof. 


\section{DISCLAIMER}

Portions of this document may be illegible in electronic image products. Images are produced from the best available original document. 


\section{THE MEASUREMENT AND MODELLING OF POSTIRRADIATION FISSION PRODUCT RELEASE FROM HTGR FUEL PARTICLES UNDER ACCIDENT CONDITIONS}

by

B. F. MYERS and R. E. MORRISSEY

Prepared under

Contract EY-76-C-03-0167

Project Agreement No. 65

for the San Francisco Operations Office

Department of Energy

\section{GENERAL ATOMIC COMPANY}




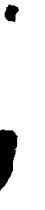

$\bullet$ 


\section{FOREWORD}

This report is submitted in compliance with milestone $H$ in subtask 1 , Core Material Redistribution, which is funded under the HTGR Safety Research Task of the HTGR Generic Technology Program, Project Agreement No. 65, 189a No. 00790, of the DOE Gas-Cooled Reactor Safety Program. 
•

• 


\section{ABSTRACT}

A study was performed to provide a description of the release of fission products from failed fuel particles during a core heatup event in an HTGR. The need for this study was established in the Accident Initiation and Progression Analysis program.

The release of fission products was measured from laser-failed BISO $\mathrm{ThO}_{2}$, TRISO $\mathrm{UC}_{2}$, and weak acid resin (WAR) particles over a range of burnups. The burnups were $0.25,1.4$ and $15.7 \%$ FIMA for $\mathrm{ThO}_{2}$ particles, 23.5 and $74 \%$ FIMA for $\mathrm{UC}_{2}$ particles, and 60\% FIMA for WAR particles. The fission products measured were nuclides of xenon, iodine, krypton, tellurium, and cesium.

Two types of experiments were performed: isothermal and temperature rise experiments. The range of the temperatures was from $1200^{\circ}$ to $2300^{\circ} \mathrm{C}$. In the temperature rise experiments, the heating rates were between $50^{\circ}$ and $450^{\circ} \mathrm{C} / \mathrm{h}$.

The isothermal experiments provided a basis for developing a release model and the temperature rise experiments provided a test for the model in describing the release in a core heatup event.

The central feature of the developed release model is a fractional release function which describes the release as a function of time, temperature, and burnup. This function was formulated as semiempirical but, for specific conditions, was shown to be equivalent to a corresponding function derivable from a diffusion equation which accounts for trapping.

In the release model, the fission product population is divided into rapidly released and slowly released subpopulations. For the conditions 
of a core heatup event, the rapidly released subpopulation accounts for almost all the release.

The releases predicted with the model and the observed releases were in agreement. In the case of xenon and krypton nuclides, the predicted and observed releases differed by less than $18 \%$, well within the associated uncertainties. Iodine and tellurium nuclides were found to behave like xenon nuclides except in a few instances.

A physical interpretation of the release model was made. This provided an understanding of the dominant mechanisms governing release in a core heatup event. It also strengthened the credibility of the model by relating the model parameters to physical events and to literature values of physical quantities commensurate with the parameter values.

The application of the experimental data and model to the calculation of fission product release during a core heatup event is discussed. 
CONTENTS

FOREWORD . . . . . . . . . . . . . . . . . . . . . . . . . iii

ABSTRACT . . . . . . . . . . . . . . . . . . . . . . v v

1. INTRODUCTION . . . . . . . . . . . . . . . . . . . 1-1

References ....................... . 1-5

2. EXPERIMENTAL PROCEDURE AND APPARATUS . . . . . . . . . . . . . . 2-1

2.1. Failed Fuel Particles . . . . . . . . . . . . . . 2-1

2.2. Reirradiation of Fuel Particles . . . . . . . . . . . . . 2-2

2.3. Heating of the Reirradiated Failed Fuel Particles . . . . 2-3

2.3.1. Experimental Apparatus ... . . . . . . . . 2-3

2.3.2. Heating Experiments . . . . . . . . . . 2-8

2.4. Analysis of Fuel Particles and Collectors for Fission

Products . . . . . . . . . . . . . . . . 2-11

References . . . . . . . . . . . . . . . . . . 2-12

3. DESCRIPTION OF MATERIALS USED . . . . . . . . . . . . . . 3-1

References . . . . . . . . . . . . . . . . . . 3-1

4. EXPERIMENTAL RESULTS . . . . . . . . . . . . . . . . 4-1

4.1. Relative Release Behavior of Xenon and Iodine . . . . . . 4-2

4.2. Isothermal and Temperature Rise Experiments . . . . . . . 4-9

4.2.1. Isothermal Experiments . . . . . . . . . . 4-9

4.2.2. Temperature Rise Experiments......... . 4-24

References . . . . . . . . . . . . . . . 4-34

5. DEVELOPMENT OF A MODEL FOR FISSION PRODUCT RELEASE . . . . . . . . 5-1

5.1. Fission Product Release Model . . . . . . . . . . . 5-1

5.2. Fractional Release Function at Constant Temperature . . . . 5-2

5.3. Temperature Dependence of the Fractional Release Function - 5-4

5.4. Calculation of Release Based on the Model . . . . . . . . 5-7

6. APPLICATIONS OF THE RELEASE MODEL . . . . . . . . . . . . . 6-1

6.1. Comparison of Observed and Calculated Releases . . . . . . 6-1 
6.1.1. Xenon and Krypton . . . . . . . . . . . . 6-1

6.1.2. Iodine and Tellurium . . . . . . . . . 6-10

6.1.3. Cesium ................... 6-11

6.2. Parameters of the Release Model .. . . . . . . . 6-13

6.2.1. Relative Importance of the Profile Parameters . . . 6-14

6.2.2. Profile Parameters in the Isothermal and

Temperature Rise Experiments . . . . . . . 6-14

6.2.3. Uncertainty in the Mode1 Parameters . . . . . 6-15

6.3. Characteristics of the Release Model . . . . . . . . 6-18

References ...................... 6- 6- . . . . .

7. PHYSICAL INTERPRETATION OF THE RELEASE MODEL . . . . . . . . . . 7-1

7.1. An Interpretative Framework for the Release Model . . . . 7-1

7.2. Release in the Temperature Region Below $\mathrm{T}^{*} . . . . . . . .7-5$

7.2.1. A Theoretical Fractional Release Function . . . . 7-5

7.2.2. Comparison of Theoretically Derived and

Semiempirical Fractional Release Functions . . . . 7-7

7.2.3. Further Interpretation of $\mathrm{f}_{\beta}$. . . . . . . . 7-10

7.2.4. Further Interpretation of $\alpha$. . . . . . . . 7-17

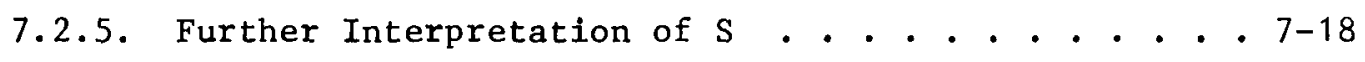

7.2.6. Recoiled Fission Products ........... . 7-20

7.2.7. Applicability of Theoretical Fractional Release

Function . . . . . . . . . . . . . 7-24

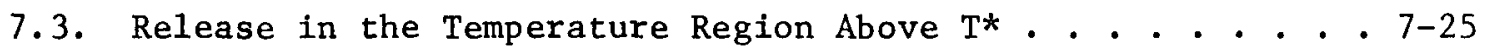

7.3.1. Qualitative Aspects of Release Above $\mathrm{T}^{*}$. . . . 7-25

7.3.2. Further Interpretation of $\mathrm{f}_{\beta} \cdot . \cdot . . . . . .7-26$

7.3.3. Further Interpretation of $\alpha$. . . . . . . . 7-27

7.3.4. Inventory of Short-1ived Fission Gas Nuclides

in Bubbles Above $\mathrm{T}^{*}$. . . . . . . . . . . . 7-29

7.4. Further Aspects of the Interpretation . . . . . . . . 7-30

7.4.1. Structural Changes in the Fuel Material . . . . . 7-30

7.4.2. Structure of Fuel Material Surfaces . . . . . 7-31

7.4.3. Composition Changes in the Kernel . . . . . . 7-32

References . . . . . . . . . . . . . . . . 7-32

8. APPLICATION OF THE EXPERIMENTAL DATA AND RELEASE MODEL TO

CORE HEATUP EVENTS . . . . . . . . . . . . . . . . . . . 8-1

References . . . . . . . . . . . . . . . . . . 8-6 
9. SUMMARY . . . . . . . . . . . . . . . . . . . . 9-1

10. ACKNOWLEDGMENTS . . . . . . . . . . . . . . . . . 10-1

APPENDIX A - LIST OF SYMBOLS . . . . . . . . . . . . . . . . . . A-1

APPENDIX B - ESTIMATION OF FRACTIONAL RELEASE OF CESIUM FROM FUEL KERNELS DURING IRRADIATION UNDER REACTOR AND

CAPSULE CONDITIONS . . . . . . . . . . . . . . . . . . B-1

APPENDIX C - MODIFICATION TO OLANDER'S SOLUTION OF THE DIFFUSION-

TRAPPING EQUATION . . . . . . . . . . . . . . . . C-1

\section{FIGURES}

2-1. Schematic diagram of experimental apparatus . . . . . . . . 2-4

2-2. Schematic diagram of furnace, collectors, and particle

holder . . . . . . . . . . . . . . . . . . 2-5

4-1. Comparison of fractional release of xenon and iodine nuclides between $1200^{\circ}$ and $2300^{\circ} \mathrm{C}$. . . . . . . . . . 4-7

4-2. Fractional release profile for $\mathrm{Xe}-135$ at $1430^{\circ} \mathrm{C}$ from laser-failed $\mathrm{ThO}_{2}$ particle with $0.25 \%$ FIMA . . . . . . . . 4-10

4-3. Comparison of the dependence of fractional release on $t$ and $\sqrt{t}$.................... . 4-17

4-4. Comparison of $f_{\beta}$ values for lodine and xenon nuclides determined in isothermal experiments . . . . . . . . 4-21

4-5. Fractional release curves for xenon and lodine 1 n Exp. 7240-92 at $2013 \mathrm{~K}$ with laser-failed UC 2 particles at $74 \%$ FIMA ............. . . . . . . 4-23

4-6. Release profile for Xe-135 from laser-falled ThO particles with $1.4 \%$ FIMA in temperature rise experiments . . . 4-32

5-1. Representative fractional release profile at constant temperature .. . . . . . . . . . . . . 5-3

5-2. Representative dependence on temperature of the parameters $\left(f_{B}, S\right.$, and $t .8$ ) of the fractional release profile . . . . . 5-5

6-1. Comparison of observed and predicted xenon release from laser-failed BISO $\mathrm{ThO}_{2}$ particles with $15.7 \%$ FIMA . . . . . . 6-2

6-2. Comparison of observed and predicted krypton release from laser-failed BISO $\mathrm{ThO}_{2}$ particles with $15.7 \%$ FIMA . . . . . . 6-4

6-3. Comparison of observed and predicted xenon release, in a long experiment, from laser-failed $\mathrm{BISO} \mathrm{ThO}_{2}$ particles with $0.25 \%$ FIMA ............2........ 6-5

6-4. Comparison of measured and calculated cumulative number of xenon atoms released in temperature rise experiments . . . . 6-7 
6-5. Comparison of measured and calculated cumulative number of krypton ( $\mathrm{Kr}-85 \mathrm{~m}, \mathrm{Kr}-87$, and $\mathrm{Kr}-88$ ) atoms released in temperature rise experiments . . . . . . . . . . . 6-8

6-6. Dependence of the accuracy of model predictions of fission gas release on the number of subsystems . . . . . . . . . 6-21

7-1. Parameter $f_{\beta}(T)$ for release of xenon nuclides from laser-failed $\mathrm{ThO}_{2}$ particles at selected burnups . . . . . . 7-3

7-2. Parameter $f_{\beta}(T)$ for release of xenon nuclides from laser-failed UC 2 particles at selected burnups . . . . . . . . 7-4

7-3. Determination of equivalent surface area for $\mathrm{ThO}_{2}$ with $15.7 \%$ FIMA ............... . . . . . 7-12

B-1. Time dependence of burnup in Peach Bottom (FTE-14) and capsules P13R, HT-12, and HT-15 . . . . . . . . . . . B-2

TABLES

3-1. Summary of irradiation conditions and selected properties for test particles .. . . . . . . . . . . . 3-2

4-1. Fractional release of iodine isotopes in experiments on the relative release of xenon and iodine . . . . . . . . . . . 4-4

4-2. Upper and lower bounds based on variation in the iodine contribution to the fractional release of xenon . . . . . . . 4-5

4-3. Parameters characterizing the fractional release profiles for Xe-135 in isothermal experiments . . . . . . . . . . 4-11

4-4. Parameters characterizing the fractional release profiles for $\mathrm{Kr}-85 \mathrm{~m}$ in isothermal experiments . . . . . . . . . . 4-12

4-5. Parameters characterizing the fractional release profiles for $\mathrm{Kr}-87$ in isothermal experiments . . . . . . . . . 4-13

4-6. Parameters characterizing the fractional release profiles for $\mathrm{Kr}-88$ in 1sothermal experiments . . . . . . . . . . . 4-14

4-7. Parameters characterizing the fractional release for I-131, I-133, and I-135 in isothermal experiments . . . . . . 4-18

4-8. Parameters characterizing the fractional release for $\mathrm{Te}-132$ in isothermal experiments . . . . . . . . . 4-19

4-9. Parameters characterizing the fractional release for Cs-134 and Cs-137 in isothermal experiments . . . . . . . 4-25

4-10. Coefficients in the power series expression for temperature as a function of time... . . . . . . . . . . 44-27

4-11. Measurements of the number of atoms of xenon and krypton released during temperature rise experiments . . . . . . . 4-28 
4-12. Initial inventories of xenon and krypton in temperature

rise experiments . . . . . . . . . . . . . . . . . 4-31

4-13. Fractional release of I-131, I-133, I-135, and $\mathrm{Te}-132$ in temperature rise experiments . . . . . . . . . . . . 4-33

4-14. Fractional release of $\mathrm{Cs}-134$ and $\mathrm{Cs}-137$ in temperature rise experiments . . . . . . . . . . . . . . . 4-35

6-1. Parameters of the fission product release model as a function of fission gas element, fuel material, and burnup . . 6-6

6-2. Parameters of the fission product release model as a function of fuel material and burnup for cesium . . . . . . . 6-12

6-3. Sensitivity of release to change in model parameters and percentage uncertainty in parameters corresponding to $30 \%$ uncertainty in measured release . . . . . . . . . 6-17

6-4. Comparison of uncertainties in model parameters from isothermal and temperature rise experiments corresponding to a $30 \%$ uncertainty in measured release . . . . . . . . 6-19

7-1. Activation energies and characteristic temperatures associated with $\mathrm{f}_{B}$ for xenon and krypton nuclides in $\mathrm{ThO}_{2}$ and $\mathrm{UC}_{2}$ at selected burnups and for temperatures

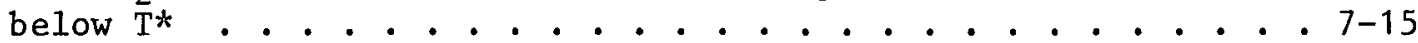

7-2. Activation energies and preexponential factors associated with $\mathrm{S}$ for xenon and krypton nuclides in $\mathrm{ThO}_{2}$ and $\mathrm{UC}_{2}$ at selected burnups and for temperatures below $\mathrm{T}^{*}$. . . . . . . . 7-19

7-3. Activation energies and characteristic temperatures associated with $f_{\beta}$ for xenon and krypton nuclides in $\mathrm{ThO}_{2}$ and $\mathrm{UC}_{2}$ at selected burnups and for temperatures above $\mathrm{T}^{*} . . . . . . . . . . . . . . . .7-21$

7-4. Activation energies and preexponential factors assoclated with $\alpha$ for xenon and krypton nuclides in $\mathrm{ThO}_{2}$ and $\mathrm{UC}_{2}$ at selected burnups and for temperatures above $T^{*}$. . . . . . 7-28

8-1. Recommended values of the model parameters for application to core heatup events . . . . . . . . . . . . . 8-4

B-1. Calculated fractional release, $f$, of ceslum from kernels during irradiation of particles in reactor and capsules . . . . B-5 


\section{INTRODUCTION}

In this report, measurements and analyses are presented on fission product release from falled HTGR fuel particles during postirradiation simulated accident conditions. This major work was funded by the Department of Energy under the HTGR Safety Research Task of the HTGR Generic Technology Program.

The need for the work represented by this report was based on probabilistic risk analysis and licensing considerations. The need based on probabilistic risk analysis was derived from work in phase $I$ of the

Accident Initiation and Progression Analysis (AIPA) (Ref. 1-1) * concerning fission product transport mechanisms. A relative ranking of factors important for fission product transport was obtained by considering accident sequences, ranking them according to a measure of their relative risk, and calculating the contribution of specific fission product transport mechanisms to the radiological doses predicted for each sequence. The most important factor was the rate of release of fission products from the fuel particles during a core heatup resulting from a loss of forced circulation. Subsequently, phase II results of the AIPA study tended to confirm the importance of this factor, especially for sequences leading to containment failure (Ref. 1-2); however, a quantitative ranking procedure was not employed in phase II work. The important fission products in regard to radiological dose and containment were found to be xenon, iodine, krypton, cesium, tellurium, and rubidium, rough1y ranking in this order.

The need based on licensing considerations was derived from a prior Nuclear Regulatory Commission (NRC) review of the Fulton and Summit plant

*

* References appear at the end of each section. 
applications and of the General Atomic Standard Safety Analysis Report (GASSAR); this review concerned the time-dependent release during the HTGR siting event, the maximum hypothetical fission product release (MHFPR). In treating the MHFPR with the General Atomic model, previous data for the time-dependent release of fission products (Ref. 1-3) were used, whereas in the model of the NRC staff, the conservative assumption of instantaneous release of fission products from failed fuel particles was adopted.

Both the probabilistic risk analysis and licensing considerations indicate the importance of establishing a firm data base and model for describing the time-dependent release of fission products from fuel particles. The previous data base (Ref. 1-3) and model (Ref. 1-4) used to describe time-dependent release of fission products have significant associated uncertainties. The data base and model have been used, in the SORS computer code (Ref. 1-4), to calculate the time-dependent release throughout the core for given fuel failure and temperature transient conditions in both licensing and AIPA applications.

The uncertainties in the previous data base (Ref. 1-3) derive from the following limitations of the data: (1) in many cases the release data were obtained with particles having nonreference fuel such as (Th,U) ${ }_{2}$, $(\mathrm{Th}, \mathrm{U}) \mathrm{C}_{2}$, $\mathrm{ThC}_{2}$, and $\mathrm{UO}_{2}$; (2) the data were obtained in heating tests at a constant temperature and therefore the application of the results of such tests to a core heatup event were uncertain; and (3) in many cases, the temperature range was restricted and only particles with low burnup were tested. These conditions introduced a potentially large uncertainty in release when the data were extrapolated to high temperature and over the full burnup range experienced by the reference fuels in reactor operation.

In the previous model, the fractional release of fission products from failed and intact fuel particles was calculated according to the equation

$$
F_{r e l}=1-e^{-R t} \text {, }
$$


where $F_{\text {rel }}$ is the integrated fractional release, $R$ is the release rate coefficient, and $t$ is time. The coefficient $R$ is dependent on temperature according to the equation

$$
\log _{10} R=A-\frac{10^{4} B}{T}
$$

where $A$ and $B$ are constants and $T$ is the temperature. The model, as represented by Eqs. 1-1 and 1-2, had not been tested under temperature transient conditions and did not fit the previous time-dependent release data (Ref. 1-3) from constant temperature experiments except over limited time intervals. Thus, the model had potentially large uncertainties. The present program was designed to reduce the above uncertainties by:

1. Measuring the release of fission products from failed HTGR reference fuel particles for a representative range of temperatures and burnups, including measurements at constant temperature and for temperature transients.

2. Developing an analytical model that could represent the release data.

The HTGR fuel particles (Ref. 1-5) used in the present experiments consisted of BISO coated fertile particles with dense $\mathrm{ThO}_{2}$ kernels of about 500- $\mu \mathrm{m}$ diameter, TRISO coated fissile particles with dense $\mathrm{UC}_{2}$ kernels of about 200- $\mu \mathrm{m}$ diameter, and TRISO coated weak acid resin (WAR) derived particles with porous $U_{x} C_{y}$ kernels. The fissile particles were fabricated with high-enriched uranium (HEU fuel), but the results of the present study will apply also to release from kernels fabricated with medium- or low-enriched uranium (MEU or LEU fuel) for the same burnup and temperature. For the experiments, the particle coatings were failed in a reproducible manner which permitted fission products released from the kernel to escape from the particle. 
The range of the temperature was from $1200^{\circ}$ to $2300^{\circ} \mathrm{C}$; in experiments with rising temperature, the heating rates varied from $50^{\circ}$ to $450^{\circ} \mathrm{C} / \mathrm{h}$.

The design burnup range for reference HTGR fuel extends to about $7 \%$ FIMA for $\mathrm{ThO}_{2}$ and 78\% FIMA for $\mathrm{UC}_{2}$. The selected burnups were restricted by the availability of irradiated fuel particles at the time of selection and by the scope of the present study to $0.25,1.4$, and $15.7 \%$ FIMA for $\mathrm{ThO}_{2} ; 23.5$ and $74 \%$ FIMA for $\mathrm{UC}_{2}$; and $60 \%$ FIMA for the WAR kernel particles.

The analytical model was developed on the basis of the observed release behavior in the constant temperature and temperature rise experiments. The model is a semiempirical model of the time-dependent release from failed fuel particles and is interpretable in terms of physical mechanisms.

The work presented in this report is successful in reducing the uncertainties described above. This is evidenced by the systematic testing of failed reference fuel particles over pertinent conditions, by the precision of the data, and by the construction of an improved analytical model which satisfactorily represents the release data over all experimental conditions. A large factor in enhancing the confidence in the results of this work is the inclusion of experiments under simulated core heatup temperature rise conditions and the ability to describe the release of fission products under these conditions on the basis of release behavior in constant temperature experiments.

In the succeeding sections of this report, descriptions are given of the experiment, the materials used, the experimental results, the development of a model for fission product release, application of the release model to the experimental results, the physical interpretation of the release model, and the application of the experimental data and release model to core heatup events. 
REFERENCES

1-1. "HTGR Accident Initiation and Progression Analysis Status Report, Volume VI, Event Consequences and Uncertainties Demonstrating Safety R\&D Importance of Fission Product Transport Mechanisms," ERDA Report GA-A13617, General Atomic Company, January 1976.

1-2. "HTGR Accident Initiation and Progression Analysis Status Report, Phase II Risk Assessment," DOE Report GA-A15000, Genera1 Atomic Company, April 1978.

1-3. "HTGR Fuels and Core Development Program, Quarterly Progress Report for the Period Ending February 28, 1977," ERDA Report GA-A14298, General Atomic Company, March 1977.

1-4. Schwartz, M. H., D. B. Sedgley, and M. M. Mendonca, "SORS: Computer Programs for Analyzing Fission Product Release from HTGR Cores During Transient Temperature Excursions," General Atomic Report GA-A12462 (GA-LTR-10), April 15, 1974.

1-5. Gulden, T. D., and H. Nickel, "Coated Particle Fuels," Nucl. Technol. 35 206 (1977). 


\section{EXPERIMENTAL PROCEDURE AND APPARATUS}

The experimental procedure for measuring the release of fission products from failed fuel particles involved the following steps:

1. Failing the fuel particles.

2. Reirradiation of the fuel particles to generate short-lived nuclides.

3. Heating of the reirradiated, failed fuel particles to induce fission product release.

4. Analysis of the fuel particles and the collectors used to trap the fission products.

\section{1. FAILED FUEL PARTICLES}

Fuel particles selected for these experiments were failed in a reproducible manner by laser drilling. In this technique, a laser beam is used to form a hole extending from the particle surface to the kernel surface. The diameter of the hole is about $10 \mu \mathrm{m}$. The laser used was a KORAD laser welder, Model $\mathrm{KW}$, which includes an objective lens for focusing.

During laser drilling, the particles are contained in a sealed compartment which is purged with helium. The laser beam enters the compartment through a window. The depth of penetration of the laser beam into the particle coatings depends on the laser power. This power level is adjusted to permit the laser beam to just reach the kernel surface. The adjustment is based on metallographic examination of other laserdrilled particles. 
After laser drilling, the holes in the particles are visually examined. Any particles which appear to have fuel kernel debris surrounding the hole are rejected. Furthermore, it will be apparent from the results presented below that any small variation in the depth of penetration about the kernel surface has a negligible effect on the release behavior.

\subsection{REIRRADIATION OF FUEL PARTICLES}

The laser-failed fuel particles were reirradiated in order to generate an inventory of short-lived nuclides. The short-lived nuclides of interest were $\mathrm{Xe}-133, \mathrm{Xe}-135, \mathrm{I}-131, \mathrm{I}-132, \mathrm{I}-133, \mathrm{I}-135, \mathrm{Kr}-85 \mathrm{~m}$, $\mathrm{Kr}-87, \mathrm{Kr}-88$, and $\mathrm{Te}-132$. The fuel particles had been previously irradiated in capsule tests or in the Peach Bottom HTGR (see Section 3).

The reirradiations were conducted for the most part in the Mark I TRIGA reactor. The reactor was operated at a power of $250 \mathrm{~kW}$ (thermal) and provided a flux of $4.2 \times 10^{16} \mathrm{n} / \mathrm{m}^{2} \cdot \mathrm{s}$. The laser-failed particles were contained in a crucible in a helium atmosphere; this crucible was contained in a second crucible which was inserted into the body of an in-core furnace (Ref, 2-1). The furnace was purged with purified helium. During the reirradiation, the temperature of the particles was always less than $100^{\circ} \mathrm{C}$. Thus, the transport of fission products during reirradiation was negligible.

A few reirradiations were conducted in the Mark F TRIGA reactor. This reactor was operated at a power of $1.5 \mathrm{MW}$ (thermal) and provided a flux of either $1.4 \times 10^{15}$ or $2.4 \times 10^{17} \mathrm{n} / \mathrm{m}^{2} \cdot \mathrm{s}$ depending on the position of the furnace. Other conditions were the same as for the Mark I irradiation.

The laser-failed fuel particles were irradiated for 2 hours in the Mark I TRIGA reactor or 1 hour in the Mark F TRIGA reactor. Half of the fluence was accumulated a day before the tests and half on the day of 
the tests. The delay in testing after the first reirradiation permitted the formation of an adequate xenon inventory via radiodecay of iodine. The second reirradiation provided an adequate inventory of the short-lived krypton isotopes. The inventories of xenon and iodine at the beginning of the experiments were on the order of $10^{10}$ atoms/particle and the inventory of krypton was on the order of $10^{9}$ atoms/particle.

The inventory in the fuel particles of the long-lived $\mathrm{Kr}-85$ and stable gas nuclides, generated in the previous capsule and reactor irradiations (see Section 3), was three to five orders of magnitude larger than the inventory of the short-lived xenon and krypton nuclides. This circumstance simulates the relative inventories expected under core heatup conditions.

\subsection{HEATING OF THE REIRRADIATED FAILED FUEL PARTICLES}

\subsubsection{Experimental Apparatus}

To induce the release of fission products, the reirradiated laserfailed fuel particles were heated in a flowing stream of helium. The helium carried the released fission products to various collection sites. A schematic diagram of the apparatus used in studying fission product release is shown in Fig. 2-1. The major components of the apparatus are a King-type furnace (Ref. 2-2) and the various collectors.

The furnace consists of a graphite tube which is resistively heated, associated radiation shields, and a cover as shown in Fig. 2-2. The graphite tube is about $50 \mathrm{~cm}$ in length. In operation, the heating element and shields are maintained under vacuum. The graphite tube surrounds a tantalum tube which is $72 \mathrm{~cm}$ long with an outside diameter of $1.25 \mathrm{~cm}$. The failed fuel particles are held in the center of the tantalum tube, which coincides with the center of the furnace. One end of the tantalum tube is connected to the helium supply and the other end leads to the collectors. To avoid failure of the tantalum tubes in service, they were replaced after about $8 \mathrm{~h}$ of use. 

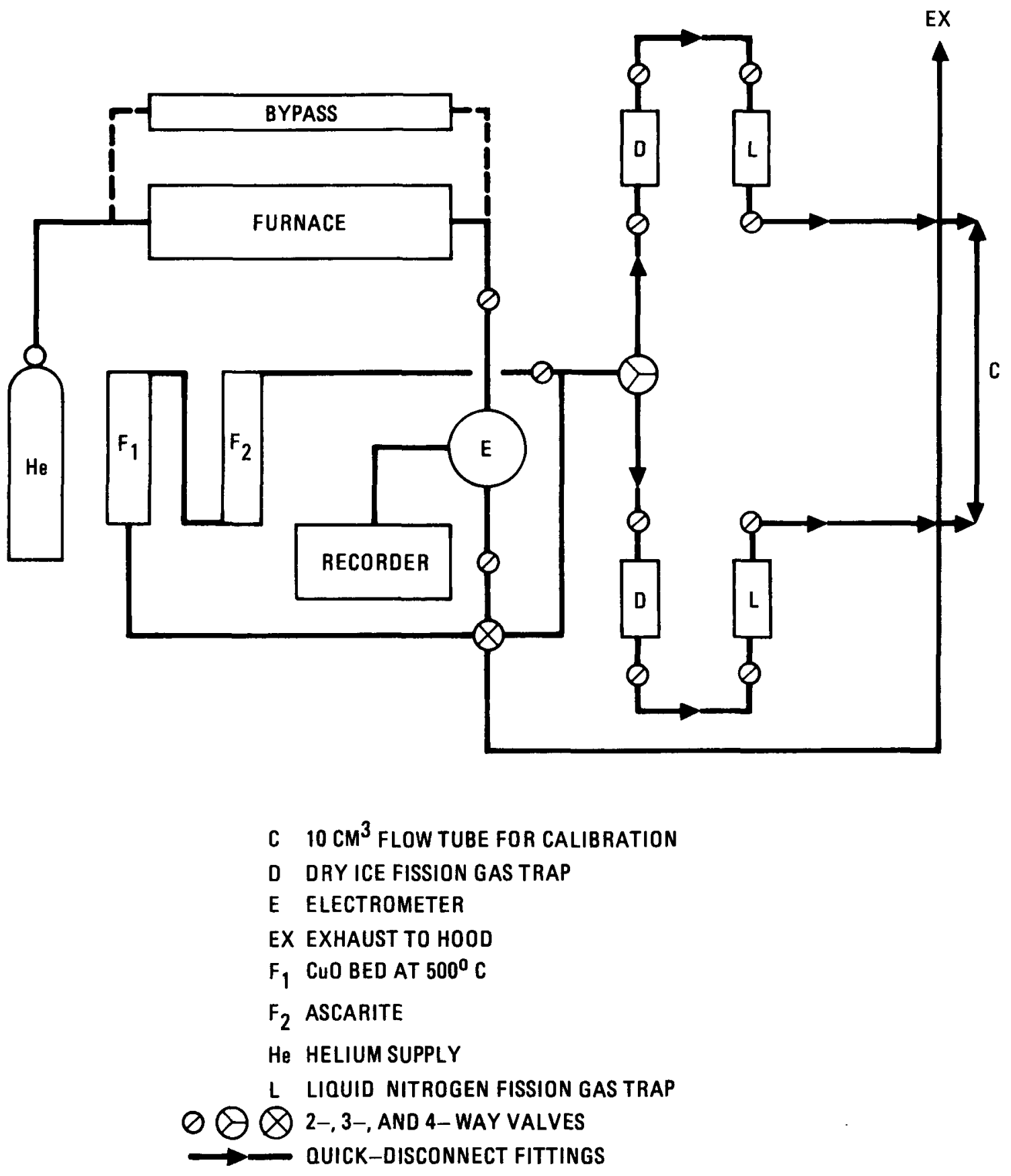

Fig. 2-1. Schematic diagram of experimental apparatus 


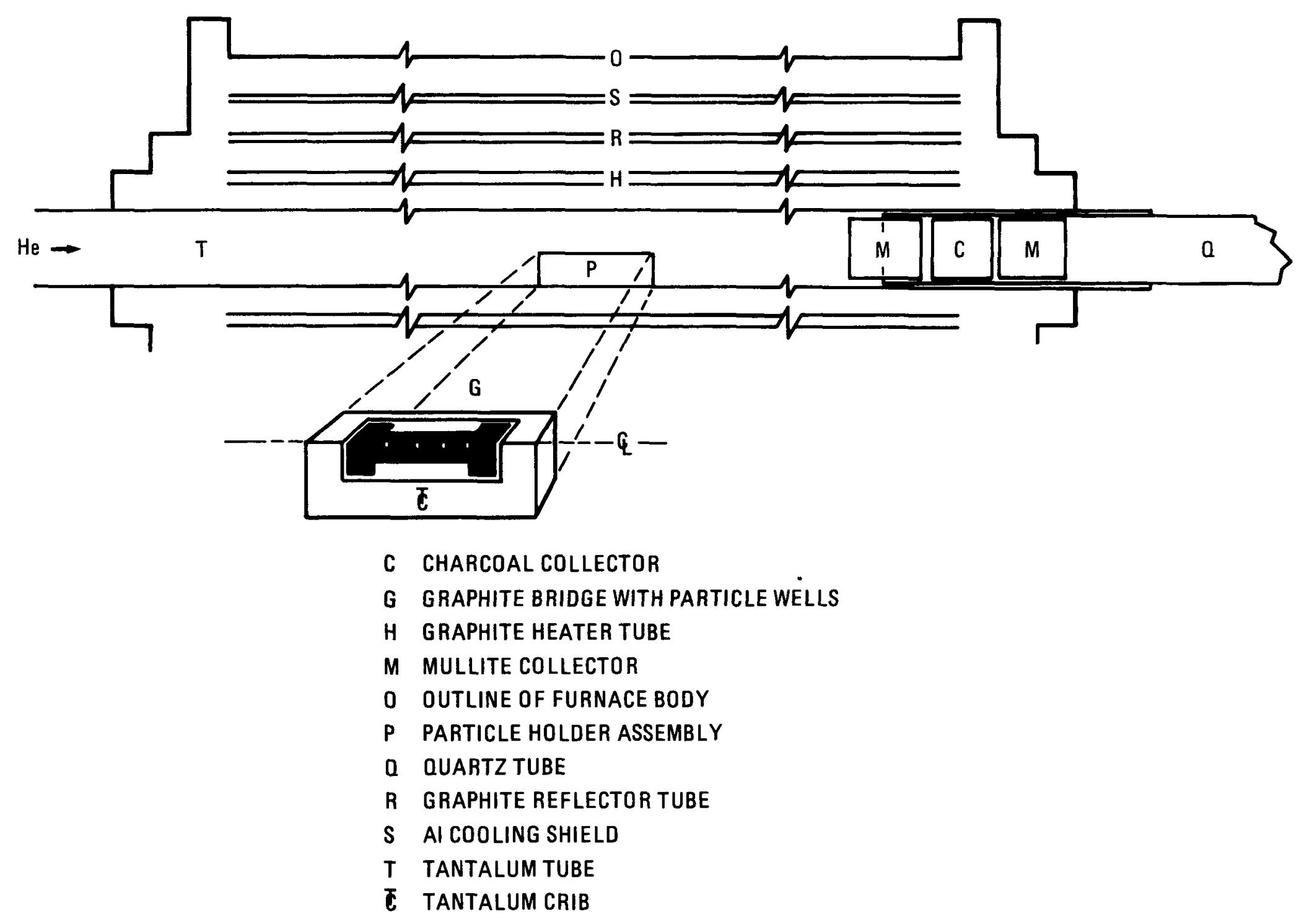

Fig. 2-2. Schematic diagram of furnace, collectors, and particle holder 
Between one and four laser-failed fuel particles were held in individual particle wells drilled into a graphite bridge, as shown in Fig. 2-2. The bridge, in turn, was held in a tantalum crib positioned in the center of the tantalum tube; the position was maintained by notches made in the outer surface of the tube. The overall dimensions of the crib were $0.6 \mathrm{~cm}$ high $\times 0.9 \mathrm{~cm}$ wide $\times 1.6 \mathrm{~cm}$ long.

The collectors can be classified according to the temperature at which they were held during experimentation. The low-temperature collectors trapped xenon and krypton. These gas traps contained activated charcoal in an aluminum block designed to facilitate counting and cooling. The low-temperature collectors were tested by passing a standard gas mixture containing $\mathrm{Kr}-85$ through the liquid-nitrogen-cooled charcoal and then measuring the radioactivity. On the average, the detected activity was within $4 \%$ of the activity flowing into the charcoal for the eight gas traps used in this study. The gas traps were also checked to ensure that there were no significant leaks. Two gas traps were aligned in series as shown in Fig. 2-1. The first trap to receive fission products was held at "dry ice" temperature and collected all of the released xenon and part of the released krypton. The second trap was held at liquid nitrogen temperature and collected the remainder of the released krypton.

The high-temperature collectors trapped principally iodine, tellurium, and cesium. The temperature of the traps was not monitored but ranged between several hundred and $1000^{\circ} \mathrm{C}$. These traps were held, as shown in Fig. 2-2, in a custom machined, quartz tube which snugly fitted into the end of the tantalum tube. The quartz tube was $23 \mathrm{~cm}$ in length. The traps were, in order, mullite, charcoal, and mullite. The mullite collectors were 2.5-cm-1ong sleeves cut from Coors MV30 tubes; the charcoal collector was a $1.5-\mathrm{cm}-1$ long cylinder (with a central passageway) made by mixing activated charcoal with nylon graphite cement and curing at $1800^{\circ} \mathrm{C}$. The mullite was intended to serve as the cesium collector, the charcoal as the iodine collector, and both mullite and charcoal as tellurium collectors. 
The effective use of mullite and charcoal to collect cesium, tellurium, and iodine depends on the temperature of the collector. In the case of cesium, the mullite must be above $1000^{\circ} \mathrm{C}$; if the mullite is placed in a section of the furnace where the temperature is below $900^{\circ} \mathrm{C}$ (i.e., in the tantalum tube), a significant amount of the cesium will deposit on the tantalum tube (Ref. 2-3) upstream of the mullite. The effectiveness of a particular arrangement of collectors can be determined by comparing the amount of fission products trapped by the collectors with the amount released as determined from pretest and posttest gamma counting of the fuel particles.

The minor components of the apparatus consist of the bypass tube, the electrometer, and the filters. The by-pass tube isolates the particles in the furnace from the remainder of the system; the use of this feature is described in Section 2.3.2. The electrometer was used as a rough monitor of the gaseous fission product release throughout the experiment. The filters were required in experiments using laser-failed $\mathrm{ThO}_{2}$ particles. To prevent carbothermic reduction of the $\mathrm{ThO}_{2}$ (Ref. 2-4), $\mathrm{CO}$ was added to the helium at temperatures above $1300^{\circ} \mathrm{C}$. The $\mathrm{CO}$ was removed from the helium before entering the gas traps by heating the gas to $500^{\circ} \mathrm{C}$ over a $\mathrm{CuO}$ bed and removing the $\mathrm{CO}_{2}$ formed on ascarite.

In all experiments, the helium flow rate, $\mathrm{f}_{\mathrm{r}}$, was maintained at $115 \mathrm{~cm}^{3} / \mathrm{min}$. The transit time of a slug of gas in the experimental apparatus between the particles and the fission gas collectors was less than 3 min excluding passage through the electrometer. The electrometer represented a well-mixed volume, $V$, of $250 \mathrm{~cm}^{3}$ which significantly increased the transit time. However, under the conditions of the experiments, the effect of such a well-mixed volume was to displace the release profile forward in time by $V / f_{r}$. The distortion of the release profile by the well-mixed volume was negligible for times equal to or greater than $2 \mathrm{~V} / \mathrm{f}_{\mathrm{r}}$. Thus the effective transit time was about $5 \mathrm{~min}$, with negligible distortion in the measured release profile after the first 4 min. The estimate of the transit time given here is consistent with delay in the initial rise of 
the release profile as deduced from measurements of release at times that are large compared with the estimated transit time (see Section 4.2 on $t_{0}$ values).

\subsubsection{Heating Experiments}

The laser-failed fuel particles in the furnace were brought to the starting temperature of the experiment and thereafter the temperature was automatically controlled using a Barber Coleman controller and card programmer. The temperature of the particle holder was periodically measured during the experiment with an optical pyrometer. In addition, the change in temperature was continuously monitored with a thermocouple inserted into the gap between the heated graphite tube and the tantalum tube. The rates of change in temperature deduced from the pyrometer and thermocouple were in agreement. Between pyrometer readings, the temperatures were deduced by interpolation using the thermocouple results as a guide.

The optical pyrometer had been calibrated against an NBS standard. The effect on the pyrometer readings of the viewing window and of the emissivity of the tantalum particle holder was taken into account. The viewing window was cleaned between each experiment. The surface of the particle holder exhibited roughness and oxidation and, over the temperature range of the heating experiments, had a higher brightness temperature in the furnace than a graphite surface roughened with a 36 grit abrasive. The error in the true temperature is estimated to be less than $\pm 20 \mathrm{~K}$.

During the time required to bring the furnace and fuel particles to the initial temperature of the experiment, some release of fission products will have occurred. This release was taken into account by using a starting time 3 min earlier, on the average, than the time at which the initial temperature was reached. The corrections to the starting time were based on measuring the fission product release during the rise to the initial temperature of the experiment. 
Three variations of heating experiments were used:

1. The objective of the first kind of heating experiment was to determine the relative release behavior of xenon and iodine. This experiment was preliminary to those experiments (see items 2 and 3 below) intended to satisfy the objectives given in Section 1. Since iodine is a precursor to xenon, the release behavior of iodine must be accurately known in order to account for its contribution to xenon release. However, iodine is a condensable fission product and could not be conveniently measured with the available equipment as frequently or accurately during the experiment as was xenon. These problems were circumvented by measuring the relative release of iodine.

In the first kind of experiment, the laser-failed particles were heated at constant temperature for a limited time ( $\sim \mathrm{h}$ ) while the xenon release was monitored. At the end of the heating period, the particles were cooled to room temperature and the monitoring was continued. At room temperature, the collected xenon came from (a) the residual xenon content in the accessible pores of the cooled particles, and (b) decay of iodine which had been released from the particles during the heating period. The bypass tube, described in Section 2.3.1, was used to separate contributions (a) and (b). When the bypass tube was in use, the particles were sealed in the furnace and the quartz tube was inserted into the bypass tube. In this configuration, all of the iodine released from the particles during the heating period of the experiment was included in the gas train. During the heating period, any surfaces between the particles and the quartz tube were too hot to permit condensation of released iodine.

The heating period was between 1.1 and $1.4 \mathrm{~h}$ and after cooling, monitoring of the release of xenon from the two sources described 
above continued for 4 to $5 \mathrm{~h}$. Generally, two samples of collected xenon were taken during the heating period and five samples after cooling; of the latter samples, three were taken when the bypass tube was in use.

These experiments were conducted with laser-failed $\mathrm{ThO}_{2}$ fuel particles having a burnup of $0.25 \%$ FIMA. In one case, a test particle which was broken in half was used. The temperature of the experiments ranged from $1220^{\circ}$ to $2270^{\circ} \mathrm{C}$.

2. The objective of the second kind of heating experiment was to measure fission product release at constant temperature. The release data obtained provided the basis for developing the release model (Section 5) and determining the values of its parameters.

The experiments were performed at three temperatures: $1430^{\circ}$, $1740^{\circ}$, and $2060^{\circ} \mathrm{C}$. Isothermal experiments were conducted at only three temperatures because of the time constraints of this study.

Release of fission products was monitored for about $7 \mathrm{~h}$. In the experiments, five samples of fission gas and two samples of condensable flssion products were taken.

3. The objective of the third kind of heating experiment was measurement of release of fission products during periods of rising temperature. This type of experiment simulates the core heatup; therefore, the release measurements are of primary importance in the present study and provide a test for models describing the release in a core heatup. In the temperature rise experiments, the heating rates were between $50^{\circ}$ and $450^{\circ} \mathrm{C} / \mathrm{h}$. 
The release of fission products was monitored for about $5 \mathrm{~h}$; in one experiment with a heating rate near $50^{\circ} \mathrm{C} / \mathrm{h}$, however, the release was monitored for $24 \mathrm{~h}$. In these experiments, five samples of fission gas and two samples of condensable fission products were generally taken.

\subsection{ANALYSIS OF FUEL PARTICLES AND COLLECTORS FOR FISSION PRODUCTS}

The fuel test particles and collectors were anlayzed with a computerized, gamma ray spectroscopy system (Ref. 2-5). The system included a $\mathrm{Ge}(\mathrm{Li})$ detector, a multichannel analyzer, and a computer system with appropriate codes for analyzing the recorded gamma spectra. The counting geometries for vials containing particles and collectors and for the fission gas traps were appropriate to the system. The detector was periodically calibrated against an NBS traceable standard.

Analyses were normally made for the following fission products: $\mathrm{Xe}-133, \mathrm{Xe}-135, \mathrm{I}-131, \mathrm{I}-132, \mathrm{I}-135, \mathrm{Te}-132, \mathrm{Cs}-134$, and Cs-137. However, for particles with burnups greater than $0.3 \%$ FIMA, the particle inventory of Xe-133 could not be determined with sufficient accuracy to warrant further consideration; the activity of Ce-144 interfered with the measurement of the activity of Xe-133.

The activity was measured for three types of samples:

1. The fuel particles were counted before and after each experiment. These measurements provided the initial inventory of fission products and were used to accurately calculate the total release of fission product based on pretest and posttest inventories when the release exceeded about $20 \%$. The fuel particles were also visually examined before and after each experiment.

2. The low-temperature fission gas traps were counted to obtain directly the quantity of xenon and krypton released at selected times during the experiment. The total release measured in this 
manner was compared with that calculated from the particle inventories as indicated in item 1 above. This comparison was a useful check on the establishment of a mass balance.

3. The mullite sleeves, the charcoal cylinder, and the quartz tube were counted to obtain the quantity of condensable fission products released. The quartz tube was leached with $10 \mathrm{ml}$ of $12 \mathrm{M} \mathrm{HNO}{ }_{3}$ containing a few drops of $\mathrm{HF}$, and the resulting solution was counted.

In several preliminary experiments, the graphite bridge and tantalum tube were also analyzed; retention of the fission products listed above on these components was negligible.

For each experiment, new mullite sleeves and a new charcoal cylinder and graphite bridge were used. Between experiments, the fission gas traps were heated at $230^{\circ} \mathrm{C}$ for $2 \mathrm{~h}$ in a stream of helium in order to remove the fission gas trapped during the previous experiment. This was an effective procedure as indicated by a counting of the traps thus treated.

The released fission products which diffused counter to the helium flow and deposited on the cool (upstream) sections of the tantalum tube were negligible. This was demonstrated in an experiment in which a quartz tube with mullite and charcoal collectors was inserted in each end of the tube. The quartz tube, collectors, and tantalum tube were analyzed. AlI the activity on the tantalum tube was due to cesium, strontium, and antimony. The cesium deposited upstream was estimated to be less than $1 \%$ of the released cesium.

\section{REFERENCES}

2-1. Anderson, E. E., et a1., "An In-Core Furnace for the High-Temperature Irradiation Testing of Reactor Fuels," Nucl. Technol. 11, 259. (1971). 
2-2. Zumwalt, L. R., E. E. Anderson, and P. E. Gethard, "Fission Product Retention Characteristics of Certain (Th,U) $\mathrm{C}_{2}$-Graphite Fuels," in Materials and Fuels For High Temperature Nuclear Energy Applications, M. T. Simnad and L. R. Zumwalt (eds.), M.I.T. Press, Cambridge, Massachusetts, 1964, Chapter 9.

2-3. Sterling, S. A., General Atomic Company, private communication. 2-4. Stansfield, 0. M., et al., "Performance of $\mathrm{ThO}_{2}$ in HTGR Fuel Particles," DOE Report GA-A14745, General Atomic Company, March 1978.

2-5. Hill, D. W., "GULF: A Computerized Gamma Ray Spectroscopy System," General Atomic Report GA-A14397, to be pub1ished. 


\section{DESCRIPTION OF MATERIALS USED}

The test fuel particles contained kernels of $\mathrm{ThO}_{2}, \mathrm{UC}_{2}$, and WAR-derived $\mathrm{UC}_{\mathrm{x}} \mathrm{O}_{\mathrm{y}}$. These fuel particles had been irradiated prior to the present study either in capsules or in a fuel test element in the Peach Bottom reactor. Selected properties of these kernels and a summary of the irradiation conditions are presented in Table 3-1.

The $\mathrm{ThO}_{2}$ and $\mathrm{UC}_{2}$ kernels were initially dense, while the WAR kernel had a relatively low density. These kernels are made according to the methods described in Refs. 3-7, 3-8, and 3-9, respectively.

The variation in the $0 /$ Th ratio from the stoichiometric composition of $\mathrm{ThO}_{2}$ is less than $0.5 \%$. For $\mathrm{UC}_{2}$, the $\mathrm{C} / \mathrm{U}$ ratio is within $3 \%$ of the value 2. Since the combined-C to $U$ ratio is not greater than 1.96 (Ref. $3-10$ ), free carbon is likely to be present. However, for the kernels in Table 3-1, the actual values are not known. The WAR kernel had the composition 76.8 wt \% U, 15.7 wt \% C, and 7.5 wt \% 0 before being coated (Ref. 3-11).

\section{REFERENCES}

3-1. Holzgraf, J. F., et a1., "Postirradiation Examination Evaluation of Peach Bottom Fuel Test Elements FTE-14 and FTE-15," DOE Report GA-A13944, General Atomic Company, to be published.

3-2. "HTGR Fuels and Core Development Program, Quarterly Progress Report For The Period Ending August 30, 1974," USAEC Report GA-A13126, General Atomic Company, September 30, 1974.

3-3. Kania, M. J., et al., "Irradiation Performance of HTGR Fertile Fuel in HFIR Target Capsules HT-12 through HT-15: Part 1 - Experiment Description and Fission Product Behavior," ERDA Report ORNL TM-5305, Oak Ridge National Laboratory, February 1977. 
TABLE 3-1

SUMMARY OF IRRADIATION CONDITIONS AND SELECTED PROPERTIES FOR TEST PARTICLES

\begin{tabular}{|c|c|c|c|c|c|c|c|c|c|c|c|}
\hline $\begin{array}{c}\text { Fuel } \\
\text { Material }\end{array}$ & $\begin{array}{l}\text { Capsule and } \\
\text { Batch No. }\end{array}$ & $\begin{array}{l}\text { Irrad. } \\
\text { Time } \\
\text { (d) }\end{array}$ & $\begin{array}{c}\text { Kernel } \\
\text { Dia. } \\
\text { ( } \mu \mathrm{m})\end{array}$ & $\begin{array}{l}\text { Initial } \\
\text { Kernel } \\
\text { Density } \\
\left(\mathrm{g} / \mathrm{cm}^{3}\right)\end{array}$ & $\begin{array}{l}\text { Mean } \\
\text { Particle } \\
\text { Irrad. } \\
\text { Temp. } \\
\left({ }^{\circ} \mathrm{C}\right)\end{array}$ & $\begin{array}{l}\text { Max. } \\
\text { Particle } \\
\text { Irrad. } \\
\text { Temp. } \\
\left({ }^{\circ} \mathrm{C}\right)\end{array}$ & $\begin{array}{l}\text { Fast } \\
\text { Fluence }(a) \\
\left(10^{25} \mathrm{n} / \mathrm{m}^{2}\right)\end{array}$ & $\begin{array}{c}\text { Fast } \\
\text { Flux (b) } \\
\left(10^{18} \mathrm{n} / \mathrm{m}^{2} \cdot \mathrm{s}\right)\end{array}$ & $\begin{array}{l}\text { Burnup } \\
\text { (\% FIMA) }\end{array}$ & $\begin{array}{l}\text { Mean } \\
\text { Fission } \\
\text { Rate } \\
\text { Density } \\
\text { (1020 } \\
\text { fissions/ } \\
\left.\mathrm{m}^{3} \cdot \mathrm{s}\right)\end{array}$ & Ref. \\
\hline $\mathrm{ThO}_{2}$ & $\begin{array}{l}\text { FTE-14 } \\
4252-01-070\end{array}$ & $316^{(c)}$ & 480 & 9.86 & 1325 & $N A^{(d)}$ & 1.42 & NA & 0.25 & 0.02 & $3-1$ \\
\hline $\mathrm{ThO}_{2}$ & $\begin{array}{l}\mathrm{HT}-12-43 \\
4252-03-012-5\end{array}$ & $38.6^{(e)}$ & 505 & 9.90 & 1090 & 1240 & 2.8 & 8.5 & 1.4 & 1.1 & $\begin{array}{l}3-2 \\
3-3\end{array}$ \\
\hline $\mathrm{ThO}_{2}$ & $\begin{array}{l}\text { HT }-15-10 \\
4252-06-012-8\end{array}$ & $160^{(e)}$ & 509 & 9.94 & 1341 & 1440 & 11.7 & 8.5 & 15.7 & 2.9 & $\begin{array}{l}3-2 \\
3-3\end{array}$ \\
\hline $\mathrm{UC}_{2}$ & $\begin{array}{l}\text { FTE-14 } \\
4161-01-030\end{array}$ & $316^{(c)}$ & 200 & 10.9 & 1095 & $\sim 1300$ & 1.3 & NA & 23.5 & 2.2 & $3-1$ \\
\hline $\mathrm{UC}_{2}$ & $\begin{array}{l}\text { P13R-3-4 } \\
6151-00-035\end{array}$ & $285^{(f)}$ & 201 & 11.0 & $\begin{array}{l}1015- \\
1075\end{array}$ & 1400 & 13.5 & 6.0 & 74 & 7.7 & $\begin{array}{l}3-4 \\
3-5\end{array}$ \\
\hline WAR & $\begin{array}{l}\mathrm{HB}-5 \\
6551-055\end{array}$ & $\mathrm{NA}$ & 342 & 2.71 & $\sim 600$ & NA & NA & $\mathrm{NA}$ & $\sim 60$ & NA & $3-6$ \\
\hline
\end{tabular}

\footnotetext{
(a) $E>29 \mathrm{fJ}$.

(b) $E>29$ fJ $\times 10^{-15}$.

(c) Effective ful1 power days at Peach Bottom.

(d) $N A=$ not available.

(e) 100-MW power days.

(f) 50-MW power days.
} 
3-4. Scott, C. B., D. P. Harmon, and J. F. Holzgraf, "Postirradiation Examination of Capsules P13R and P13S," ERDA Report GA-A13827, General Atomic Company, October 8, 1976.

3-5. Young, C. A., and D. P. Harmon, "Preirradiation Report: Fuel Materials for P13R and P13S Irradiation Capsules," USAEC Report GA-A13026, General Atomic Company, November 1974.

3-6. Sterling, S. A., General Atomic Company, private communication.

3-7. Haas, P. A., "Sol-Gel Preparation of Spheres: Design and Operation of Fluidized Bed Columns," USAEC Report ORNL-4398, Oak Ridge National Laboratory, September 1969.

3-8. Simnad, M. T., "Drop-Fusion Method for Producing Spherical Fuel Particles for HTGR and UHTREX Fuel Elements," Gulf General Atomic Report GA-9939, March 26, 1970.

3-9. Precourt, R. J., and R. D. Whipple, "The 'WAR' Fissile Kernel Process," General Atomic Report GA-A13902, April 12, 1976.

3-10. Sears, M. B., and L. M. Ferris, "Studies on the U-C Constitutional Diagram Between UC and UC," J. Nucl. Mater. 32101 (1969).

3-11. Sterling, S. A., "HB-2 Preirradiation Report," General Atomic Report GA-A13774, December 1975. 


\section{EXPERIMENTAL RESULTS}

The experimental results are discussed in two parts. The preliminary experiments on the relative release behavior of xenon and iodine are presented first, followed by the experiments on fission product release under isothermal and temperature rise conditions.

The experimental results consist of the fractional release or the number of atoms released as a function of time and temperature. The fractional release of a nuclide $\mathrm{N}$, in the absence of any precursor, is defined by the following relation:

$$
f_{N}(t)=N_{r}(t) e^{\lambda N^{t}} / N^{o}(0),
$$

$$
\begin{aligned}
& \text { where } \begin{aligned}
\mathrm{f}_{\mathrm{N}}(t)= & \text { fractional release of nuclide } \mathrm{N}, \\
\mathrm{N}_{\mathrm{r}}(t)= & \text { atom population of nuclide released from the kernel or } \\
& \text { particle, } \\
\lambda_{\mathrm{N}}= & \text { decay constant of nuclide }(1 / \mathrm{t}), \\
\mathrm{N}^{0}(0)= & \text { the initial population of nuclide in the kernel, } \\
t= & \text { time measured from beginning of release at } t=0 .
\end{aligned}
\end{aligned}
$$

The fractional release is thus calculated by correcting for radiodecay to the beginning of release.

The fractional release, as defined by Eq. 4-1, has the limits 0 and 1 for $t=0$ and $\infty$, respectively. This can be demonstrated by using the population balance relation:

$$
N_{i}(t)+N_{r}(t)=N^{o}(0) e^{-\lambda} N^{t},
$$


where $\mathrm{N}_{i}(t)$ is the atom population of the nuclide retained by the kernel or particle. Combining Eqs. 4-1 and 4-2 leads to the following relation:

$$
f_{N}(t)=N_{r}(t) /\left[N_{r}(t)+N_{i}(t)\right] \quad .
$$

At $t=0, N_{r}(0)=0$ and $f_{N}(0)=0$; at $t=\infty, f_{N}(\infty)=1$ provided $N_{i}$ becomes zero before $\mathrm{N}_{r}$.

\subsection{RELATIVE RELEASE BEHAVIOR OF XENON AND IODINE}

To determine the relative release behavior of xenon and iodine, independent measurements of the fractional release of xenon and iodine are required. The method of obtaining these quantities has been described under item 1 in Section 2.3.2.

The particles used in these experiments were laser-failed BISO $\mathrm{ThO}_{2}$ particles with a burnup of $0.25 \%$ FIMA. Other data on these particles are presented in the first row of Table 3-1. In one experiment (number 7240-44) a particle broken in half was used.

The particles were reirradiated to generate the short-1ived nuclides of xenon and iodine, whose release was measured. As a result of $\mathrm{f}$ ission fragment recoil, about $2 \%$ of these nuclides escaped from the kernel and most were embedded in the coatings of the particles. Consequently, in experiments where the recoil fraction was greater than or comparable to the fractional release, the contribution from the diffusive release of embedded, recoil atoms to the fractional release had to be assessed in order to accurately establish the relative release behavior of xenon and iodine from the kernel. The contribution from recoils is shown in Section 7.2.6 to be negligible.

The experimental results for xenon and iodine are now considered. The fractional releases of iodine were based on measuring (1) the xenon generated by iodine radiodecay; (2) the lodine trapped on the mullite, 
charcoal, and quartz tube collectors; (3) the tellurium trapped on the collectors; and (4) the particle iodine activity at the beginning and end of each experiment when the fractional release was greater than 0.2 . The four types of measurement were used to obtain the fractional releases for iodine isotopes of mass numbers (1) 133 and 135; (2) 131, 133, and 135, (3) 132; and (4) 131, 133, and 135, respectively. The fractional release values obtained are listed in Table 4-1.

Determination of the fractional release of xenon requires that an analytical expression for the time dependence of the fractional release be known. This expression is necessary in order to exactly account for the contribution of iodine radiodecay to the xenon collected during the heating period. Although such an expression is developed in Section 5, the development is dependent, to a degree, on the results of the analysis discussed here. Consequently, to avold a circular development, the fractional release of xenon must be determined by an alternate (approximate) method.

The alternate method for determining the fractional release of xenon involves calculating upper and lower bounds based on variation in the iodine contribution to the fractional release of xenon. Fortunately, the difference between these upper and lower bounds to the fractional release turns out to be smaller than the experimental errors. This is a result of the short duration of the heating period during which iodine radiodecay contributes less than $14 \%$ to the inventory of collected xenon (except in Exp. 7240-42, an abnormally long experiment).

The bounds are presented in Table 4-2; these data have been calculated by using the following relation:

$$
f_{X e}=\frac{X_{r}-\left(\lambda_{I} / \lambda_{X e}\right) I_{r}\left(1-e^{-\lambda} X_{e}^{t}\right) \delta_{h L}}{\left(X_{i}^{o}+\lambda_{I} I_{I}^{o} t \delta_{h L}\right) e^{-\lambda} X e^{t}},
$$


TABLE 4-1

FRACT IONAL RELEASE OF IODINE ISOTOPES IN EXPERIMENTS ON THE RELATIVE RELEASE OF XENON AND IODINE

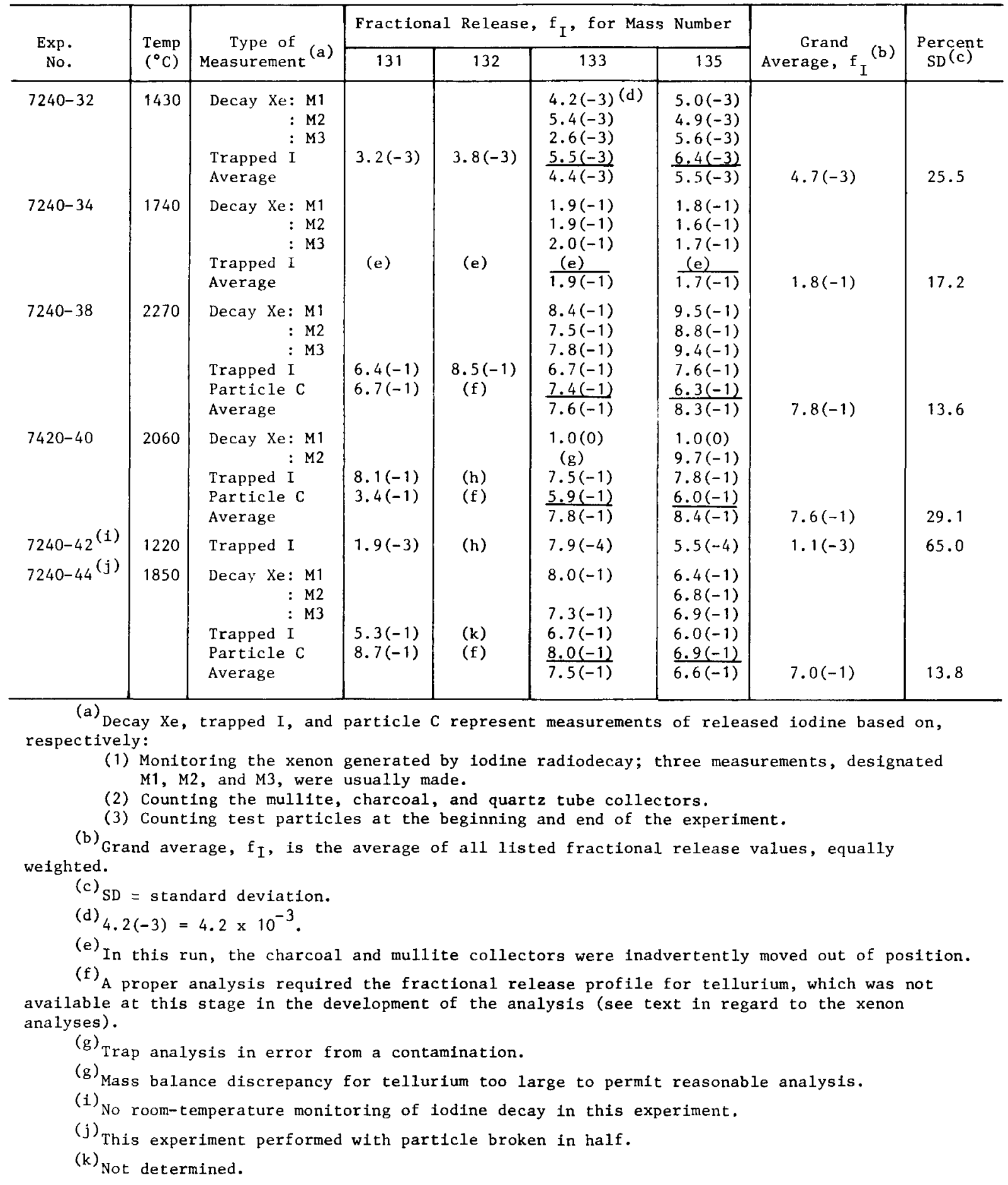


TABLE 4-2

UPPER (U) AND LOWER (L) BOUNDS BASED ON VARIATION IN THE IODINE CONTRIBUTION TO THE FRACTIONAL RELEASE OF XENON

IN EXPERIMENTS ON THE RELATIVE RELEASE OF XENON AND IODINE

\begin{tabular}{l|c|c|c|c|c}
\hline & \multirow{2}{*}{$\begin{array}{c}\text { Exp. } \\
\text { No. }\end{array}$} & \multirow{2}{*}{$\begin{array}{c}\text { Temp } \\
\left({ }^{\circ} \mathrm{C}\right)\end{array}$} & $\mathrm{L}$ & \multicolumn{2}{c}{$\mathrm{f}_{\mathrm{Xe}-135}$} \\
\cline { 3 - 6 } $7240-32$ & 1430 & $7.1(-3)(\mathrm{a})$ & $7.8(-3)$ & $4.7(-3)$ & $5.1(-3)$ \\
$7240-34$ & 1740 & $1.5(-1)$ & $1.6(-1)$ & $8.6(-2)$ & $9.8(-2)$ \\
$7240-38$ & 2270 & $71.0(0)$ & $\sim 1.0(0)$ & $7.6(-1)$ & $8.3(-1)$ \\
$7240-40$ & 2060 & $7.6(-1)$ & $8.1(-1)$ & $5.5(-1)$ & $6.1(-1)$ \\
$7240-42$ & 1220 & $8.1(-4)$ & $1.4(-3)$ & $4.0(-4)$ & $6.5(-4)$ \\
$7240-44$ & 1850 & $7.6(-1)$ & $8.1(-1)$ & $8.7(-1)$ & $9.3(-1)$ \\
\hline \multicolumn{2}{c}{ (a) $7.1(-3)=7.1 \times 10^{-3}}$.
\end{tabular}


where $\mathrm{Xe}_{i}^{O}, \mathrm{I}_{i}^{O}=$ atom population of $\mathrm{Xe}$ and $\mathrm{I}$ in the kernel at the beginning of the experiment,

$\delta_{h L}=$ Kronecker delta,

$\mathrm{h}=\mathrm{L}$ for lower bound calculation, $\mathrm{U}$ for upper bound calculation.

Generic definitions for other symbols have been given previously (see also List of Symbols in Appendix A).

The upper bound was obtained by neglecting the contribution of iodine to the released xenon; the fractional release of the initial xenon inventory in the particle must then be increased from its actual value to compensate for the lack of iodine as a source of part of the released xenon. The upper bound given by Eq. 4-4 was obtained by solving the differential equations for the release and decay of xenon in the absence of iodine. These equations are Eqs. 4-7 and 4-8 of Section 4.2.1.1, but without the iodine-related terms.

The lower bound was obtained by allowing (1) the xenon found in the kernel via iodine radiodecay during the experiment to be immediately accumulated at time zero, and (2) the iodine released from the particle during the experiment to be immediately released at time zero. Both these schemes increased the iodine contribution to xenon release above its actual value and consequently reduced the calculated fractional release of xenon, corresponding to direct xenon release, below its actual value. The lower bound given by Eq. 4-4 was obtained by solving (1) Eq. 4-7 with an initial xenon inventory of $\mathrm{Xe}_{i}^{0}+\lambda_{I} I_{i}^{0} t$ but without the iodine-related term, and (2) Eq. 4-8 with the quantity $I_{r}$ constant and equal to its final value in the experiment.

The fractional release of xenon and iodine nuclides can be shown to be equal by comparing the data of Tables 4-1 and 4-2 for mass numbers 133 and 135. This is illustrated in Fig. 4-1 where, on logarithmic scales, 


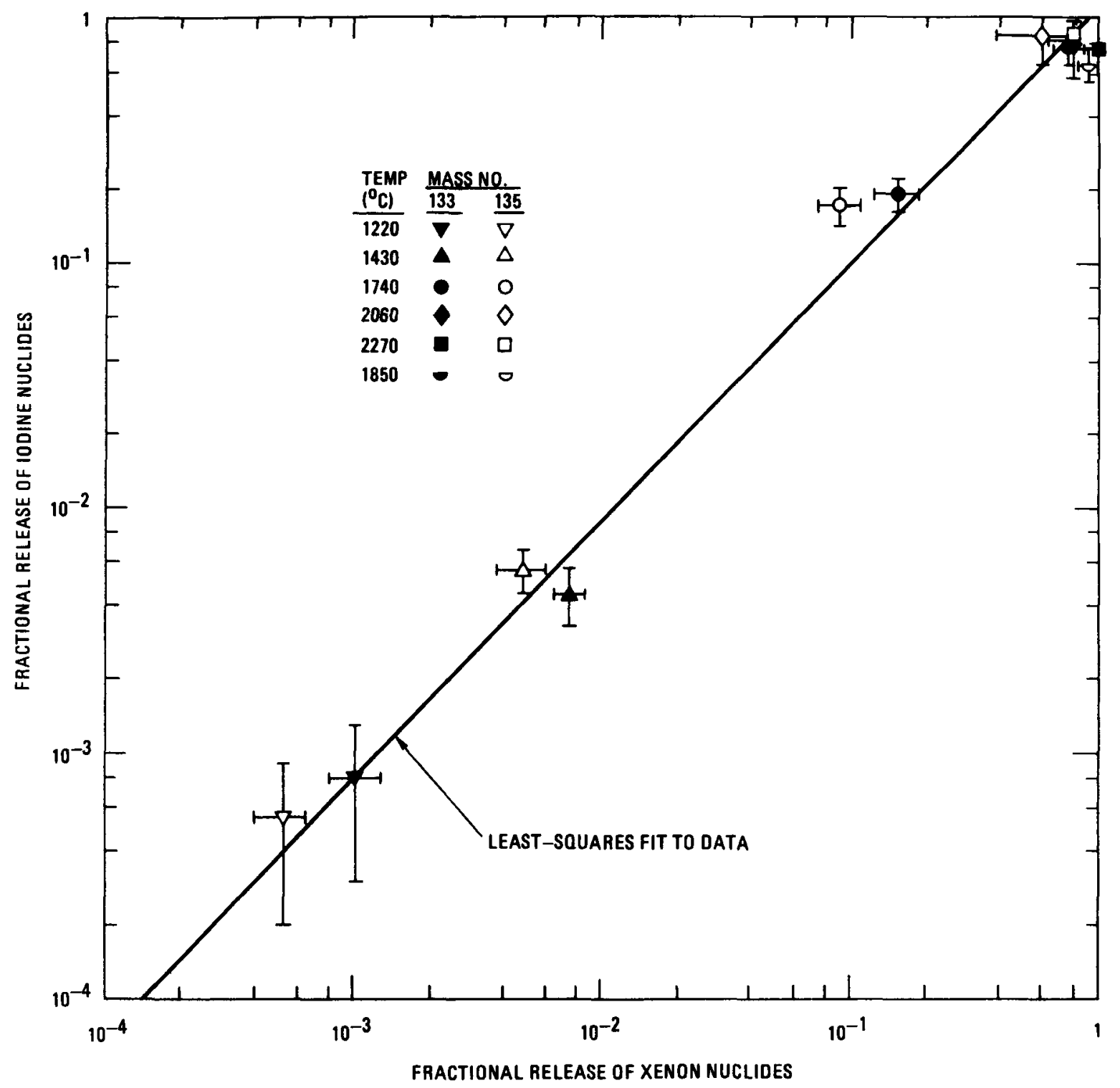

Fig. 4-1. Comparison of fractional release of xenon and iodine nuclides between $1200^{\circ}$ and $2300^{\circ} \mathrm{C}$ 
the fractional release of lodine is plotted against the fractional release of xenon for temperatures from $1220^{\circ}$ to $2270^{\circ} \mathrm{C}$ and mass numbers 133 and 135. The data plotted for fodine are the average values of fractional release given in Table 4-1 for mass numbers 133 and 135 and the data for xenon are the average of the upper and lower bounds to the fractional release given in Table 4-2.

By inspection of Fig. 4-1, it is evident that the fractional releases of xenon and iodine are equal within the experimental error. The error bars for iodine in Fig. 4-1 are taken from Table 4-1 and represent the error for the measurements on all nuclides of iodine by the three methods employed. Since there is only one xenon measurement per experiment, the same error bars are applied to corresponding nuclides of xenon. An exception to this procedure was made for the xenon data at $1220^{\circ} \mathrm{C}$. In this case, the upper and lower bounds taken from Table 4-2 were used in drawing the error bars; this was thought to be more realistic than using the abnormally large error associated with the iodine fractional release at $1220^{\circ} \mathrm{C}$.

The least-squares fit to the data in Fig. 4-1 is given by the equation

$$
\mathrm{f}_{\mathrm{I}}=1.12 \mathrm{f}_{\mathrm{Xe}}^{1.05}
$$

This fit was made by a method (Ref. 4-1) which accounts for the error in the fractional releases of both xenon and iodine. The curve of Eq. 4-5 deviates from the curve based on the equation $f_{I}=f_{X e}$ by less than $25 \%$. This discrepancy is within the experimental error.

The equality of the fractional release of xenon and iodine nuclides will be assumed in a1l subsequent analyses. While this equality has thus far only been established for $\mathrm{ThO}_{2}$ kernels with $0.25 \%$ FIMA, subsequent data and analyses presented below will confirm the equality for other burnups 
and for $\mathrm{UC}_{2}$ kernels. There is one exception, which is presented in Section 4.2.

\subsection{IOSTHERMAL AND TEMPERATURE RISE EXPERIMENTS}

The results of experiments under isothermal and temperature rise conditions are presented separately.

\subsubsection{Isothermal Experiments}

4.2.1.1. Xenon and Krypton. A representative fractional release profile for the isothermal experiments is shown in Fig. 4-2 for xenon release at $1430^{\circ} \mathrm{C}$ from a laser-failed $\mathrm{ThO}_{2}$ particle with $0.25 \%$ FIMA. This profile is characterized by four parameters: $t_{0}$, the intercept on the time axis at zero fractional release; $S$, the slope of the linear portion of the profile; $f_{\beta}$, the fractional release obtained by extrapolating the linear portion of the profile to $t_{0}$; and $t .8$, the time at which the fractional release, minus the contribution of the linear portion, reaches $0.8 \mathrm{f}_{\beta}$. The values of these parameters for all isothermal experiments are listed in Tables 4-3 through 4-6 for the nuclides Xe-135, $\mathrm{Kr}-85 \mathrm{~m}, \mathrm{Kr}-87$, and $\mathrm{Kr}-88$.

The parameters of the fractional release profile show a pronounced temperature dependence with the exception of $t_{0}{ }^{\circ}$ Between $1430^{\circ}$ and $2060^{\circ} \mathrm{C}$, $\mathrm{f}_{\beta}$ increases monotonically, and $\mathrm{t} .8$ and $\mathrm{S}$ generally increase to maximum values at intermediate temperatures and decline at higher temperatures. The temperature dependence of these parameters is treated quantitatively in Section 5 .

The values of the parameter $t_{0}$ are of the same order as the transit time of the fission gas between the fuel particles and the gas trap. The mean value of $t_{0}$ is $0.04 \mathrm{~h}$ with uncertainties of +0.05 and $-0.04 \mathrm{~h}$ including an estimate of $\pm 0.03 \mathrm{~h}$ in the start time of the experiments. The estimated transit time is $0.08 \mathrm{~h}$ (see Section 2.3.2). The trend in the 


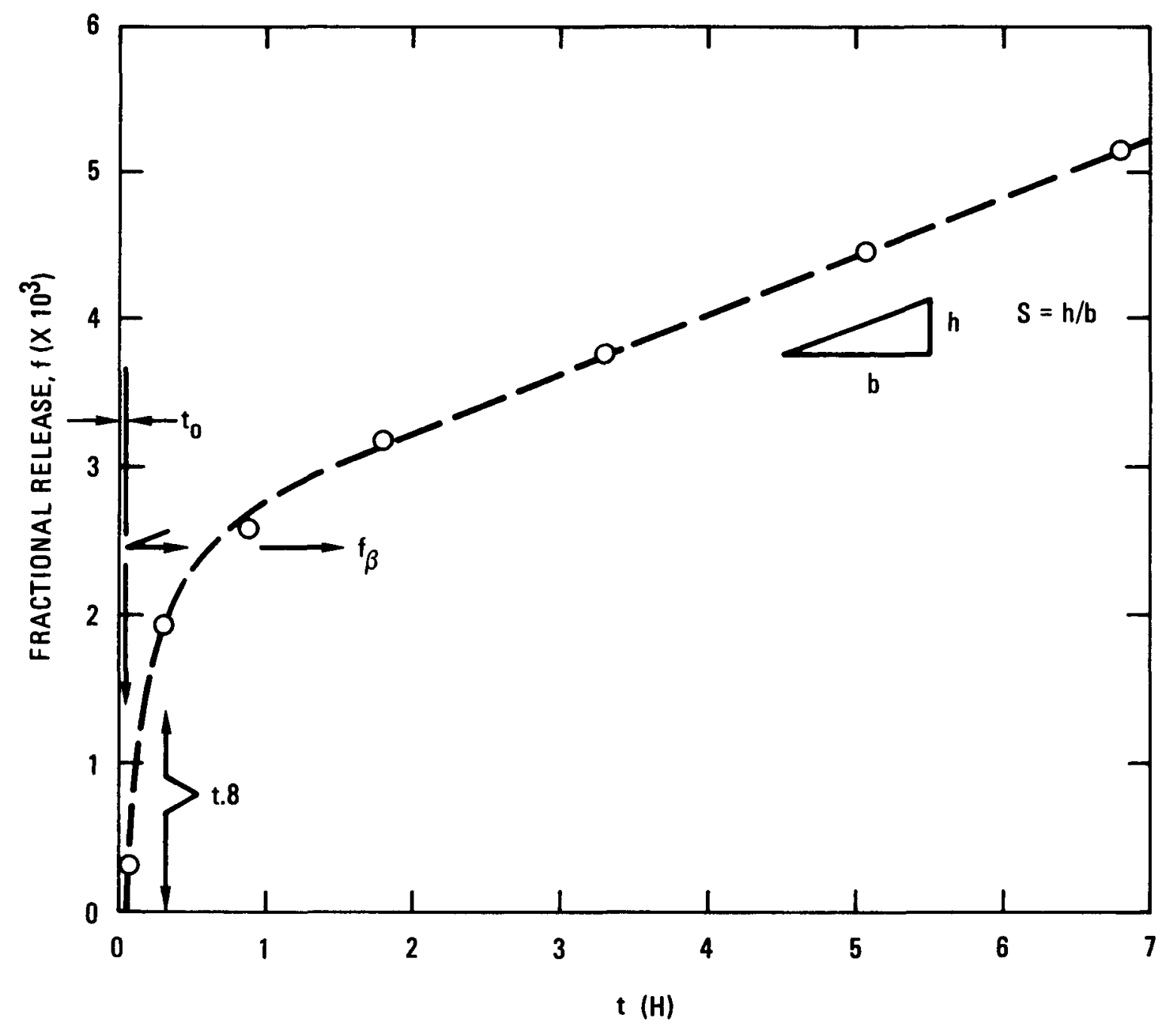

Fig. 4-2. Fractional release profile for $\mathrm{Xe}-135$ at $1430^{\circ} \mathrm{C}$ from laser-failed $\mathrm{ThO}_{2}$ particle with $0.25 \%$ FIMA 
TABLE 4-3

PARAMETERS CHARACTERIZING THE FRACTIONAL RELEASE PROFILES FOR Xe-135 IN ISOTHERMAL EXPERIMENTS

\begin{tabular}{l|c|l|c|c|c|c|c}
\hline \multicolumn{1}{|c|}{ Exp. No. } & $\begin{array}{c}\text { Temp } \\
\left({ }^{\circ} \mathrm{C}\right)\end{array}$ & Fuel & $\begin{array}{c}\text { Burnup } \\
(\% \text { FIMA })\end{array}$ & $\begin{array}{c}\mathrm{t}_{\mathrm{o}} \\
(\mathrm{h})\end{array}$ & $\begin{array}{c}\mathrm{t.8} \\
(\mathrm{h})\end{array}$ & $\mathrm{f}_{\beta}$ & $\begin{array}{c}\mathrm{S} \\
(1 / \mathrm{h})\end{array}$ \\
\hline $7240-49$ & 1430 & $\mathrm{ThO}_{2}$ & 0.25 & $7.6(-2)(\mathrm{a})$ & 0.315 & $2.5(-3)$ & $4.0(-4)$ \\
$7240-48$ & 1740 & $\mathrm{ThO}_{2}$ & 0.25 & $2.6(-2)$ & 1.024 & $3.0(-2)$ & $1.2(-2)$ \\
$7240-51$ & 2060 & $\mathrm{ThO}_{2}$ & 0.25 & $1.9(-1)$ & 0.618 & $6.3(-1)$ & $(\mathrm{b})$ \\
$7240-62$ & 1430 & $\mathrm{ThO}_{2}$ & 1.4 & $9.4(-2)$ & 0.372 & $8.1(-4)$ & $1.9(-5)$ \\
$7240-64(\mathrm{c})$ & 1740 & $\mathrm{ThO}_{2}$ & 1.4 & $5.1(-2)$ & 1.028 & $1.2(-2)$ & $5.0(-4)$ \\
$7240-66$ & 2060 & $\mathrm{ThO}_{2}$ & 1.4 & $9.8(-2)$ & 0.535 & $8.4(-1)$ & $(\mathrm{d})$ \\
$7240-70$ & 1430 & $\mathrm{ThO}_{2}$ & 15.7 & $4.9(-2)$ & 0.118 & $2.5(-2)$ & $8.0(-4)$ \\
$7240-72$ & 1740 & $\mathrm{ThO}_{2}$ & 15.7 & $8.3(-2)$ & 0.280 & $4.5(-2)$ & $1.5(-2)$ \\
$7240-74$ & 2060 & $\mathrm{ThO}_{2}$ & 15.7 & $(\mathrm{~b})$ & 0.096 & $1.0(0)$ & $(\mathrm{d})$ \\
$7240-82$ & 1430 & $\mathrm{UC}_{2}$ & 23.5 & $7.4(-2)$ & 0.585 & $9.8(-3)$ & $1.6(-3)$ \\
$7240-84$ & 1740 & $\mathrm{UC}_{2}$ & 23.5 & $7.0(-2)$ & $(\mathrm{b})$ & $9.7(-1)$ & $\sim 5.0(-3)$ \\
$7240-86$ & 2060 & $\mathrm{UC}_{2}$ & 23.5 & $6.5(-2)$ & 0.153 & $1.0(0)$ & $(\mathrm{d})$ \\
$7240-88$ & 1430 & $\mathrm{UC}_{2}$ & 74.0 & $1.6(-2)$ & 0.465 & $1.6(-2)$ & $3.5(-3)$ \\
$7240-100$ & 1585 & $\mathrm{UC}_{2}$ & 74.0 & $3.2(-2)$ & 0.649 & $6.7(-1)$ & $1.8(-2)$ \\
$7240-92$ & 1740 & $\mathrm{UC}_{2}$ & 74.0 & $3.3(-2)$ & 0.694 & $9.0(-1)$ & $(\mathrm{d})$ \\
\hline
\end{tabular}

(a) $7.6(-2)=7.6 \times 10^{-2}$.

(b) Could not be reliably determined.

(c) The parameters in this row are the average of two experiments, 7240-64 and 7240-94.

(d) Slope is very small and could not be reliably determined. 
TABLE 4-4

PARAMETERS CHARACTERIZING THE FRACTIONAL RELEASE PROFILES FOR $\mathrm{Kr}-85 \mathrm{~m}$ IN ISOTHERMAL EXPERIMENTS

\begin{tabular}{l|c|c|c|c|c|c|c}
\hline Exp. No. & $\begin{array}{c}\text { Temp } \\
\left({ }^{\circ} \mathrm{C}\right)\end{array}$ & Fue1 & $\begin{array}{c}\text { Burnup } \\
(\% \text { FIMA })\end{array}$ & $\begin{array}{c}t_{\mathrm{o}} \\
(\mathrm{h})\end{array}$ & $\begin{array}{c}t .8 \\
(\mathrm{~h})\end{array}$ & $\mathrm{f}_{\beta}$ & $\begin{array}{c}\mathrm{S} \\
(1 / \mathrm{h})\end{array}$ \\
\hline $7240-62$ & 1430 & $\mathrm{ThO}_{2}$ & 1.4 & $8.4(-2)(\mathrm{a})$ & 0.610 & $3.0(-3)$ & $3.6(-4)$ \\
$7240-64(\mathrm{~b})$ & 1740 & $\mathrm{ThO}_{2}$ & 1.4 & $1.8(-2)$ & 0.781 & $2.8(-2)$ & $1.05(-3)$ \\
$7240-66$ & 2060 & $\mathrm{ThO}_{2}$ & 1.4 & $1.7(-2)$ & 0.472 & $8.3(-1)$ & $6.8(-2)$ \\
$7240-70$ & 1430 & $\mathrm{ThO}_{2}$ & 15.7 & $\sim 0$ & 0.253 & $2.1(-2)$ & $3.7(-4)$ \\
$7240-72$ & 1740 & $\mathrm{ThO}_{2}$ & 15.7 & $\sim 0$ & 0.146 & $4.0(-2)$ & $3.0(-2)$ \\
$7240-74$ & 2060 & $\mathrm{ThO}_{2}$ & 15.7 & $1.6(-2)$ & 0.510 & $9.9(-1)$ & $1.9(-3)$ \\
$7240-82$ & 1430 & $\mathrm{UC}_{2}$ & 23.5 & $8.2(-2)$ & 0.741 & $4.5(-2)$ & $3.3(-3)$ \\
$7240-84$ & 1740 & $\mathrm{UC}_{2}$ & 23.5 & $4.5(-2)$ & $\sim 5$ & $9.5(-1)$ & $1.3(-2)$ \\
$7240-86$ & 2060 & $\mathrm{UC}_{2}$ & 23.5 & $\sim 0$ & 0.156 & $1.0(0)$ & $\sim 0$ \\
$7240-88$ & 1430 & $\mathrm{UC}_{2}$ & 74.0 & $4.0(-2)$ & 0.223 & $8.0(-3)$ & $1.8(-3)$ \\
$7240-100$ & 1585 & $\mathrm{UC}_{2}$ & 74.0 & $2.9(-2)$ & 1.74 & $7.5(-1)$ & $2.3(-2)$ \\
$7240-92$ & 1740 & $\mathrm{UC}_{2}$ & 74.0 & $3.3(-2)$ & 1.29 & $1.0(0)$ & $\sim 0$ \\
\hline
\end{tabular}


TABLE 4-5

PARAMETERS CHARACTERIZING THE FRACTIONAL RELEASE PROFILES FOR $\mathrm{Kr}-87$ IN ISOTHERMAL EXPERIMENTS

\begin{tabular}{l|c|c|c|c|c|c|c}
\hline Exp. No. & $\begin{array}{c}\text { Temp } \\
\left({ }^{\circ} \mathrm{C}\right)\end{array}$ & Fue1 & $\begin{array}{c}\text { Burnup } \\
(\% \text { FIMA })\end{array}$ & $\begin{array}{c}\mathrm{t}_{\mathrm{o}} \\
(\mathrm{h})\end{array}$ & $\begin{array}{c}\mathrm{t.8} \\
(\mathrm{h})\end{array}$ & $\mathrm{f}_{\beta}$ & $\begin{array}{c}\mathrm{S} \\
(1 / \mathrm{h})\end{array}$ \\
\hline $7240-62$ & 1430 & $\mathrm{ThO}_{2}$ & 1.4 & $8.0(-2)(\mathrm{a})$ & 0.649 & $(\mathrm{~b})$ & $3.0(-4)$ \\
$7240-64(\mathrm{c})$ & 1740 & $\mathrm{ThO}_{2}$ & 1.4 & $\sim 0$ & 0.469 & $(\mathrm{~b})$ & $1.5(-3)$ \\
$7240-66$ & 2060 & $\mathrm{ThO}_{2}$ & 1.4 & $1.7(-2)$ & 0.523 & $(\mathrm{~b})$ & $2.8(-2)$ \\
$7240-70$ & 1430 & $\mathrm{Tho}_{2}$ & 15.7 & $\sim 0$ & 0.398 & $2.1(-2)$ & $3.6(-4)$ \\
$7240-72$ & 1740 & $\mathrm{ThO}_{2}$ & 15.7 & $\sim 0$ & 0.121 & $4.5(-2)$ & $2.0(-2)$ \\
$7240-74$ & 2060 & $\mathrm{Tho}_{2}$ & 15.7 & $1.6(-2)$ & 0.417 & $7.9(-1)$ & $1.3(-2)$ \\
$7240-82$ & 1430 & $\mathrm{UC}_{2}$ & 23.5 & $8.1(-2)$ & 0.556 & $2.5(-2)$ & $3.3(-3)$ \\
$7240-84$ & 1740 & $\mathrm{UC}_{2}$ & 23.5 & $\sim 5(-2)$ & 25 & $9.3(-1)$ & $1.3(-2)$ \\
$7240-86$ & 2060 & $\mathrm{UC}_{2}$ & 23.5 & $3.0(-2)$ & 0.122 & $1.0(0)$ & $\sim 0$ \\
$7240-88$ & 1430 & $\mathrm{UC}_{2}$ & 74.0 & $4.0(-2)$ & 0.239 & $5.5(-2)$ & $1.6(-2)$ \\
$7240-100$ & 1585 & $\mathrm{UC}_{2}$ & 74.0 & $2.9(-2)$ & 0.549 & $1.3(-1)$ & $3.0(-2)$ \\
$7240-92$ & 1740 & $\mathrm{UC}_{2}$ & 74.0 & $3.3(-2)$ & 1.11 & $1.0(0)$ & $\sim 0$ \\
\hline
\end{tabular}


TABLE $4-6$

PARAMETERS CHARACTERIZING THE FRACTIONAL RELEASE PROFILES FOR Kr-88

IN ISOTHERMAL EXPERIMENTS

\begin{tabular}{|c|c|c|c|c|c|c|c|}
\hline Exp. No. & $\begin{array}{l}\text { Temp } \\
\left({ }^{\circ} \mathrm{C}\right)\end{array}$ & Fue1 & $\begin{array}{l}\text { Burnup } \\
(\% \text { FIMA) }\end{array}$ & $\begin{array}{l}t_{0} \\
(h)\end{array}$ & $\begin{array}{l}\text { t. } 8 \\
\text { (h) }\end{array}$ & $\mathrm{f}_{\beta}$ & $\begin{array}{c}S \\
(1 / h)\end{array}$ \\
\hline $7240-62$ & 1430 & $\mathrm{ThO}_{2}$ & 1.4 & $7.4(-2)(a)$ & 0.704 & $2.8(-3)$ & $2.9(-4)$ \\
\hline $7240-64^{(b)}$ & 1740 & $\mathrm{ThO}_{2}$ & 1.4 & $1.2(-2)$ & 0.781 & $3.3(-2)$ & $2.0(-3)$ \\
\hline $7240-66$ & 2060 & $\mathrm{ThO}_{2}$ & 1.4 & $1.7(-2)$ & 0.532 & $7.1(-1)$ & $5.6(-2)$ \\
\hline $7240-70$ & 1430 & $\mathrm{ThO}_{2}$ & 15.7 & $\sim 0$ & 0.356 & $2.1(-2)$ & $3 \cdot 3(-4)$ \\
\hline $7240-72$ & 1740 & $\mathrm{ThO}_{2}$ & 15.7 & no & 0.162 & $2.6(-2)$ & $3.6(-2)$ \\
\hline $7240-74$ & 2060 & $\mathrm{ThO}_{2}$ & 15.7 & $1.6(-2)$ & 0.303 & $9.7(-1)$ & $6.7(-3)$ \\
\hline $7240-82$ & 1430 & $\mathrm{UC}_{2}$ & 23.5 & $8.2(-2)$ & 0.637 & $4.5(-2)$ & $3.3(-3)$ \\
\hline $7240-84$ & 1740 & $\mathrm{UC}_{2}$ & 23.5 & ح5 $(-2)$ & $\sim 5$ & $9.5(-1)$ & $1.3(-2)$ \\
\hline $7240-86$ & 2060 & $\mathrm{UC}_{2}$ & 23.5 & حo & 0.149 & $1.0(0)$ & $v_{0}$ \\
\hline $7240-88$ & 1430 & $\mathrm{UC}_{2}$ & 74.0 & $4.0(-2)$ & 0.279 & $3.3(-2)$ & $5.2(-3)$ \\
\hline $7240-100$ & 1585 & $\mathrm{UC}_{2}$ & 74.0 & $2.9(-2)$ & 1.03 & $4 \cdot 2(-1)$ & $3.2(-2)$ \\
\hline $7240-92$ & 1740 & $\mathrm{UC}_{2}$ & 74.0 & 3. $3(-2)$ & 1.21 & $1.0(0)$ & vo \\
\hline
\end{tabular}


values of $t_{0}$ is to decline with increasing temperature and burnup, but these trends are not statistically significant. Regarding $t_{0}$ as the transit time is the most reasonable interpretation.

To obtain a fractional release profile for xenon, such as shown in Fig. 4-2, the contribution to the released xenon from iodine radiodecay had to be taken into account. This was accomplished by solving the following three differential equations for the release and decay of iodine and xenon nuclides:

$$
\begin{aligned}
& \dot{\mathrm{I}}_{i}=-\lambda_{I} \mathrm{I}_{i}-\frac{\dot{\mathrm{f}}_{I_{i}}}{1-\mathrm{f}_{I}} \text {, } \\
& \dot{\mathrm{X}}_{i}=\lambda_{\mathrm{I}} \mathrm{I}_{\mathrm{i}}-\lambda_{\mathrm{Xe}} \mathrm{Xe}_{i}-\frac{\dot{\mathrm{f}_{\mathrm{Xe}} \mathrm{Xe}_{\mathrm{i}}}}{1-\mathrm{f}_{\mathrm{Xe}}} \text {, } \\
& \dot{\mathrm{X}}_{r}=-\lambda_{\mathrm{Xe}} \mathrm{Xe}_{r}+\lambda_{\mathrm{I}} \mathrm{I}_{r}+\frac{\dot{\mathrm{f}}_{\mathrm{Xe}} \mathrm{Xe}_{i}}{1-\mathrm{f}_{\mathrm{Xe}}},
\end{aligned}
$$

where $\dot{\mathrm{X}} \equiv \mathrm{dx} / \mathrm{dt}$. Generic definitions for other symbols have been given in connection with Eq. 4-1 (see also the List of Symbols in Appendix A). These equations are solved for $\mathrm{Xe}_{\mathrm{r}}$ using $\mathrm{f}_{\mathrm{Xe}}=\mathrm{f}_{\mathrm{I}}$ and $\mathrm{Eq}$. 4-2, with $\mathrm{N}=\mathrm{I}$, to eliminate $I_{r}$. The solution is:

$$
\begin{aligned}
X_{r}= & {\left[X e_{i}^{o} e^{-\lambda} X e^{t}+\frac{\lambda_{I} I_{i}^{o}\left(e^{-\lambda} X e^{t}-e^{-\lambda} I^{t}\right)}{\lambda_{I}-\lambda \lambda_{e}}\right] f } \\
& +\lambda_{I^{I}}^{o} e^{-\lambda} X e^{t} \int_{0}^{t} e^{-\left(\lambda_{I}-\lambda_{X e}\right) t^{\prime}} f\left(t^{\prime}\right) d t^{\prime}
\end{aligned}
$$

The three terms on the right side of Eq. 4-9, reading from left to right, represent (1) release of xenon initially in the kernel, (2) release from 
the particle of xenon formed by radiodecay of iodine, and (3) xenon formed outside the particle by radiodecay of released iodine.

Equation 4-9 is solved, iteratively, for $f$ at each measurement time. In the case of xenon release at $1430^{\circ} \mathrm{C}$ from laser-failed $\mathrm{ThO}_{2}$ particles with $0.25 \%$ FIMA, this procedure has yielded the data represented by the circles in Fig. 4-2.

The fractional release is linearly dependent on time for times greater than $1 \mathrm{~h}$, as shown in Fig. 4-2. Al1 the data from the isothermal experiments support this conclusion. The linear dependence can be justified theoretically; this is considered in Section 7.

If the release occurred strictly in accordance with Fick's second law of diffusion, then the fractional release (for the equivalent sphere model) would be proportional to the square root of time for fractional release values $\leqslant 0.3$ (Ref, 4-2). However, data from the isothermal experiments clearly demonstrate that the fractional release is dependent on $t$ and not on $\sqrt{t}$. This is illustrated by the example shown in Fig. 4-3.

4.2.1.2. Iodine and Tellurium. Since only two measurements of iodine and tellurium were made in each experiment and at times greater than $1 \mathrm{~h}$, only the parameters $f_{\beta}$ and $S$ (see Fig. 4-2) can be determined. The parameters $t_{0}$ and $t .8$ cannot be determined. The values of $f_{\beta}$ and $s$ for iodine are presented in Table 4-7 and those for tellurium in Table 4-8.

The charcoal, mullite, and quartz collectors (see Section 2.4) for the released iodine and tellurium were not entirely efficient under the conditions of the experiments. For heating experiments of 1 -h duration, on $1 y$ about $85 \%$ of the released lodine was trapped on these collectors (based on the data of Table 4-1 and assuming an accurate measurement of iodine release to be monitoring of xenon from iodine radiodecay during the postheating period, as described in 1tem 1 of Section 2.3.2). Consequently, the values of $\mathrm{f}_{\beta}$ in Tables $4-7$ and $4-8$ are likely to be low; the 


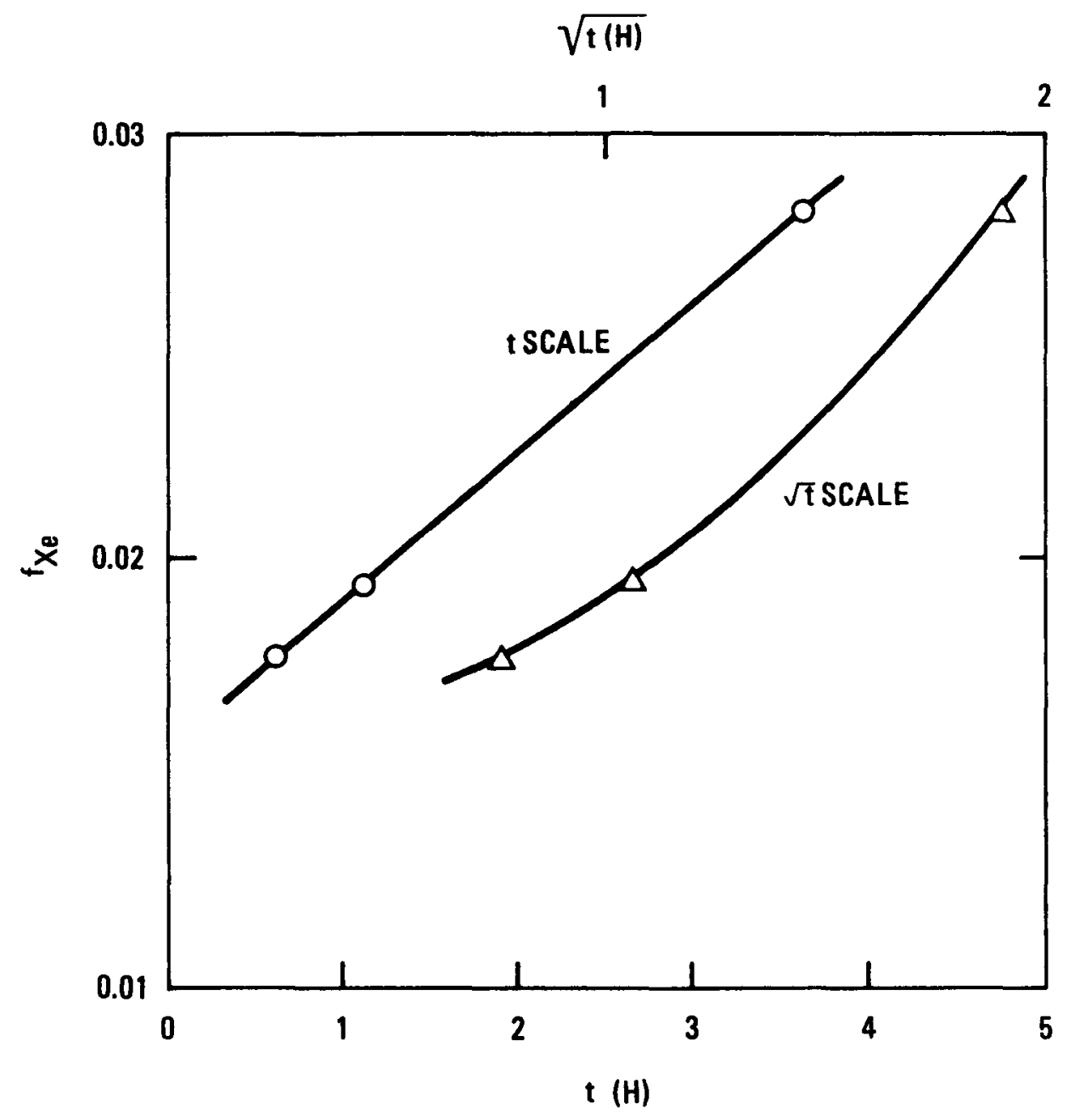

Fig. 4-3. Comparison of the dependence of fractional release on $t$ and $\sqrt{t}$. (Data are from Exp. $7240-88$ at $1430^{\circ} \mathrm{C}$. ) 
TABLE 4-7

PARAMETERS CHARACTERIZING THE FRACTIONAL RELEASE FOR I-131, I-133, AND I-135 IN ISOTHERMAL EXPERIMENTS

\begin{tabular}{|c|c|c|c|c|c|c|c|c|c|}
\hline \multirow[b]{2}{*}{ Exp. No. } & \multirow[b]{2}{*}{$\begin{array}{l}\text { Temp } \\
\left({ }^{\circ} \mathrm{C}\right)\end{array}$} & \multirow[b]{2}{*}{ Fuel } & \multirow[b]{2}{*}{$\begin{array}{c}\text { Burnup } \\
\text { (\% FIMA) }\end{array}$} & \multicolumn{2}{|c|}{$I-131$} & \multicolumn{2}{|c|}{$I-133$} & \multicolumn{2}{|c|}{$I-135$} \\
\hline & & & & $\mathbf{f}_{\beta}$ & $\begin{array}{c}S \\
(1 / h)\end{array}$ & $\mathrm{f}_{\beta}$ & $\begin{array}{c}S \\
(1 / h)\end{array}$ & $\mathrm{f}_{\beta}$ & $\begin{array}{c}S \\
(1 / h)\end{array}$ \\
\hline $7240-62$ & 1430 & $\mathrm{ThO}_{2}$ & 1.4 & $2.0(-4)(a)$ & $5.9(-5)$ & $6.2(-4)$ & $4.8(-5)$ & $5.9(-4)$ & $1.4(-4)$ \\
\hline $7240-64^{(b)}$ & 1740 & $\mathrm{ThO}_{2}$ & 1.4 & $5.2(-3)$ & $9.4(-4)$ & $5.4(-3)$ & $8 \cdot 3(-4)$ & $6.7(-3)$ & $9.9(-4)$ \\
\hline $7240-66$ & 2060 & $\mathrm{ThO}_{2}$ & 1.4 & $\mathrm{NR}(\mathrm{c})$ & $7.9(-2)$ & $5.8(-1)(d)$ & $2.9(-2)$ & $5.6(-1)(d)$ & $8.7(-2)$ \\
\hline $7240-70$ & 1430 & $\mathrm{ThO}_{2}$ & 15.7 & NR & NR & $1.0(-2)$ & $3.9(-4)$ & NR & NR \\
\hline $7240-72$ & 1740 & $\mathrm{ThO}_{2}$ & 15.7 & NR & NR & $7.6(-2)$ & $1.7(-3)$ & $3.0(-2)$ & $7.3(-3)$ \\
\hline $7240-74$ & 2060 & $\mathrm{ThO}_{2}$ & 15.7 & $9 \cdot 1(-1)(d)$ & $5.6(-3)$ & NR & NR & $9.5(-1)^{(d)}$ & $8.4(-3)$ \\
\hline $7240-82$ & 1430 & $\mathrm{UC}_{2}$ & 23.5 & $1.0(-2)$ & $1.2(-3)$ & $1.0(-2)$ & $1.6(-3)$ & $1.1(-2)$ & $1.7(-3)$ \\
\hline $7240-84$ & 1740 & $\mathrm{UC}_{2}$ & 23.5 & $\sim 5(-1)(e)$ & (e) & $27(-1)(e)$ & (e) & $\sim 7(-1)(e)$ & (e) \\
\hline $7240-86$ & 2060 & $\mathrm{UC}_{2}$ & 23.5 & $9.9(-1)^{(d)}$ & $\sim 0$ & $7.8(-1)$ & $\sim 0$ & $1.0(0)$ & $\sim_{0}$ \\
\hline $7240-88$ & 1430 & $\mathrm{UC}_{2}$ & 74.0 & NR & NR & $5.0(-3)$ & $4.2(-3)$ & $4.0(-3)$ & $4.8(-3)$ \\
\hline $7240-100$ & 1585 & $\mathrm{UC}_{2}$ & 74.0 & NR & NR & $2.5(-1)$ & $9.4(-2)$ & $2.8(-1)$ & $4.8(-2)$ \\
\hline $7240-92$ & 1740 & $\mathrm{UC}_{2}$ & 74.0 & $\mathrm{NR}$ & NR & $2.0(-2)$ & $1.8(-1)$ & $1.0(-2)$ & $1.7(-1)$ \\
\hline
\end{tabular}

(a) $2.0(-4)=2.0 \times 10^{-4}$.

(b) The parameters in this row are the average of two experiments, 7240-64 and 7240-94.

${ }^{(c)} \mathrm{NR}=$ data on this isotope not reported in gamma ray spectroscopy analysis.

(d) Normalized on basis of measured particle activity after test (see text, Section 4.2.1.2).

${ }^{(e)}$ Could not be reliably determined. 
TABLE 4-8

PARAMETERS CHARACTERIZING THE FRACTIONAL RELEASE FOR Te-132 IN ISOTHERMAL EXPERIMENTS

\begin{tabular}{|c|c|c|c|c|c|}
\hline Exp. No. & $\begin{array}{l}\text { Temp } \\
\left({ }^{\circ} \mathrm{C}\right)\end{array}$ & Fue1 & $\begin{array}{l}\text { Burnup } \\
(\% \text { FIMA })\end{array}$ & $\mathbf{f}_{\beta}$ & $\begin{array}{c}S \\
(1 / h)\end{array}$ \\
\hline $7240-62$ & 1430 & $\mathrm{ThO}_{2}$ & 1.4 & $7.0(-4)(a)$ & $4.0(-5)$ \\
\hline $7240-64^{(b)}$ & 1740 & $\mathrm{ThO}_{2}$ & 1.4 & $1.2(-2)$ & $3.2(-3)$ \\
\hline $7240-66$ & 2060 & $\mathrm{ThO}_{2}$ & 1.4 & $>3.3(-1)$ & $1.3(-2)$ \\
\hline $7240-70$ & 1430 & $\mathrm{ThO}_{2}$ & 15.7 & $\sim 9(-3)$ & $5.0(-4)$ \\
\hline $7240-72$ & 1740 & $\mathrm{ThO}_{2}$ & 15.7 & (c) & $9.3(-3)$ \\
\hline $7240-74$ & 2060 & $\mathrm{ThO}_{2}$ & 15.7 & $8.5(-1)$ & (c) \\
\hline
\end{tabular}


values of $S$ will be in error if the collection efficiency changes with time. (The experiments yielding the $\mathrm{S}$ values were of approximately $5-\mathrm{h}$ duration.)

The error in values of $f_{\beta}$ resulting from inefficiency in collection could be compensated, in a few instances, by a normalization procedure. In these instances, the $f_{\beta}$ values were multiplied by the ratio of the total release based on particle activity to the total release based on collector activity. The particle activity could be accurately determined from pretest and posttest measurements in experiments where fractional releases were greater than 0.2 .

The parameters $f_{\beta}$ and $S$ for iodine and tellurium can be further evaluated by comparison with those for xenon. Iodine is considered first.

The values of $f_{\beta}$ for iodine and xenon are compared in Fig. 4-4. A least-squares fit (Ref. 4-1) to the data is given by the equation

$$
\mathrm{f}_{\beta, I}=0.66 \mathrm{f}_{\beta, \mathrm{Xe}}^{0.96} \text {, }
$$

as shown in Fig. 4-4. The curve of Eq. 4-10 deviates from the curve based on the equation $\mathrm{f}_{\beta, \mathrm{I}}=\mathrm{f}_{\beta, \mathrm{Xe}}$ by $-25 \%$, on the average. Of this deviation, $60 \%$ can be attributed to the collector inefficiency, as discussed above. The residual discrepancy is less than experimental error. Therefore, $\mathrm{f}_{\beta, \mathrm{I}}$ is not significantly different from $\mathrm{f}_{\beta, \mathrm{Xe}}$.

An exception to the conclusion that $f_{B, I}=f_{B, X e}$ is clearly shown in Fig. $4-4$ by the data for $U_{2}$ at $1740^{\circ} \mathrm{C}$ and $74 \%$ FIMA with $f_{B, I}=0.01$ and 0.02 . In deriving Eq. 4-10, these data were omitted.

The $\mathrm{f}_{\beta, \mathrm{I}}$ values for $\mathrm{UC}_{2}$ at $1740^{\circ} \mathrm{C}$ and $74 \%$ FIMA indicate than an additional process is involved in the iodine release. Norma11y, the fractional release for iodine could be represented by a curve such as curve A 


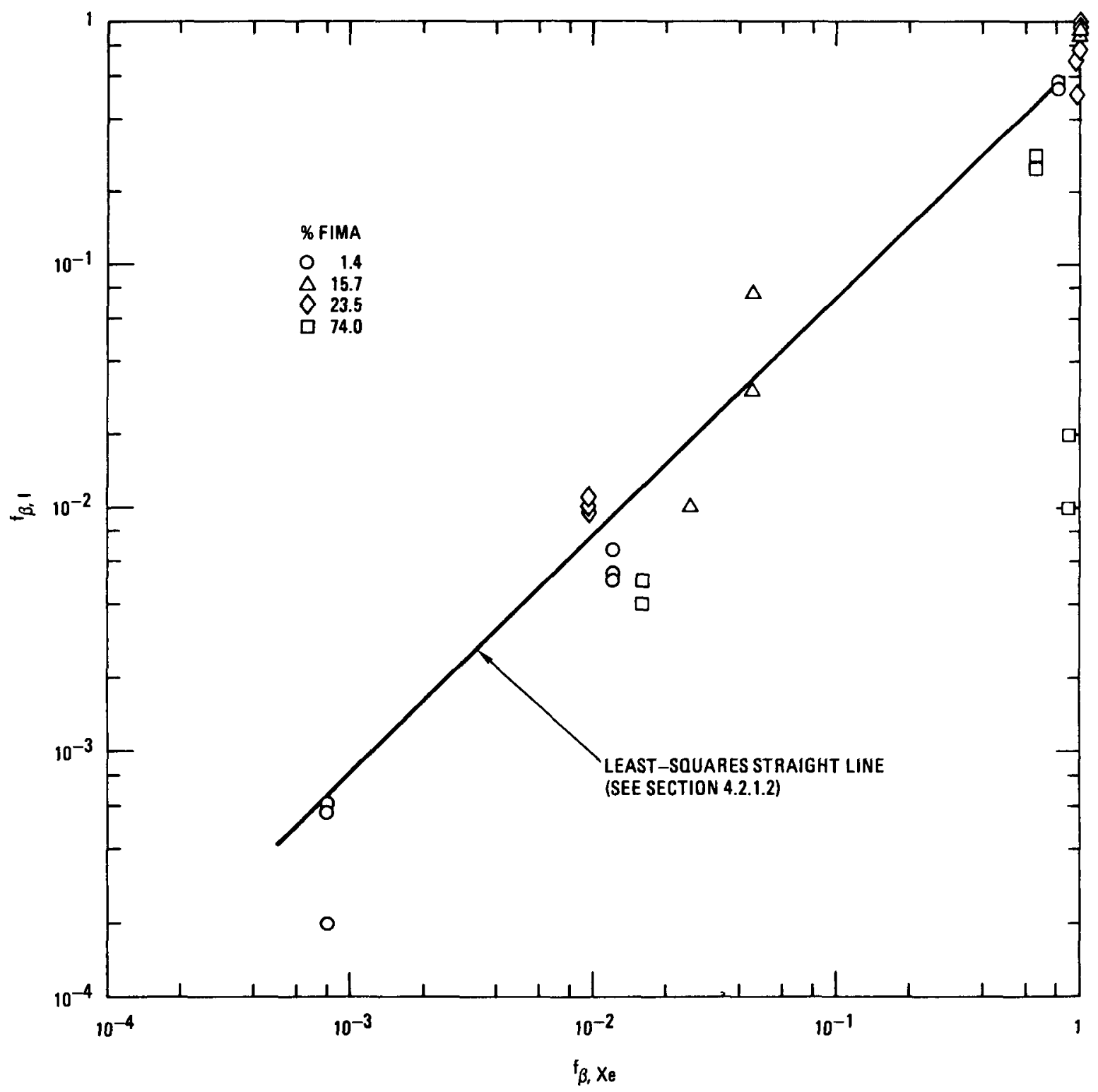

Fig. 4-4. Comparison of $f_{\beta}$ values for iodine and xenon nuclides determined in isothermal experiments 
in Fig. 4-5, which is the actual xenon release curve for $\mathrm{UC}_{2}$ at $1740^{\circ} \mathrm{C}$ and $74 \%$ FIMA. However, the corresponding curves for lodine are given by the B curves in Fig. 4-5. Thus, the mechanism of release for iodine in $\mathrm{UC}_{2}$ at high burnup is clearly different from that for xenon; a possible explanation for this is presented in Section 7 .

Comparing the values of $\mathrm{S}$ for lodine and xenon leads to a leastsquares fit given by the equation

$$
\mathrm{S}_{\mathrm{I}}=0.82 \mathrm{~s}_{\mathrm{Xe}}^{0.94}
$$

The average deviation of $S_{I}$ values calculated according to Eq. 4-11 from those calculated according to the equation $\mathrm{S}_{I}=\mathrm{S}_{\mathrm{Xe}}$ is $+25 \%$; this is we11 within the scatter of the data. Therefore, $S_{I}$ is not significantly different from $\mathrm{S}_{\mathrm{Xe}}$.

The $f_{\beta}$ and $S$ values for tellurium have been compared with those of xenon in the same manner as for lodine. The results of the comparisons are expressed by the following equations:

$$
\mathrm{f}_{B, \mathrm{Te}}=0.72 \mathrm{f}_{B, \mathrm{Xe}}
$$

and

$$
\mathrm{S}_{\mathrm{Te}}=0.59 \mathrm{~s}_{\mathrm{Xe}}^{0.87}
$$

which represent least-squares fits (Ref. 4-1) to the data. Equations 4-12 and 4-13 yield parameter values for tellurium which deviate, on the average, $-28 \%$ and $+45 \%$, respectively, from those for xenon. Although these deviations are not sma11, they are within the scatter in the data. Therefore, $\mathrm{f}_{B, \mathrm{Te}}$ and $\mathrm{S}_{\mathrm{Te}}$ cannot be considered as significantly different from $\mathrm{f}_{B, \mathrm{Xe}}$ and $\mathrm{S}_{\mathrm{Xe}}$, respectively. 


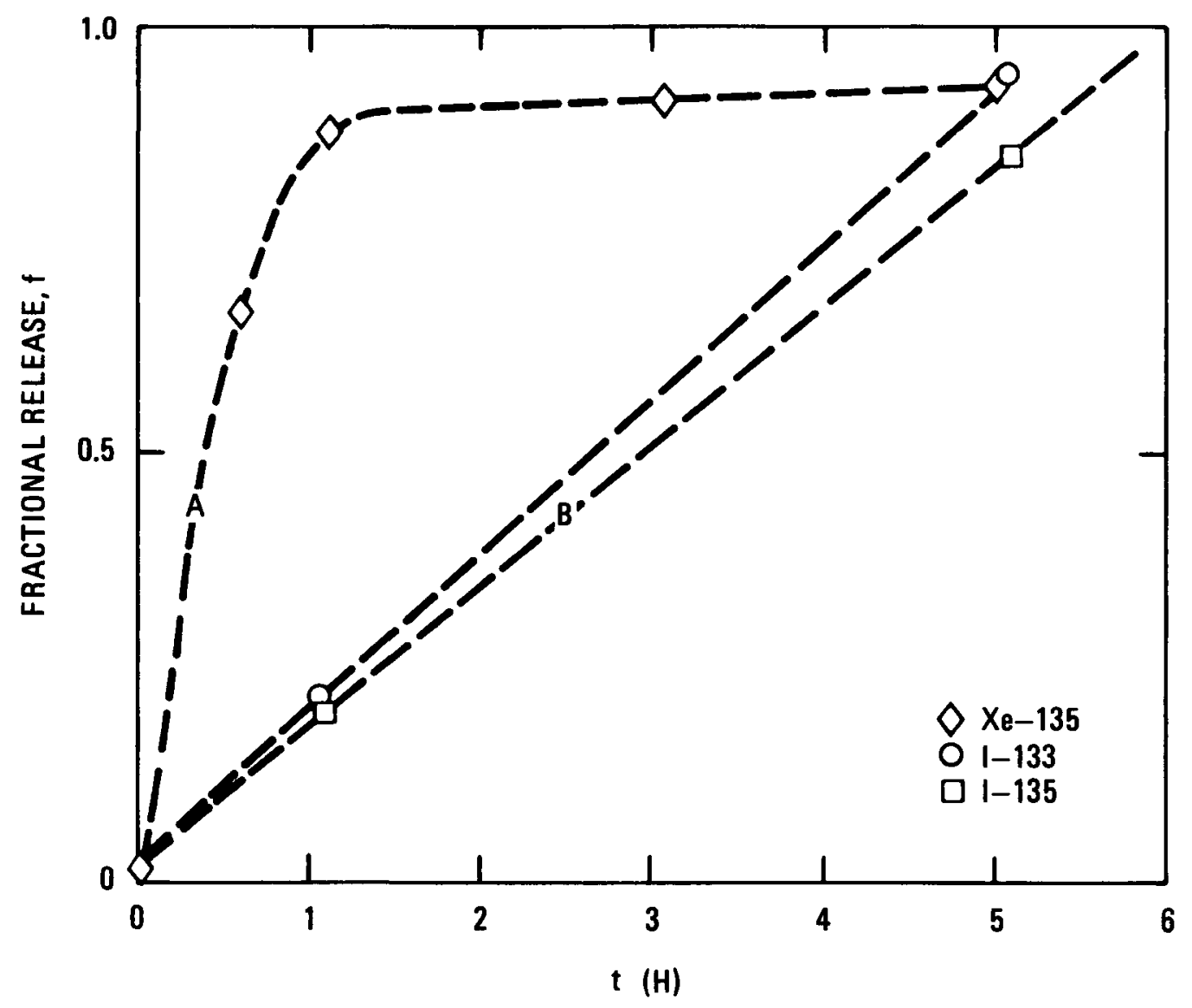

Fig. 4-5. Fractional release curves for xenon and iodine in Exp. 7240-92 at $2013 \mathrm{~K}$ with laser-failed $\mathrm{UC}_{2}$ particles at $74 \%$ FIMA 
Equations 4-12 and 4-13 apply to $\mathrm{ThO}_{2}$ particles. For experiments with carbide particles, tellurium data were difficult to obtain; the avallable data are too unreliable and meagre to warrant an analysis.

4.2.1.3. Cesium. As in the case of lodine and tellurium, two measurements of cesium release were made in each experiment and at times greater than $1 \mathrm{~h}$; from these the parameters $f_{B}$ and $S$ were determined. The values of $\mathrm{f}_{B}$ and $\mathrm{S}$ for cesium are presented in Table 4-9.

A substantial fraction of the cesium was in the particle coatings in most test particles at the beginning of the experiments. This was a consequence of the long half-life of the cesium isotopes and of the irradiation conditions of the test particles (see Table 3-1). By contrast, only the recoil fraction was in the particle coating for the short-lived nuclides of xenon, krypton, iodine, and tellurium treated above (see Section 4.1).

An estimate has been made of the fraction of cesium in the particle coatings at the beginning of the experiments. The method of estimation is presented in Appendix B; the method accounts for the time, temperature, and burnup dependence of cesium release from the fuel kernel. The estimate shows that the particle coatings contain $50 \%$ or more of the cesium inventory, except for those particles having $\mathrm{ThO}_{2}$ with $1.4 \%$ FIMA; in the latter case, the particle coatings contain essentially only that cesium released from the kernel by recoil.

Further analysis of the cesium release data is presented in Section 6 .

\subsubsection{Temperature Rise Experiments}

In the temperature rise experiments, the temperature range was 1200 to $2300 \mathrm{~K}$. The temperature profiles for each experiment were represented as a power series by

$$
T(t)=\sum_{i=0} A_{1} t(h)^{i}
$$


TABLE 4-9

PARAMETERS CHARACTERIZING THE FRACTIONAL RELEASE FOR Cs-134 AND Cs-137 IN ISOTHERMAL EXPERIMENTS

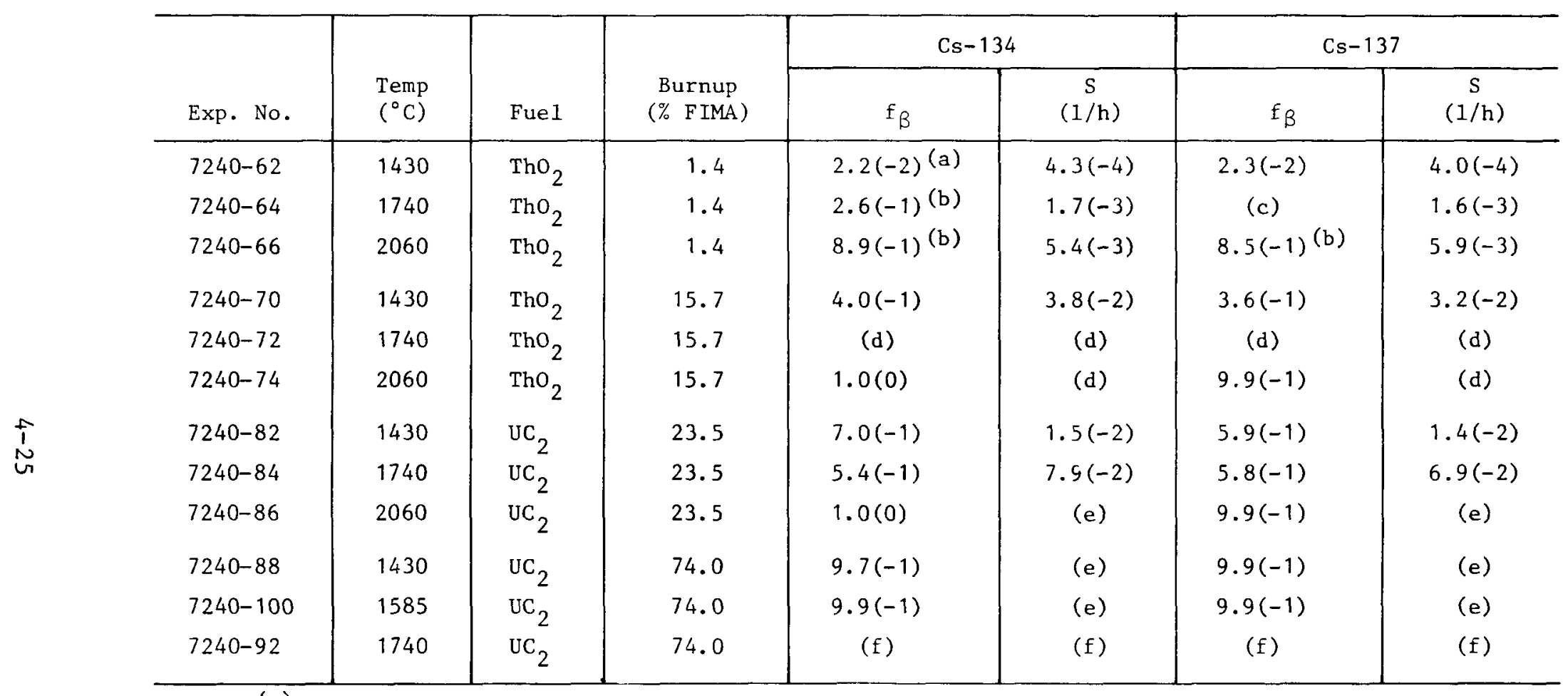

(a) $2.2(-2)=2.2 \times 10^{-2}$.

(b) These data were calculated using particle count data and S since the measured release fractions were significantly smaller than the release fractions determined from pre- and post-test particle activity measurements.

${ }^{(c)}$ An error in counting.

(d) Could not be reliably determined.

(e) Slope could not be evaluated since release of cesium is complete by the time of the first measurement of release.

(f) Mass balance indicates collection of released cesium was faulty. 
where $T$ is the temperature in kelvin and $t$ is the time in $h$. The - coefficients, $A_{i}$, are listed in Table 4-10,

4.2.2.1. Xenon and Krypton. In the temperature rise experiments, the cumulative number of atoms released is measured as a function of time. Such data for $\mathrm{Xe}-135, \mathrm{Kr}-85 \mathrm{~m}, \mathrm{Kr}-87$ and $\mathrm{Kr}-88$ are listed in Table 4-11. The initial inventories are 1isted in Table 4-12.

One measure of the precision of the data in Table 4-11 is given by $W$, the ratio of the cumulative number of released atoms as measured directly at the end of the experiment to the number calculated on the basis of the pretest and posttest particle activity. This ratio and the standard deviation are $1.0 \pm 0.2$ for xenon and $1.0 \pm 0.4$ for krypton. The larger standard deviation for krypton reflects the larger error in measuring a generally smaller inventory of atoms.

A representative release profile for the temperature rise experiments is shown in Fig. 4-6 for xenon release from a laser-falled $\mathrm{ThO}_{2}$ particle with $1.4 \%$ FIMA. The ordinate of $\mathrm{Fig} .4-6, \mathrm{Xe}_{\mathrm{r}}$, is the cumulative number of xenon atoms measured at time $t$.

The release profile of $\mathrm{Fig}$. 4-6 is characteristic in having a moderate release rate in the lower portion of the temperature range and a large release rate in the higher portion. Development of a release model in Section 5 provides a basis for understanding this release behavior.

4.2.2.2. Iodine and Tellurium. In the temperature rise experiments, two measurements of released iodine and tellurium were made. The results are given in Table 4-13 in terms of the fractional release.

The values of $W$ deduced from the data of Table $4-13$ are $0.85 \pm 0.35$ for iodine and $0.3 \pm 0.2$ for tellurium. In the case of iodine, the mean value of $W$ is the same as that found for the collector efficiency (see 
TABLE $4-10$

COEFFICIENTS IN THE POWER SERIES EXPRESSION FOR TEMPERATURE AS A FUNCTION OF TIME(a)

\begin{tabular}{|c|c|c|c|c|c|c|c|c|c|}
\hline Exp. No. & $A_{0}$ & $A_{1}$ & $A_{2}$ & $\mathrm{~A}_{3}$ & $\mathrm{~A}_{4}$ & $A_{5}$ & $A_{6}$ & $\mathrm{~A}_{7}$ & $\mathrm{~A}_{8}$ \\
\hline $7240-55(b)$ & $1.3786(3)(c)$ & $1.23244(2)$ & $-1.71533(1)$ & $7.97971(-1)$ & 1. $40895(-1)$ & $-1.97481(-2)$ & $9.28661(-4)$ & $-1.34252(-5)$ & $-2.29591(-7)$ \\
\hline $7240-99$ & 1. $20378(3)$ & $7.42187(2)$ & $-6.60048(2)$ & $4.36734(2)$ & $-1.20877(2)$ & $-1.26424(1)$ & $1.55582(0)$ & $-3.33863(0)$ & 2. $36261(-1)$ \\
\hline $7240-76$ & $1.24887(3)$ & $4.10101(2)$ & $-6.12486(1)$ & $-9.08810(0)$ & $6.63534(0)$ & $-7.89796(-1)$ & & & \\
\hline $7240-108$ & $1.27134(3)$ & $4.19267(2)$ & $1.74135(2)$ & $-3.93345(2)$ & $2.12000(2)$ & $-3.35291(1)$ & $-6.80708(0)$ & $2.79630(0)$ & $-2.47591(-1)$ \\
\hline $7240-78$ & $1.25091(3)$ & $6.40213(2)$ & $-3.64395(2)$ & $1.51231(2)$ & $-3.09032(1)$ & $2.41176(0)$ & & & \\
\hline $7240-106$ & $1.21903(3)$ & $6.85764(2)$ & $-6.36661(2)$ & $4.56155(2)$ & $-1.69062(2)$ & $3.03849(1)$ & $-2.10198(0)$ & & \\
\hline $7240-80$ & $1.28026(3)$ & $6.33850(2)$ & $-3.75093(2)$ & $1.62674(2)$ & $-3.42636(1)$ & $2.71177(0)$ & & & \\
\hline $7240-110$ & $1.27260(3)$ & $5.82666(2)$ & $-3.75350(2)$ & $2.16130(2)$ & $-7.30122(1)$ & $1.29367(1)$ & $-9.24060(-1)$ & & \\
\hline $7240-96$ & $1.26818(3)$ & $6.89231(2)$ & $-5.18787(2)$ & $3.63716(2)$ & $-1.83202(2)$ & $5.89852(1)$ & $-1.02388(1)$ & $7.12346(-1)$ & \\
\hline
\end{tabular}

${ }^{(a)} T(K)=\sum_{i=0} A_{i} t(h)^{i}$

(b) For this experiment an additional coefficient $a_{9}=6.38351(-9)$ was used.

(c) $1.3786(3)=1.3786 \times 10^{3}$. 
TABLE $4-11$

MEASUREMENTS OF THE NUMBER OF ATOMS OF XENON AND KRYPTON RELEASED DURING TEMPERATURE RISE EXPERIMENTS

\begin{tabular}{|c|c|c|c|c|c|c|c|}
\hline \multirow[b]{2}{*}{ Exp. No. } & \multirow[b]{2}{*}{ Fuel } & \multirow{2}{*}{$\begin{array}{l}\text { Burnup } \\
\text { (\% FIMA) }\end{array}$} & \multirow{2}{*}{$\stackrel{t}{(h)}$} & \multicolumn{4}{|c|}{ Cumulative Number of Atoms Measured } \\
\hline & & & & $\mathrm{Xe}-135$ & $\mathrm{Kr}-85 \mathrm{~m}$ & $\mathrm{Kr}-87$ & $\mathrm{Kr}-88$ \\
\hline $7240-99$ & $\mathrm{ThO}_{2}$ & 0.25 & $\begin{array}{l}0.65 \\
1.88 \\
3.17 \\
3.63 \\
4.13 \\
4.63 \\
4.63 \mathrm{MB}\end{array}$ & $\begin{array}{l}1.56(6) \\
2.19(7) \\
1.67(8) \\
9.12(8) \\
1.82(9) \\
2.65(9) \\
2.62(9)\end{array}$ & $\left.\right|^{\text {NM }}$ & $\left.\right|^{N M}$ & $\left.\right|^{\mathrm{NM}}$ \\
\hline $7240-76$ & $\mathrm{ThO}_{2}$ & 1.4 & $\begin{array}{l}0.483 \\
1.28 \\
2.02\end{array}$ & $\begin{array}{l}1.10(7) \\
3.51(7) \\
6.90(7)\end{array}$ & $\begin{array}{l}3.12(6) \\
8.97(6) \\
1.74(7)\end{array}$ & $\begin{array}{l}5.16(5) \\
1.27(6) \\
1.76(6)\end{array}$ & $\begin{array}{l}4.93(6) \\
1.13(7) \\
1.90(7)\end{array}$ \\
\hline $7240-108$ & $\mathrm{ThO}_{2}$ & 1.4 & $\begin{array}{l}0.40 \\
2.25 \\
3.33 \\
4.00 \\
4.43 \\
4.43 \mathrm{MB}\end{array}$ & $\begin{array}{l}8.99(6) \\
7.13(7) \\
2.52(8) \\
4.12(9) \\
1.07(10) \\
1.25(10)\end{array}$ & $\begin{array}{l}3.99(6) \\
4.16(7) \\
7.67(7) \\
1.26(9) \\
1.55(9) \\
7.25(8)\end{array}$ & $\begin{aligned} & 5.37(5) \\
& 2.33(6) \\
& 2.74(6) \\
& 3.65(7) \\
& 3.32(7) \\
&<6.99(7)(e)\end{aligned}$ & $\begin{array}{l}3.29(6) \\
2.83(7) \\
4.66(7) \\
7.46(8) \\
8.70(8) \\
7.78(8)\end{array}$ \\
\hline
\end{tabular}


TABLE 4-11 (Continued)

\begin{tabular}{|c|c|c|c|c|c|c|c|}
\hline \multirow[b]{2}{*}{ Exp. No. } & \multirow[b]{2}{*}{ Fuel } & \multirow{2}{*}{$\begin{array}{l}\text { Burnup } \\
\text { (\% FIMA) }\end{array}$} & \multirow{2}{*}{$\begin{array}{c}t \\
(h)\end{array}$} & \multicolumn{4}{|c|}{ Cumulative Number of Atoms Measured } \\
\hline & & & & $\mathrm{Xe}-135$ & $\mathrm{Kr}-85 \mathrm{~m}$ & $\mathrm{Kr}-87$ & $\mathrm{Kr}-88$ \\
\hline $7240-106$ & $\mathrm{ThO}_{2}$ & 15.7 & $\begin{array}{l}0.467 \\
2.58 \\
3.30 \\
4.05 \\
4.63 \\
4.63 \mathrm{MB}\end{array}$ & $\begin{array}{l}4.22(8) \\
1.42(9) \\
4.36(9) \\
2.04(10) \\
2.97(10) \\
2.31(10)\end{array}$ & $\begin{array}{l}8.27(7) \\
1.72(8) \\
4.58(8) \\
1.69(9) \\
2.30(9) \\
2.55(9)\end{array}$ & $\begin{array}{r}1.88(7) \\
1.64(7) \\
3.80(7) \\
1.06(8) \\
1.18(8) \\
<1.32(8)\end{array}$ & $\begin{array}{l}7.14(7) \\
1.21(8) \\
3.18(8) \\
1.16(9) \\
1.45(9) \\
9.80(8)\end{array}$ \\
\hline $7240-110$ & $\mathrm{UC}_{2}$ & 74.0 & $\begin{array}{l}0.383 \\
2.15 \\
3.30 \\
3.83 \\
4.55 \\
4.55 \mathrm{MB}\end{array}$ & $\begin{array}{l}1.68(7) \\
7.28(8) \\
7.69(8)(f) \\
1.67(9)(f) \\
2.15(9)(f) \\
2.57(9)\end{array}$ & $\begin{array}{l}4.15(6) \\
3.55(7) \\
3.27(7)(f) \\
7.32(7)(f) \\
8.63(7)(f) \\
1.13(8)\end{array}$ & $\begin{array}{l}1.41(6) \\
4.51(6) \\
2.71(6)(f) \\
5.66(6)(f) \\
4.78(6)(f) \\
8.00(6)\end{array}$ & $\begin{array}{l}4.18(6) \\
3.03(7) \\
2.54(7)(f) \\
5.67(7)(f) \\
6.03(7)(f) \\
8.39(7)\end{array}$ \\
\hline
\end{tabular}


TABLE 4-11 (Continued)

\begin{tabular}{|c|c|c|c|c|c|c|c|}
\hline \multirow[b]{2}{*}{ Exp. No. } & \multirow[b]{2}{*}{ Fue1 } & \multirow{2}{*}{$\begin{array}{l}\text { Burnup } \\
(\% \text { FIMA })\end{array}$} & \multirow{2}{*}{$\begin{array}{c}t \\
(h)\end{array}$} & \multicolumn{4}{|c|}{ Cumulative Number of Atoms Measured } \\
\hline & & & & $\mathrm{Xe}-135$ & $\mathrm{Kr}-85 \mathrm{~m}$ & $\mathrm{Kr}-87$ & $\mathrm{Kr}-88$ \\
\hline $7240-96$ & WAR & $\sim 60$ & $\begin{array}{l}0.1 \\
2.27 \\
3.55 \\
4.20 \\
4.60 \\
4.60 \mathrm{MB}\end{array}$ & $\begin{array}{l}7.58(8) \\
7.28(9) \\
8.22(9) \\
8.32(9) \\
8.79(9) \\
8.51(9)\end{array}$ & $\begin{array}{l}2.15(8) \\
9.12(8) \\
8.11(8) \\
7.41(8) \\
6.99(8) \\
1.43(9)(g)\end{array}$ & $\begin{array}{l}7.99(7) \\
1.24(8) \\
6.68(7) \\
4.75(7) \\
3.83(7) \\
3.92(7)\end{array}$ & $\begin{array}{l}2.54(8) \\
8.26(8) \\
6.52(8) \\
5.62(8) \\
5.13(8) \\
9.70(8)(8)\end{array}$ \\
\hline
\end{tabular}

(a) $2.25(6)=2.25 \times 10^{6}$.

(b) NM signifies not monitored.

(c) This number corrected for xenon loss from trap after loss of trap coolant. The correction was based on measured xenon and iodine activity in particle at beginning of test and assumption of complete release of xenon and iodine from particle at $24 \mathrm{~h}$.

(d) ${ }_{M B}$ represents mass balance; the atom population entries in this row have been obtained from measurements of the particle activity before and after the experiment.

(e) A maximum value; measurement of fuel particle activity is unreliable.

(f) In experiment 7240-110, the particle holder tilted and dumped the particles between 2.15 and $3.20 \mathrm{~h}$. The unusual alteration in the release data is attributed to this accident.

(g) Questionable. 
TABLE $4-12$

INITIAL INVENTORIES OF XENON AND KRYPTON IN TEMPERATURE RISE EXPERIMENTS

\begin{tabular}{|c|c|c|c|c|c|c|c|}
\hline \multirow[b]{2}{*}{ Exp. No. } & \multirow[b]{2}{*}{ Fue1 } & \multirow{2}{*}{$\begin{array}{l}\text { Burnup } \\
\text { (\% FIMA) }\end{array}$} & \multicolumn{5}{|c|}{ Initial Inventory of Atoms } \\
\hline & & & $\mathrm{Xe}-135$ & $I-135$ & $\mathrm{Kr}-85 \mathrm{~m}$ & $\mathrm{Kr}-87$ & $\mathrm{Kr}-88$ \\
\hline $7240-55$ & $\mathrm{ThO}_{2}$ & 0.25 & $4.66(9)(a)$ & $6.04(9)$ & $\mathrm{NM}(\mathrm{b})$ & NM & NM \\
\hline $7240-76$ & $\mathrm{ThO}_{2}$ & 1.4 & $3.17(10)$ & $1.44(10)$ & $3.58(9)$ & $4.68(9)$ & $2.47(9)$ \\
\hline $7240-78$ & $\mathrm{ThO}_{2}$ & 15.7 & $2.83(10)$ & $1.80(10)$ & $5.25(9)$ & $1.23(9)$ & $3.62(9)$ \\
\hline $7240-80$ & $\mathrm{UC}_{2}$ & 23.5 & $6.56(9)$ & $1.37(10)$ & $1.94(9)$ & $1.13(9)$ & $2.38(9)$ \\
\hline $7240-96$ & WAR & $\sim 60.0$ & $8.00(9)$ & $9.06(9)$ & $2.96(9)(c)$ & $4.86(8)$ & $3.04(9)(c)$ \\
\hline $7240-99$ & $\mathrm{ThO}_{2}$ & 0.25 & $8.74(9)$ & $2.62(9)$ & $\mathrm{NM}$ & NM & NM \\
\hline $7240-106$ & $\mathrm{ThO}_{2}$ & 15.7 & $3.25(10)$ & $1.92(10)$ & $6.27(9)$ & $1.67(9)$ & $4.36(9)$ \\
\hline $7240-108$ & $\mathrm{ThO}_{2}$ & 1.4 & $2.91(10)$ & $1.74(10)$ & $3.42(9)$ & $7.89(8)$ & $4.15(9)$ \\
\hline $7240-110$ & $\mathrm{UC}_{2}$ & 74.0 & $3.41(9)$ & $1.49(9)$ & $2.54(8)$ & $1.04(8)$ & $2.84(8)$ \\
\hline
\end{tabular}




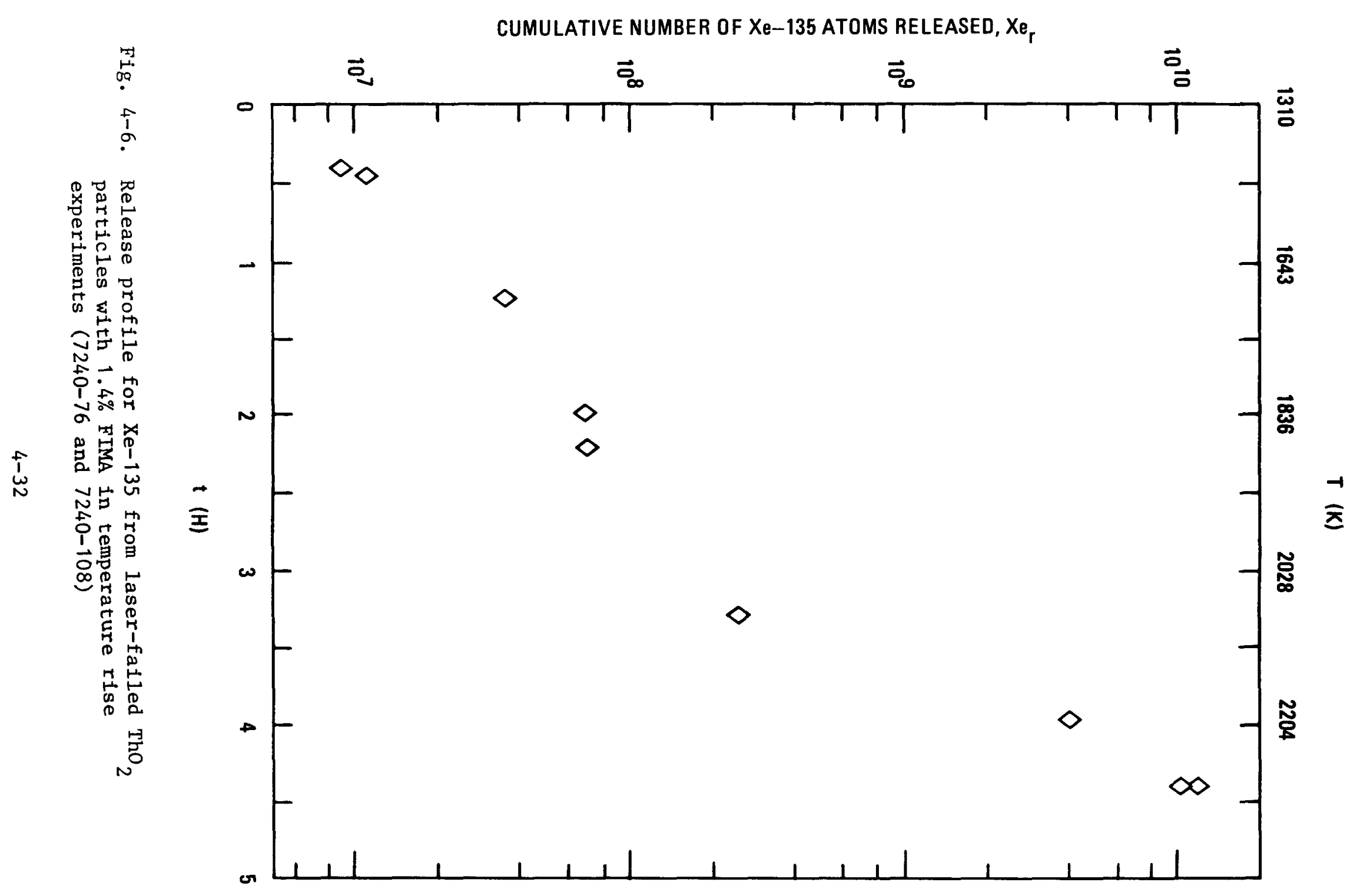


TABLE 4-13

FRACTIONAL RELEASE OF I-131, I-133, I-135, AND Te-132 IN TEMPERATURE RISE EXPERIMENTS

\begin{tabular}{|c|c|c|c|c|c|c|c|}
\hline \multirow[b]{2}{*}{ Exp. No. } & \multirow{2}{*}{$\begin{array}{l}\text { Temp } \\
\text { Range } \\
\text { (K) }\end{array}$} & \multirow{2}{*}{$\begin{array}{l}\text { Burnup } \\
\text { (\% F F }\end{array}$} & \multirow{2}{*}{$\begin{array}{c}t \\
(\mathrm{~h})\end{array}$} & \multicolumn{4}{|c|}{ Fractional Release } \\
\hline & & & & $I-131$ & $I-133$ & $I-135$ & $\mathrm{Te}-132$ \\
\hline $7240-108$ & $\begin{array}{l}1270- \\
2250\end{array}$ & $\begin{array}{l}1.4 \\
1.4 \\
1.4\end{array}$ & $\begin{array}{l}3.35 \\
4.43 \\
4.43 \mathrm{MB}\end{array}$ & $\begin{array}{l}1.1(-2)(a) \\
6.0(-1) \\
3.4(-1)\end{array}$ & $\begin{array}{l}8.1(-3) \\
4.2(-1) \\
5.9(-1)\end{array}$ & $\begin{array}{l}1.0(-2) \\
4.5(-1) \\
5.1(-1)\end{array}$ & $\begin{array}{l}3.4(-2) \\
7.8(-2) \\
7.7(-1)\end{array}$ \\
\hline $7240-76$ & $\begin{array}{l}1250- \\
2280\end{array}$ & 1.4 & 4.43 & (c) & (c) & (c) & $9.0(-1)$ \\
\hline $7240-78$ & $\begin{array}{l}1250- \\
2240\end{array}$ & $\begin{array}{l}15.7 \\
15.7 \\
15.7\end{array}$ & $\begin{array}{l}2.13 \\
4.83 \\
4.83 \mathrm{MB}\end{array}$ & $\begin{array}{l}2.9(-2) \\
4.8(-1) \\
9.2(-1)\end{array}$ & $\begin{array}{l}1.3(-2) \\
8.3(-1) \\
9.7(-1)\end{array}$ & $\begin{array}{l}1.3(-2) \\
7.2(-1) \\
9.3(-1)\end{array}$ & $\begin{array}{l}1.1(-1) \\
2.0(-1) \\
9.7(-1)\end{array}$ \\
\hline $7240-106$ & $\begin{array}{l}1250- \\
2280\end{array}$ & $\begin{array}{l}15.7 \\
15.7\end{array}$ & $\begin{array}{l}4.63 \\
4.63 \mathrm{MB}\end{array}$ & $\begin{array}{l}\text { (d) } \\
\text { (d) }\end{array}$ & $\begin{array}{l}8.8(-1) \\
8.8(-1)\end{array}$ & $\begin{array}{l}7.5(-1) \\
9.3(-1)\end{array}$ & $\begin{array}{l}3.7(-1) \\
9.6(-1)\end{array}$ \\
\hline $7240-80$ & $\begin{array}{l}1270- \\
2280\end{array}$ & $\begin{array}{l}23.5 \\
23.5 \\
23.5\end{array}$ & $\begin{array}{l}1.93 \\
4.37 \\
4.37 \mathrm{MB}\end{array}$ & $\begin{array}{l}\text { (e) } \\
(e) \\
\text { (f) }\end{array}$ & $\begin{array}{l}2.7(-2) \\
8.2(-1) \\
\quad \text { (f) }\end{array}$ & $\begin{array}{l}\text { 3. } 3(-2) \\
8.6(-1) \\
\text { (f) }\end{array}$ & $\begin{array}{l}6.1(-2) \\
6.0(-1) \\
9.6(-1)\end{array}$ \\
\hline $7240-110$ & $\begin{array}{l}1270- \\
2250\end{array}$ & $\begin{array}{l}74.0 \\
74.0 \\
74.0\end{array}$ & $\begin{array}{l}3.33 \\
4.55 \\
4.55 \mathrm{MB}\end{array}$ & $\begin{array}{l}\text { (d) } \\
\text { (d) } \\
\text { (d) }\end{array}$ & $\begin{array}{l}(\mathrm{g}) \\
(\mathrm{g}) \\
(\mathrm{g})\end{array}$ & $\begin{array}{l}(g) \\
(g) \\
(g)\end{array}$ & $\begin{array}{l}1.1(-1) \\
1.6(-1) \\
5.6(-1)\end{array}$ \\
\hline $7240-96$ & $\begin{array}{l}1260- \\
2300\end{array}$ & $\begin{array}{l}60.0 \\
60.0 \\
60.0\end{array}$ & $\begin{array}{l}3.05 \\
4.60 \\
4.60 \mathrm{MB}\end{array}$ & $\begin{array}{c}(h) \\
(h) \\
1.0(0)\end{array}$ & $\begin{array}{l}7.0(-1) \\
7.6(-1) \\
1.0(0)\end{array}$ & $\begin{array}{l}4.4(-1) \\
4.8(-1) \\
1.0(0)\end{array}$ & $\begin{array}{l}\text { (d) } \\
\text { (d) } \\
\text { (d) }\end{array}$ \\
\hline
\end{tabular}

(a) $1.1(-2)=1.1 \times 10^{-2}$.

(b) $M B$ represents mass balance; the fractional release entries in this row have been obtained from measurements of the particle activity before and after the experiment.

(c) Measurements not made in latter part of run.

(d) Measurement on initial particle inventory not available.

(e) Mass balance in error by factor of two.

(f) Measurement on final particle inventory not available.

(g) A very large uncertainty in initial particle activity measurements makes release calculations totally unreliable.

(h) Analysis incomplete. 
Section 4.2.1.2), as would be expected if the fractional release calculated from the pretest and posttest particle activity were accurate. The $W$ value for tellurium is discussed in Section 4.2.2.3 below.

The data of Table 4-13 are considered further in Section 6 .

4.2.2.3. Cesium. As for iodine and tellurium, only two measurements were made for cesium. The results are given in Table 4-14 in terms of the fractional release.

The values of $W$ deduced from the data of Table 4-14 for cesium vary widely from 0.07 to 1.0 . This wide variation, as well as the small $\mathrm{W}$ values deduced for tellurium in Section 4.2.2.2, can be explained as follows. During the temperature rise experiment, the collectors for iodine, tellurium, and cesium were removed and replaced by a new set of collectors in the middle of the experiment. The new set of collectors was positioned at a greater distance from the center of the furnace than the set replaced in anticipation of higher temperatures during the second part of the experiment. The intention was to subject both sets of collectors to the same temperatures during their residence in the apparatus. However, the new set of collectors was apparently positioned in a zone of lower temperature than intended. Consequently, the less volatile elements, tellurium and cesium, condensed upstream of the collectors in the second part of the experiment. This led to low $\mathrm{W}$ values when the release was small and to large $W$ values when the release was large in the first part of the experiment.

The data of Table 4-14 are further considered in Section 6 .

REFERENCES

4-1. York, D., "Least-Squares Fitting of a Straight Line," Can. J. Phys. 44, 1079 (1966).

4-2. Olander, D. R., "Fundamental Aspects of Nuclear Reactor Fuel Elements," ERDA Report TID-26711-P1, Apr:11 1976. 
TABLE $4-14$

FRACTIONAL RELEASE OF Cs-134 AND Cs-137

IN TEMPERATURE RISE EXPERIMENTS

\begin{tabular}{|c|c|c|c|c|c|}
\hline \multirow[b]{2}{*}{ Exp. No. } & \multirow{2}{*}{$\begin{array}{l}\text { Temp } \\
\text { Range } \\
(\mathrm{K})\end{array}$} & \multirow{2}{*}{$\begin{array}{c}\text { Burnup } \\
\text { (\% F IMA) }\end{array}$} & \multirow{2}{*}{$\begin{array}{c}t \\
(h)\end{array}$} & \multicolumn{2}{|c|}{ Fractional Release } \\
\hline & & & & Cs -134 & Cs -137 \\
\hline $7240-108$ & $\begin{array}{l}1270- \\
2250\end{array}$ & $\begin{array}{l}1.4 \\
1.4 \\
1.4\end{array}$ & $\begin{array}{l}3.35 \\
4.43 \\
4.43 \mathrm{MB}(\mathrm{b})\end{array}$ & $\begin{array}{l}3.6(-2)(a) \\
4.1(-2) \\
6.5(-1)\end{array}$ & $\begin{array}{l}2.5(-2) \\
2.9(-2) \\
4.3(-1)\end{array}$ \\
\hline $7240-76$ & $\begin{array}{l}1250- \\
2280\end{array}$ & 1.4 & $4.43 \mathrm{MB}$ & $6.6(-1)$ & $7.9(-1)$ \\
\hline $7240-78$ & $\begin{array}{l}1250- \\
2240\end{array}$ & $\begin{array}{l}15.7 \\
15.7 \\
15.7\end{array}$ & $\begin{array}{l}2.13 \\
4.83 \\
4.83 \mathrm{MB}\end{array}$ & $\begin{array}{l}6.5(-1) \\
6.6(-1) \\
9.9(-1)\end{array}$ & $\begin{array}{l}5.5(-1) \\
5.6(-1) \\
9.9(-1)\end{array}$ \\
\hline $7240-106$ & $\begin{array}{l}1250- \\
2280\end{array}$ & $\begin{array}{l}15.7 \\
15.7\end{array}$ & $\begin{array}{l}4.63 \\
4.63 \mathrm{MB}\end{array}$ & $\begin{array}{l}1.0(-1) \\
9.7(-1)\end{array}$ & $\begin{array}{l}8.9(-2) \\
9.8(-1)\end{array}$ \\
\hline $7240-80$ & $\begin{array}{l}1270- \\
2280\end{array}$ & $\begin{array}{l}23.5 \\
23.5 \\
23.5\end{array}$ & $\begin{array}{l}1.93 \\
4.37 \\
4.37 \mathrm{MB}\end{array}$ & $\begin{array}{l}8.1(-1) \\
8.1(-1) \\
9.9(-1)\end{array}$ & $\begin{array}{c}6.8(-1) \\
6.8(-1) \\
(c)\end{array}$ \\
\hline $7240-110$ & $\begin{array}{l}1270- \\
2250\end{array}$ & $\begin{array}{l}74.0 \\
74.0 \\
74.0\end{array}$ & $\begin{array}{l}3.33 \\
4.55 \\
4.55 \mathrm{MB}\end{array}$ & $\begin{array}{l}9.6(-1) \\
9.6(-1) \\
1.0(0)\end{array}$ & $\begin{array}{l}9.7(-1) \\
9.7(-1) \\
1.0(0)\end{array}$ \\
\hline $7240-96$ & $\begin{array}{l}1260- \\
2300\end{array}$ & $\begin{array}{l}60.0 \\
60.0 \\
60.0\end{array}$ & $\begin{array}{l}3.05 \\
4.60 \\
4.60 \mathrm{MB}\end{array}$ & $\begin{array}{l}1.0(0) \\
1.0(0) \\
1.0(0)\end{array}$ & $\begin{array}{l}1.0(0) \\
1.0(0) \\
1.0(0)\end{array}$ \\
\hline
\end{tabular}

(a) $3.6(-2)=3.6 \times 10^{-2}$.

(b) $M B$ represents mass balance; the fractional release entries in this row have been obtained from measurements of the particle activity before and after the experiment.

(c) Measurement on initial particle inventory not available. 


\section{DEVELOPMENT OF A MODEL FOR FISSION PRODUCT RELEASE}

Development of a model for fission product release provides (1) a means for predicting release under the conditions of a core heatup event, (2) a framework for incorporating all the experiments, and (3) a basis for understanding the mechanisms of release.

The central feature of the model is the fractional release function which describes the release as a function of time and temperature. This function, as developed, is semiempirical but, as will be shown in section 7 for specific conditions, is practically identical to a fractional release function which can be derived from a diffusion equation.

The development of the model is based primarily on the results of the isothermal experiments described in Section 4.2.1. These results are also used to evaluate the parameters of the model. The temperature rise experiments, described in Section 4.2.2, provide a test for the model and permit a refinement in the evaluation of the parameters at temperatures not sampled in the isothermal experiments.

\subsection{FISSION PRODUCT RELEASE MODEL}

The fission product release model to be described has the following characteristics:

1. The fission product atom population for each nuclide is divided into two subpopulations, as follows:

a. A subpopulation which is rapidly released from the fuel material.

b. A subpopulation which is slowly, but steadily, released. 
The distribution of the atom population between the two subpopulations changes with temperature.

2. Subpopulation $1 \mathrm{a}$ is further divided into a large number of independent subsystems, each containing a fixed number of the fission product atoms of a specific nuclide. The number of subsystems changes with temperature.

3. As the temperature rises, the subsystems of 2 sequentially begin to migrate from their initial locations in the fuel and the fractional release profile for each subsystem is unfolded in time.

The first characteristic is related to the fractional release profile observed in isothermal experiments; this is discussed in Section 5.2. The second and third characteristics are related to the temperature dependence of components of the fractional release function; this is discussed in Section 5.3 .

\subsection{FRACTIONAL RELEASE FUNCTION AT CONSTANT TEMPERATURE}

The representative fractional release profile for constant temperature is shown in Fig. 5-1. This profile can be reduced to two components as shown in the figure. These components are describable in terms of the profile parameters $t_{0}, t .8, f_{B}$, and $s$, introduced in Section 4.2.1.1 and identified in Fig. 4-2.

The component labeled RR in Fig. 5-1 represents the subpopulation (of $1 \mathrm{a}$ above) which is rapidly released from the fuel. This subpopulation is the fraction $f_{\beta}$ of the total fission product atom population. The component RR is given by the product $f_{\alpha}(t) \cdot f_{\beta}$, where $f_{\alpha}$ is a function which describes the time dependence of the rapid release fraction. The function $\mathrm{f}_{\alpha}$ is given by

$$
f_{\alpha}(t)=\left(1-e^{-\alpha \Delta t}\right)^{1 / 2},
$$




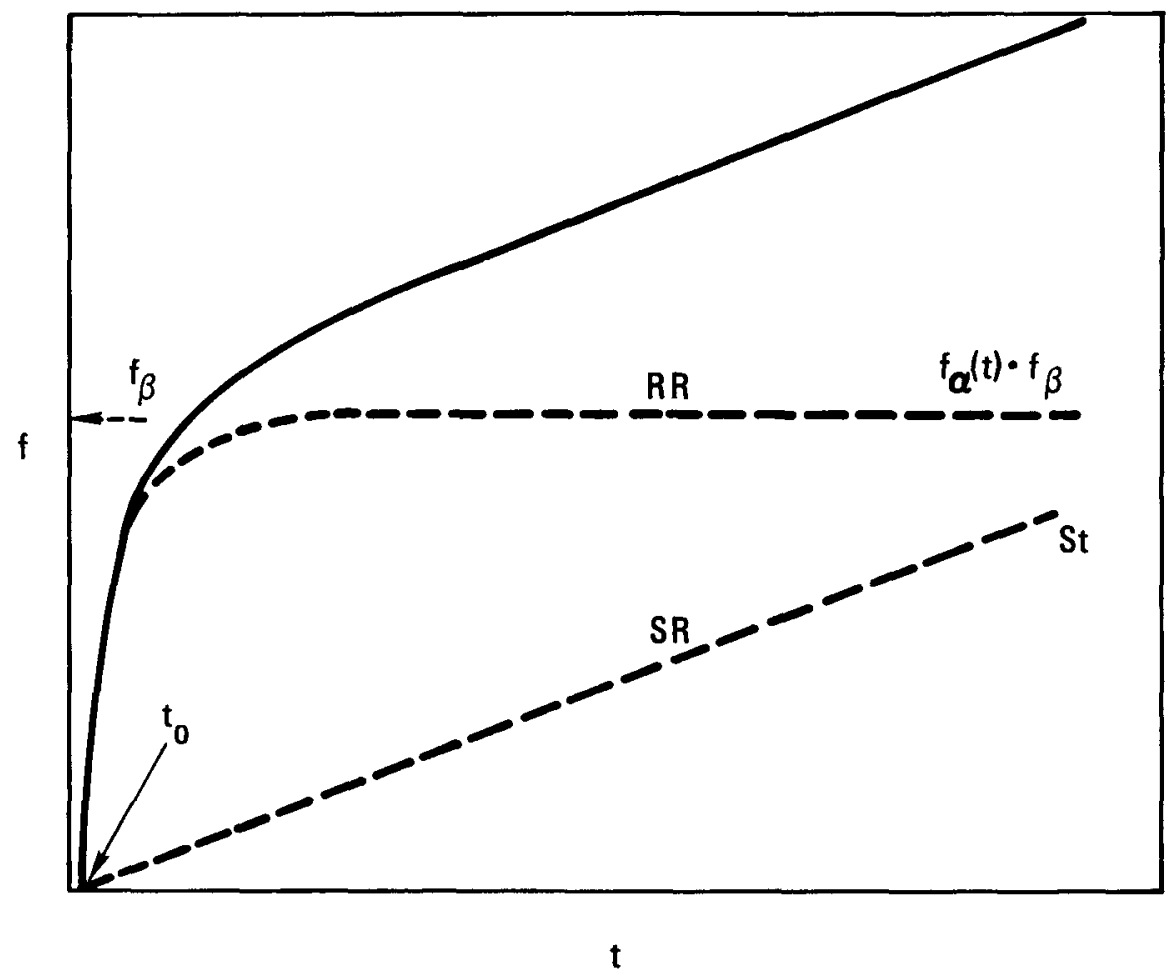

Fig. 5-1. Representative fractional release profile at constant temperature 
where $\Delta t \equiv t-t_{0}$ and the parameter $\alpha$ is simply $1 / t .8$. Equation $5-1$ has the limits $f_{\alpha}(0)=0$ and $f_{\alpha}(\infty)=1$. The functional form for $f_{\alpha}$ will be justified in Section 7 .

The component labeled SR in Fig. 5-1 represents the subpopulation (of $1 \mathrm{~b}$ above) which is slowly, but steadily, released. It is given by the product $S t$, where $S$ is the slope of the linear portion of the fractional release profile as described in Section 4.2.1.1.

The sum of the components RR and SR gives again the fractional release profile, i.e.,

$$
f(t)=f_{\alpha}(t) \cdot f_{\beta}+s \cdot t
$$

\subsection{TEMPERATURE DEPENDENCE OF THE FRACTIONAL RELEASE FUNCTION}

As stated in Section 4.2.1.1, the parameters of the fractional release profile, $f_{\beta}, t .8$, and $S$, have pronounced temperature dependencies. These dependencies are shown in Fig. 5-2 in a detail which anticipates the results presented below.

To represent the temperature dependence of the fractional release profile parameters, the following empirical functions have been used:

$$
\begin{aligned}
& f_{\beta}=(1-C) f_{\beta 1}+C f_{\beta 2}, \\
& f_{\beta i}=\left\{1+\exp \left[\beta_{i}\left(\frac{10^{4}}{T}-\tau_{\beta i}\right)\right]\right\}^{-1}, \quad i=1,2 \\
& s=s^{0} e^{-\sigma / T}\left(1-f_{\beta}\right),
\end{aligned}
$$



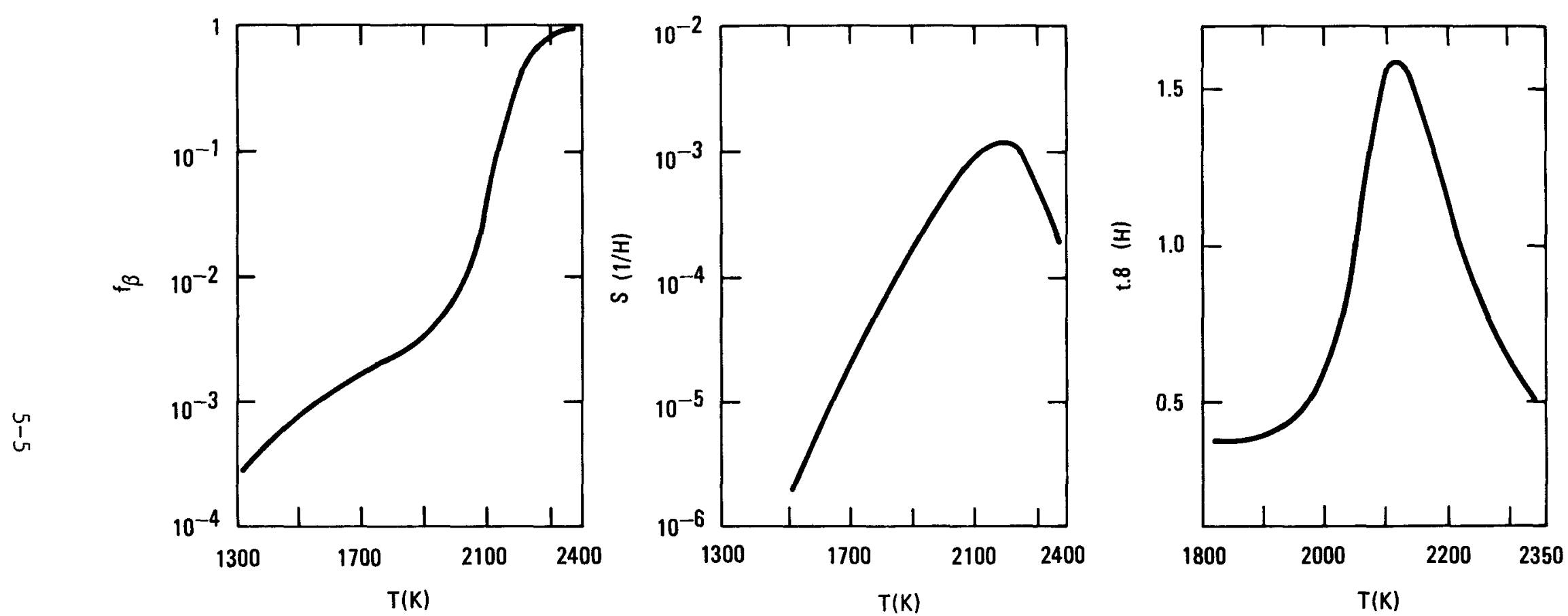

Fig. 5-2. Representative dependence on temperature of the parameters $\left(f_{B}, S\right.$, and $t .8$ ) of the fractional release profile. (Based on data in Table 6-1 for Xe release from $\mathrm{ThO}_{2}$ with $1.4 \%$ FIMA.) 


$$
\begin{aligned}
& \alpha=a_{1} g_{1}+a_{2}\left(1-g_{1}\right) e^{-\alpha_{2} / T}, \\
& g_{1}=(1-C) f_{B 1} / f_{B},
\end{aligned}
$$

where $c, \beta_{i}, \tau_{\beta i}, s^{\circ}, \sigma, a_{1}, a_{2}$, and $\alpha_{2}$ are the parameters of the empirical functions. They will be referred to as model parameters to distinguish them from the profile parameters. The model parameters, $\beta_{i}$, $\sigma$, and $\alpha_{2}$, can be expressed in terms of activation energies $Q$ by the following relations:

$$
\begin{aligned}
& Q_{\beta i}=10^{4} \beta_{i} R_{g}, \\
& Q_{\sigma}=\sigma R_{g}, \\
& Q_{\alpha 2}=\alpha_{2} R_{g},
\end{aligned}
$$

where $R_{g}$ is the gas constant.

The model parameters were evaluated on the basis of the temperature variation of the profile parameters by using Eqs. 5-3 through 5-6 and the profile parameter data, from the isothermal experiments, given in Tables 4-3 through 4-6, 4-8, and 4-9. Since isothermal experiments were performed at only three temperatures, the temperature rise experiments were used to adjust the estimated values of two ( $C$ and $\tau_{B 1}$ ) of the five model parameters associated with the profile parameter $f_{\beta}$ (see Section 6.2.2). Also, the quantity $a_{1}$ appearing in Eq. 5-6 may be temperature dependent; however, with isothermal experiments at three temperatures, only the model parameters $a_{1}, a_{2}$, and $\alpha_{2}$ could be evaluated.

Some physical interpretation of the empirical functions (Eqs. 5-3 through 5-7) is given in Section 7. 
The quantity $f_{\beta}$ is $f$ ixed at constant temperature. This indicates that only a fixed number of atoms, called a subsystem above, can be released at that temperature by way of the mechanism governing the rapid release fraction. If the temperature is incremented, $f_{\beta}$ increases and then an additional fixed number of atoms becomes available for release. The increase in temperature provides the additional energy necessary to allow release of the atoms in the subsystem.

Subsystems which sequentially become available for migration are treated independently in the model and the release history is calculated for each subsystem. If, in the fuel material, the atoms are distributed similarly for each subsystem, then the release of the subsystems can be treated similarly except in accounting for the timing of release. In the model, such treatment is adopted.

\subsection{CALCULATION OF RELEASE BASED ON THE MODEL}

The release is obtained by solving the three differential equations presented in Section 4.2.1, but in a form applicable to any nuclide and its precursor. In all cases treated in this report, only the nuclide or the nuclide and one precursor need to be considered. Thus, the equations can be written as

$$
\begin{aligned}
& \dot{\mathrm{P}}_{i}=-\lambda_{\mathrm{P} \mathrm{P}_{i}-\frac{\dot{\mathrm{f}}_{\mathrm{P}_{i}}}{1-\mathrm{f}_{\mathrm{P}}}} \text {, } \\
& \dot{\mathrm{N}}_{i}=\lambda_{P} \mathrm{P}_{i}-\lambda_{N \mathrm{~N}_{i}}-\frac{\dot{\mathrm{f}}_{N^{N}}}{1-\mathrm{f}_{N}} \text {, }
\end{aligned}
$$

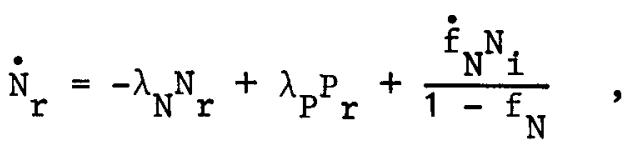


where $P$ represents the precursor and $N$ the nuclide. Other symbols have been defined in Section 4 and in the List of Symbols in Appendix A. For the case of xenon release when the iodine precursor is important, the results of Sections 4.1 and 4.2 .1 .2 are used; thus $f_{P} \equiv f_{N}$.

The model enters into the solution of Eqs. 5-11 through 5-13 through evaluation of the quantity $\dot{\mathrm{f}}(\equiv \mathrm{df} / \mathrm{dt}$ ).

$$
\dot{\mathrm{f}}=\sum_{j=1}^{J} \dot{\mathrm{f}}_{\alpha, j} \Delta \mathrm{f}_{B, j}+\mathrm{s},
$$

where $j$ is the subsystem index with values $1,2, \ldots, \mathrm{J}$,

$$
\Delta f_{B, j}=f_{B}\left(T_{j}\right)-t_{B}\left(T_{j-1}\right),
$$

where $\Delta f_{B, j}$ is the fraction of the fission product atom population in subsystem $j$; subsystem $j$ is generated when the temperature is increased from $T_{j-1}$ to $T_{j}$.

$$
\dot{\mathrm{f}}_{\alpha, \mathrm{j}}=\alpha \mathrm{e}^{-\alpha \Delta \mathrm{t}} \mathrm{e}, \mathrm{j} / 2 \mathrm{f}_{\alpha}
$$

where $\Delta t t_{e, j}$ is the effective time for subsystem $j$. The effective time is evaluated in each time step of the computation. If the time step has index $k$, then for time step $k$,

$$
\Delta t_{e, j}=-\frac{\ln \left(1-f_{\alpha, j, k-1}^{2}\right)}{\alpha} .
$$

The effective time ensures continuity of the values of $f_{\alpha}$ for each subsystem $j$. The quantities $f_{\alpha}, \alpha, f_{\beta}$, and $s$ of Eqs. 5-14 through 5-17 have been defined either by Eq. 5-1 or in Fig. 4-2. 
In solving Eqs. 5-11 through 5-13, the quantity $f_{\alpha, j}(0)$ is set equal to a sma11, positive number to ensure a finite value of $\dot{\mathrm{f}}_{\alpha, j}$ at time zero. Also $\dot{f}$ was set equal to zero when $f$ exceeded 0.999 to avoid $f$ values greater than 1.0 .

The number of subsystems generated was related to the number of time steps in the computation (other methods are, of course, possible). For most of the calculations to be discussed in Section 6, a subsystem was generated for each time step; this corresponded to generating a subsystem for each $2 \mathrm{~K}$ rise in temperature when the model was used to predict fission gas release in the temperature rise experiments. The effect of generating a subsystem for temperature intervals up to $176 \mathrm{~K}$ is examined in Section 6. 
6. APPLICATIONS OF THE RELEASE MODEL

The predictions of the release model (Section 5) are compared with the observed releases of fission products in the temperature rise experiments (Section 4.2.2). The parameters of the release model and the sensitivity of the predictions to alterations in the model are examined.

\subsection{COMPARISON OF OBSERVED AND CALCULATED RELEASES}

\subsubsection{Xenon and Krypton}

Representative comparisons of the model predictions and observed releases are first presented. Then, the general level of agreement between the model and all experimental results on xenon and krypton is discussed.

Excellent agreement between the observed and predicted release of xenon from laser-failed BISO $\mathrm{ThO}_{2}$ particles with $15.7 \%$ FIMA is demonstrated in Fig. 6-1. This agreement is shown for two experiments, 7240-78 and $7240-106$.

In Fig. 6-1, the experimental data for the two experiments 11lustrate the high precision achieved. These two experiments were conducted 2 months apart and were the same except for the inftial xenon and lodine inventories and the temperature profile. The initial populations of xenon and iodine in Exp. $7240-78$ were $15 \%$ and $7 \%$ smaller, respectively, than in Exp. 7240-106, but the temperatures were consistently about 3\% higher in Exp. 7240-78 than in Exp. 7240-106.

Between 2.5 and $4 \mathrm{~h}$, as shown in Fig. 6-1, the differences in the model predictions reflect the effect of the higher temperatures in 


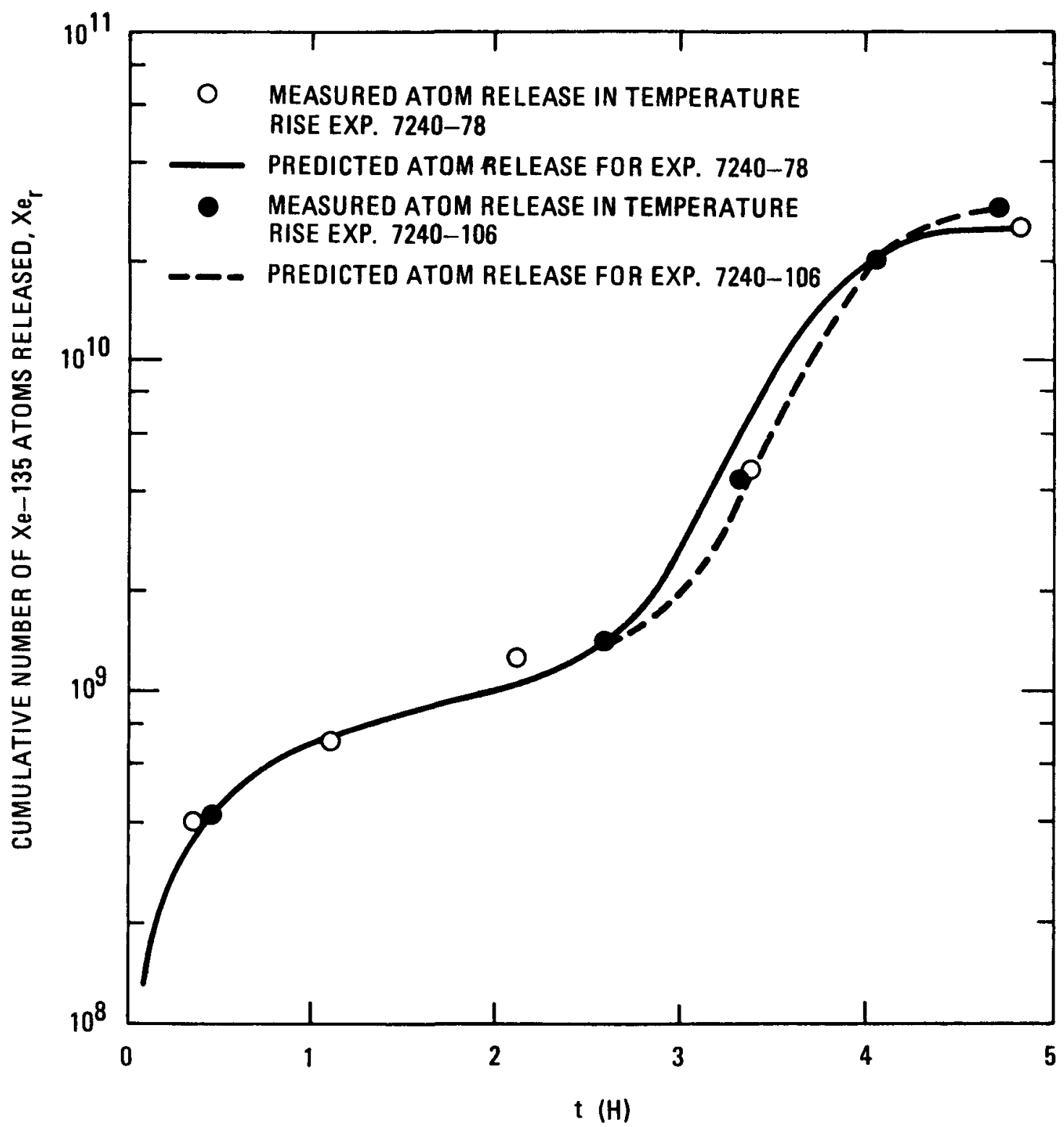

Fig. 6-1. Comparison of observed and predicted xenon release from laser-failed BISO $\mathrm{ThO}_{2}$ particles with $15.7 \%$ FIMA 
Exp. 7240-78 and at times greater than $4 \mathrm{~h}$, they reflect the effect of the lower Initial particle inventories of xenon and iodine in Exp. 7240-78. Note that the model parameters were the same for the two predictions shown in Fig. 6-1.

Excellent agreement between the observed and predicted release for isotopes of different half-lives is shown in Fig. 6-2 for the element krypton. The same values of the model parameters were used for all the predictions shown in Fig. 6-2.

Good agreement between the observed and predicted release has also been obtained in a relatively long experiment as shown in Fig. 6-3. The duration of all but one of the temperature rise experiments (Table 4-11) was less than $5 \mathrm{~h}$; the duration of Exp. 7240-55 was $24 \mathrm{~h}$, by contrast.

The comparison in F1g. 6-3 is marred by a loss of xenon from the trap sample at $15.75 \mathrm{~h}$; failure to maintain the coolant level allowed the trap to become relatively warm and xenon escaped. To compensate for this loss, the assumption was made that all xenon had been released from the particles by $24 \mathrm{~h}$. This assumption is reasonable in view of the decline in the measured xenon release for times greater than $20 \mathrm{~h}$. By using this assumption, the release data at $t \geq 15.75 \mathrm{~h}$ were corrected. The corrected data are shown in Fig. 6-3 by the squares; the circles are the uncorrected data and for $t<15.75 \mathrm{~h}$, coincide with the squares.

For the prediction shown in Fig. 6-3, the model parameters used were derived from the experiments with laser-failed $\mathrm{BISO}$ Th0 2 particles having 1.4\% FIMA except for $S^{\circ}$ which was increased by a factor of 20 .

The model parameters as a function of fission gas element, fuel material ( $\mathrm{ThO}_{2}$ and $\mathrm{UC}_{2}$ ), and burnup are listed in Table 6-1.

The general level of agreement between the calculated and measured cumulative number of atoms released is shown in Fig. 6-4 for xenon and in Fig. 6-5 for krypton. These figures include all the data from the 


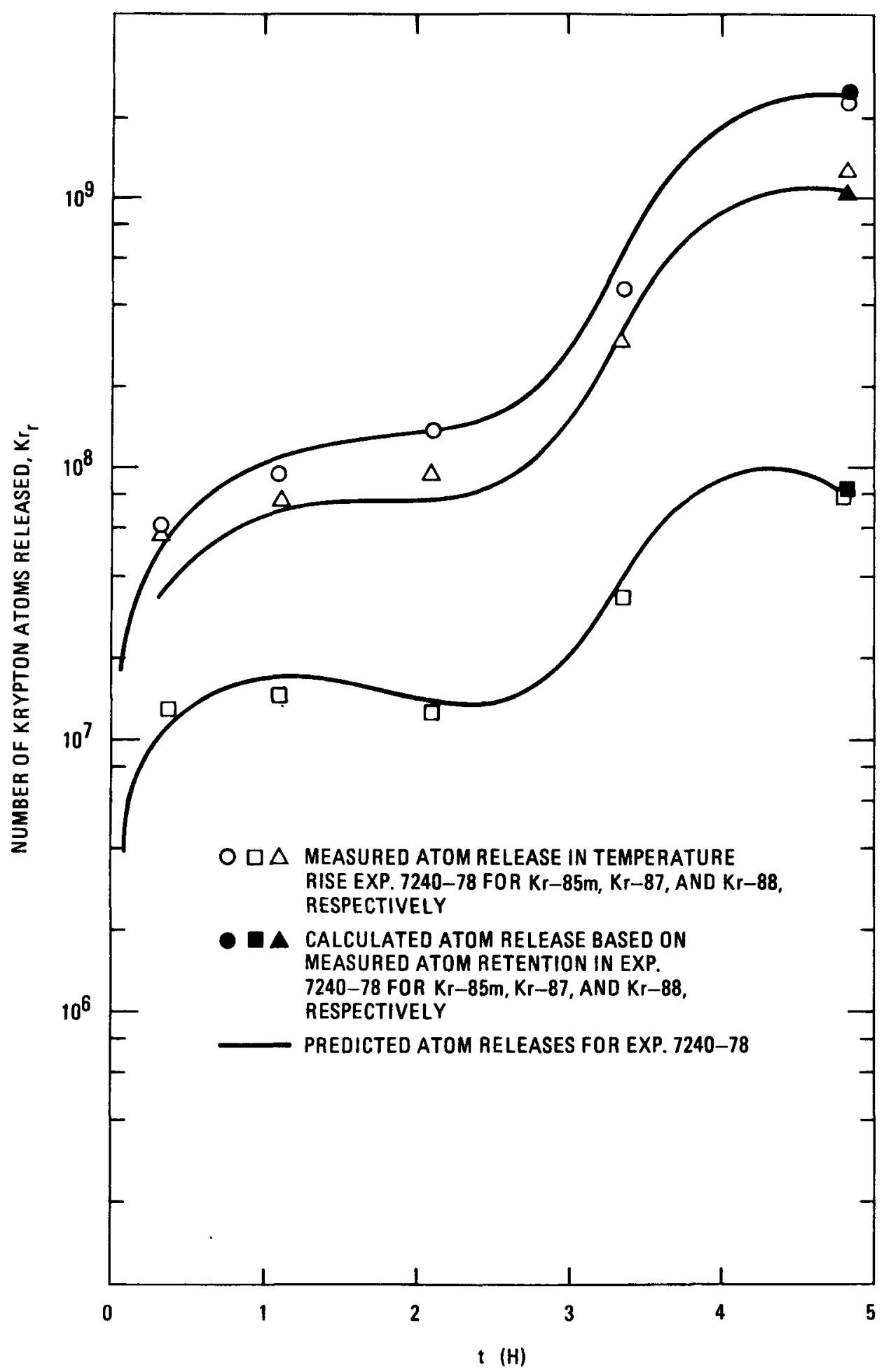

Fig. 6-2. Comparison of observed and predicted krypton release from laser-failed $\mathrm{BISO} \mathrm{ThO}_{2}$ particles with $15.7 \%$ FIMA 


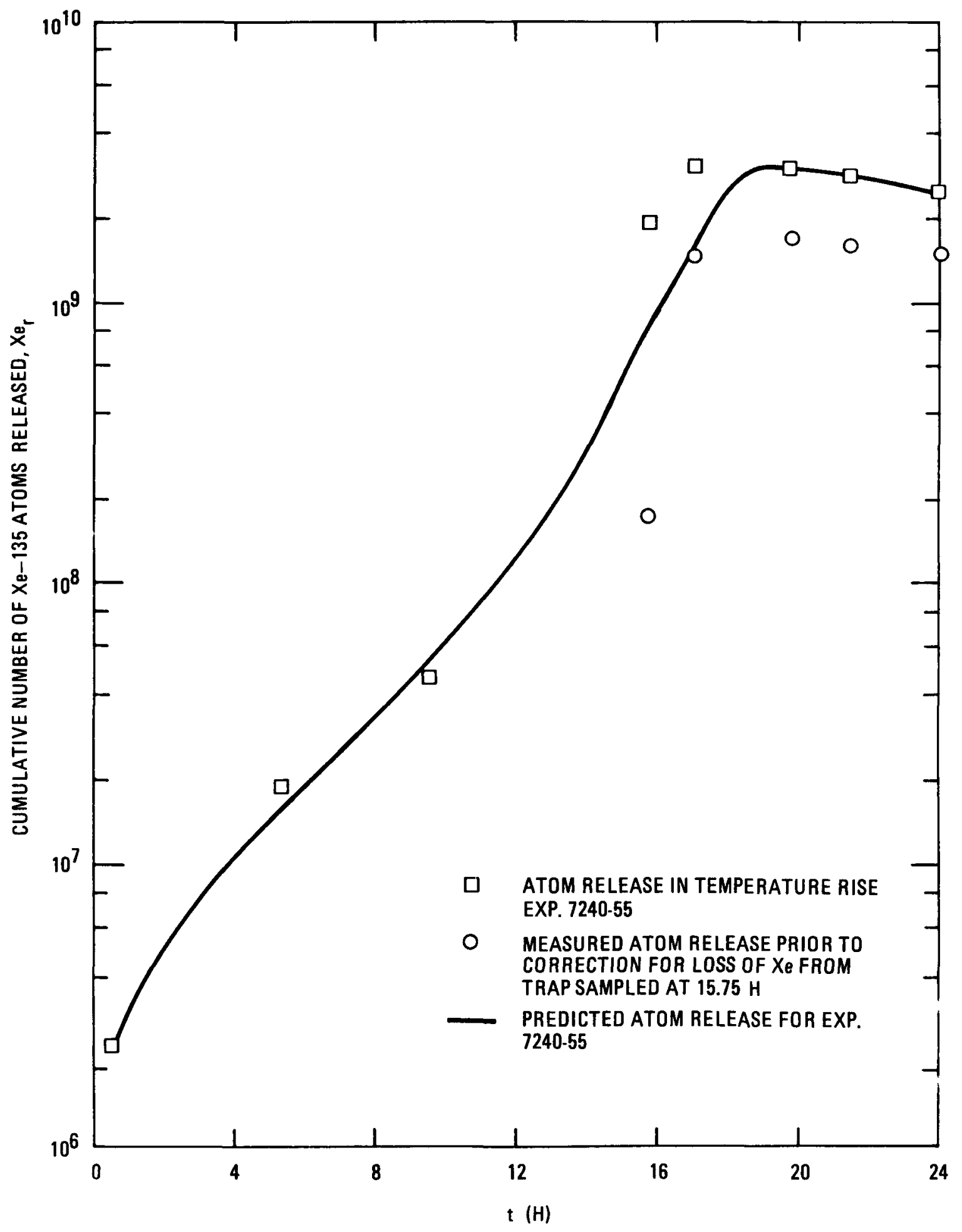

Fig. 6-3. Comparison of observed and predicted xenon release, in a long experiment, from laser-failed $\mathrm{BISO} \mathrm{ThO}_{2}$ particles with $0.25 \%$ FIMA 
TABLE 6-1

PARAMETERS OF THE FISSION PRODUCT RELEASE MODEL AS A FUNCTION OF FISSION GAS ELEMENT, FUEL MATERIAL, AND BURNUP

\begin{tabular}{|c|c|c|c|c|c|c|c|c|c|}
\hline & & \multicolumn{4}{|c|}{$\mathrm{ThO}_{2}$} & \multicolumn{4}{|c|}{$\mathrm{UC}_{2}$} \\
\hline Profile & Model (a) & $\mathrm{Xe}$ & $\mathrm{Kr}$ & $\mathrm{Xe}$ & $\mathrm{Kr}$ & $\mathrm{Xe}$ & $\mathrm{Kr}$ & $\mathrm{Xe}$ & $\mathrm{Kr}$ \\
\hline$\alpha$ & $a_{1}$ & 2.69 & 1.55 & 8.45 & 3.96 & 1.71 & 1.57 & 4.52 & 4.08 \\
\hline \multirow{6}{*}{$\mathbf{f}_{\beta}$} & $\mathrm{a}_{2}$ & $6.03(5)^{(b)}$ & $5.57(5)$ & $3.36(6)$ & $1.12(6)$ & $1.82(12)$ & $7.02(10)$ & $1.0(11)$ & $3.09(11)$ \\
\hline & $\mathrm{C}$ & 0.9917 & 0.976 & 0.94 & 0.94 & 0.99 & 0.985 & 0.99 & 0.98 \\
\hline & $\beta_{1}$ & 1.2 & 1.5 & 0.90 & 0.90 & 1.3 & 1.25 & 1.1 & 0.8 \\
\hline & $\tau_{B 1}$ & 4.78 & 5.35 & 5.8 & 5.8 & 6.33 & 7.52 & 7.04 & 9.62 \\
\hline & $\beta_{2}$ & 11.81 & 11.81 & 11.81 & 11.81 & 10.3 & 10.3 & 10.3 & 10.3 \\
\hline & $\tau_{B 2}$ & 4.51 & 4.59 & 4.69 & 4.66 & 5.35 & 5.41 & 5.41 & 5.47 \\
\hline
\end{tabular}




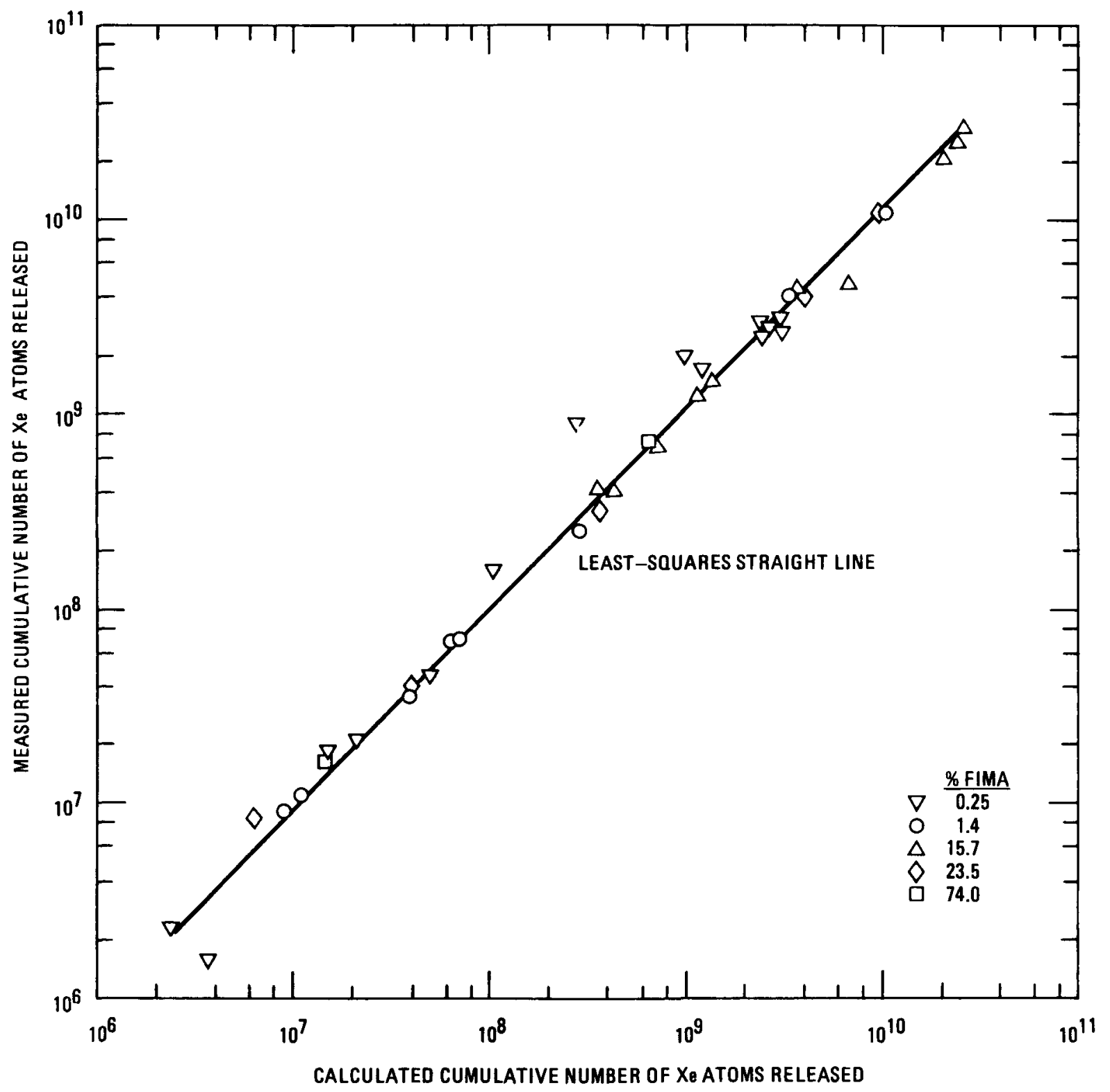

Fig. 6-4. Comparison of measured and calculated cumulative number of xenon atoms released in temperature rise experiments 


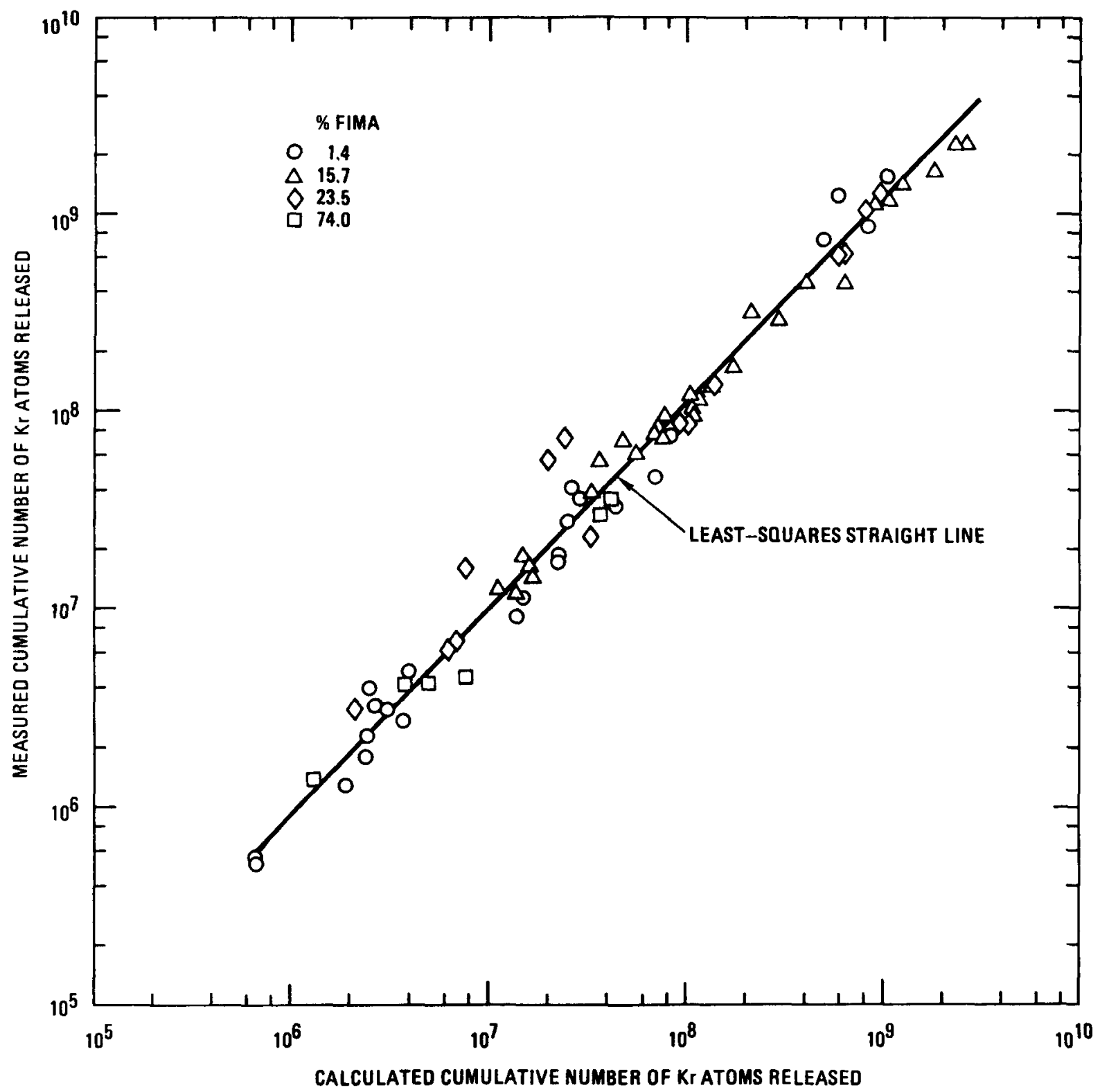

Fig. 6-5. Comparison of measured and calculated cumulative number of krypton ( $\mathrm{Kr}-85 \mathrm{~m}, \mathrm{Kr}-87$, and $\mathrm{Kr}-88$ ) atoms released in temperature rise experiments 
temperature rise experiments with $\mathrm{Th}_{2}$ and $\mathrm{UC}_{2}$ particles; the calculated values are based on the model parameters given in Table 6-1. For Fig. 6-4, the relationship between the calculated and measured cumulative number of xenon atoms is

$$
\mathrm{Xe}_{\text {calc }}=1.71 \mathrm{Xe}_{\text {meas }}^{0.972} .
$$

This is the least-squares fit to the data by a method of Ref. 6-1. The Xe calc' calculated according to Eq. 6-1, deviates from those values calculated according to the equation Xe ${ }_{\text {calc }}=X_{\text {meas }}$ by less than $\pm 15 \%$ over the range of the measured populations. The corresponding relationship for krypton atoms is

$$
\mathrm{Kr}_{\text {calc }}=1.78 \mathrm{Kr}_{\text {meas }}^{0.965}
$$

The $\mathrm{Kr}_{\text {calc }}$ calculated according to $\mathrm{Eq} \cdot 6-2$ deviates from those values calculated according to the equation $\mathrm{Kr}_{\text {calc }}=\mathrm{Kr}_{\text {meas }}$ by less than $\pm 18 \%$ over the range of the measured populations.

In contrast to the fission gas release from $\mathrm{ThO}_{2}$ and $\mathrm{UC}_{2}$ particles, the release of xenon and krypton from WAR particles was very rapid in the temperature rise experiment. By $2.3 \mathrm{~h}(\mathrm{~T}<1880 \mathrm{~K}), 90 \%$ of the initial inventory was released. This is undoubtedly due to the relatively low initial density of the WAR kernel (see Table 3-1) and the high burnup of $60 \%$ FIMA experienced by the test particle.

No isothermal experiments were conducted with the WAR particles and no further analysis of the temperature rise experiment, Exp. 7240-96, was attempted.

The data in Table 4-11 on the WAR particle which are based on particle inventories for $\mathrm{Kr}-85 \mathrm{~m}$ and $\mathrm{Kr}-88$ are questionable. The data for $\mathrm{Xe}-135$ and $\mathrm{Kr}-87$ indicate complete release of these elements by the end of the 
experiment at $4.6 \mathrm{~h}$. This would be expected for a particle with $60 \%$ FIMA treated to the temperature profile of Exp. 7240-96. However, for $\mathrm{Kr}-85 \mathrm{~m}$ and $\mathrm{Kr}-88$, the data indicate release of only half the initial inventories. If the fractional release data for all the nuclides are normalized to one at $4.6 \mathrm{~h}$, then the absolute standard deviation at any measurement time is less than 4\%; this result suggests the discrepancy lies in the particle inventory measurements.

\subsubsection{Iodine and Tellurium}

When the fractional release data for iodine in the temperature rise experiments, given in Table 4-13, are compared with the corresponding (fractional release) data for xenon, the two sets of data can be related as follows:

$$
f_{I}=1.06 \mathrm{f}_{\mathrm{Xe}}^{1.11}
$$

Equation 6-3 is derived from a least-squares fitting. The ratio of $\mathrm{f}_{\mathrm{I}}$ obtained from Eq. 6-3 to $f_{I}$ obtained from the equation $f_{I}=f_{X e}$ is $0.8 \pm 0.2$. Thus, when account is taken of the collection efficiency of 0.85 for iodine, the data of Table 4-13 for iodine support the conclusion of Section 4.1 that $\mathrm{f}_{\mathrm{I}}=\mathrm{f}_{\mathrm{Xe}}$ and are consistent with the conclusion of Section 4.1 that the profile parameters $\mathrm{f}_{\beta}$ and $\mathrm{S}$ are the same for lodine and xenon. These conclustons indicate that the model parameters given in Table 6-1 for xenon may also be used for iodine.

Comparisons of the observed and calculated releases for tellurium in the temperature rise experiments were not conclusive, in general. The collection of released tellurium was unreliable, as described in Section 4.2.2.3. The most reliable data for tellurium, given in Table 4-8, were those based on pretest and posttest particle activity measurements. In most cases, the fractional releases were close to one at the end of the experiment and, under these circumstances, the comparisons are insensitive to the values of the model parameters. However, the situation was different in Exp. 7240-108. 
In Exp. 7240-108, the observed and calculated fractional releases of tellurium at the end of the experiment $(4.43 \mathrm{~h}$ ) were 0.77 and 0.47 , respectively. This is a significant difference. Mode1 parameters for xenon were used in the calculation of release since identical release behavior for tellurium and xenon was expected. In Section 4.2.1.2, the conclusion was reached that the profile parameters $f_{B}$ and $S$ for tellurium and xenon are not significantly different. Therefore, the present result implies a difference in the profile parameter $t .8(\equiv 1 / \alpha)$ for tellurium and xenon. Indeed, if the value of $t .8$ is reduced to $0.1 \mathrm{~h}$ (from values of $t .8 \geq 0.3 \mathrm{~h}$ for xenon), the calculated release of tellurium becomes 0.75 as compared with the observed 0.77 . This result suggests that tellurium is more quickly released from the fuel material via the mechanism for the rapid release fraction (see Section 5.2) than is xenon but otherwise is similar to xenon in release characteristics.

The foregoing conclusions imply that the model parameters given in Table 6-1 for xenon may also be used for tellurium except in the case of the model parameters of the $\mathrm{f}_{\alpha}$ function. In the latter case, $\alpha$ is tentatively set equal to $10 \mathrm{~h}^{-1}$ for all fuel materials, burnups, and temperatures; thus, $a_{1}=a_{2}=10 \mathrm{~h}^{-1}$ and $\alpha_{2}=0$.

6.1.3. Cesium

The cesium release data are treated in two parts. First, the data are considered for the $\mathrm{ThO}_{2}$ particles with $1.4 \%$ FIMA in which the cesium was retained in the kernel during capsule irradiation; then the data are considered for the remaining particles in which a significant fraction of the cesium inventory was released to the coatings during capsule and reactor irradiation. The distribution of cesium between kernel and coatings in the test particles has been discussed in Section 4.2.1.3.

For the release data from the $\mathrm{ThO}_{2}$ particles with $1.4 \%$ FIMA, the model parameters are given in Table 6-2. As stated previously (Section 4.2.1.3), only two quantities, $f_{\beta}$ and $s$, sould be determined from the 
TABLE 6-2

PARAMETERS OF THE FISSION PRODUCT RELEASE MODEL AS A FUNCTION OF FUEL MATERIAL AND BURNUP FOR CESIUM

\begin{tabular}{|c|c|c|c|c|c|}
\hline \multicolumn{2}{|c|}{ Parameters } & \multicolumn{2}{|c|}{$\mathrm{ThO}_{2}$} & \multicolumn{2}{|c|}{$\mathrm{UC}_{2}$} \\
\hline Profile & Model (a) & $1.4 \%$ FIMA & $15.7 \%$ FIMA & $23.5 \%$ FIMA & $74.0 \%$ FIMA \\
\hline$\alpha$ & (b) & (b) & (b) & (b) & (b) \\
\hline \multirow[t]{5}{*}{$f_{\beta}{ }^{(c)}$} & C & 0.96 & 0.6 & 0.4 & (d) \\
\hline & $\beta_{1}$ & 0.9 & (e) & (e) & (d) \\
\hline & $\tau_{\beta 1}$ & 6.09 & $\infty$ & $\infty$ & (d) \\
\hline & $\beta_{2}$ & 4.62 & $4.62^{(f)}$ & 6.0 & (d) \\
\hline & $\tau_{\beta 2}$ & 4.72 & 5.00 & 4.6 & (d) \\
\hline \multirow[t]{2}{*}{$\mathrm{s}^{(\mathrm{c})}$} & $\mathrm{S}^{\mathrm{O}}$ & $2.64(0)^{(g)}$ & $2.23(2)$ & $7.14(2)$ & (h) \\
\hline & $\sigma$ & $1.49(4)$ & $1.49(4)^{(f)}$ & $1.86(4)$ & (h) \\
\hline
\end{tabular}

(a) The units of the model parameters are: $1 / \mathrm{h}$ for $\alpha$ and $\mathrm{S}^{\circ}$; $\mathrm{K}$ for $\beta_{1}, \beta_{2}$, and $\sigma ; 10^{4} / \mathrm{K}$ for $\tau_{\beta 1}$ and $\tau_{\beta 2} ; C$ is dimensionless.

(b) The function $f_{\alpha}$ is set equal to one; see section 6.1.3.

(c) In the case of $\mathrm{ThO}_{2}$ with $15.7 \%$ FIMA and for $\mathrm{UC}_{2}$ particles, the significance of these parameters changes for cesium release data; see Section 6.1.3.

(d) The function $f_{\beta}$ is set equal to one; see Table 4-9.

(e) Value is arbitrary.

(f) Assumed to be the same as in the $1.4 \%$ FIMA case.

(g) $2.64(0)=2.64 \times 10^{0}$.

(h) Slope could not be obtained since release was complete by time of first measurement. 
isothermal experiments. Therefore, in using the model to predict cesium release, the $f_{\alpha}$ function (see Section 5.2) is set equal to one.

The relationship between the calculated and measured cumulative number of cesium atoms released for $\mathrm{ThO}_{2}$ with $1.4 \%$ FIMA is given by

$$
\mathrm{f}_{\mathrm{Cs}, \mathrm{calc}}=1.14 \mathrm{f}_{\mathrm{Cs}, \text { meas }}^{1.027}
$$

The $\mathrm{f}_{\mathrm{Cs}}$, calc calculated according to Eq. 6-4 deviates from the values calculated according to the equation $\mathrm{f}_{\mathrm{Cs}, \text { calc }}=\mathrm{f}_{\mathrm{Cs}}$, meas by less than $15 \%$ over the range of the measured fractional release values.

For cesium release from $\mathrm{ThO}_{2}$ with $15.7 \%$ FIMA and from $\mathrm{UC}_{2}$ with 23.5 and $74 \%$ FIMA, the significance of the profile parameters, $f_{B}$ and $S$, changes. They now represent not only cesium released from the kernel but also cesium released from the coating during the heating experiments. However, these two contributions to cesium release cannot be accurately distinguished. Hence, only the upper limit to kernel release is obtained. The model parameters for use in the upper limit, fractional release function are 1isted in Table 6-2.

While the contributions to $f_{\beta}$ from the kernel and coating release of cesium cannot be accurately distinguished, a comparison of the calculated coating inventory with the experimental values of $f_{\beta}$ shows the coating contribution to be the most important factor in most cases. The calculated coating inventory is given in Table B-1 of Appendix B and the $f_{\beta}$ values are given in Table 4-9.

\subsection{PARAMETERS OF THE RELEASE MODEL}

The relative importance of the profile parameters is first examined and then the uncertainties associated with the profile and model parameters are discussed. 


\subsubsection{Relative Importance of the Profile Parameters}

The most important profile parameter in the temperature rise experiments is $f_{\beta}$, which is a measure of the rapid release fraction as discussed in Section 5. At the end of these experiments, the contribution to the total release from the rapid release fraction is $96 \%$ or larger for the $5-h$ duration experiments and $90 \%$ for the $24-h$ duration experiment.

During the course of the temperature rise experiments, the contribution of the slow release fraction, which is represented by the profile

parameter $\mathrm{S}$, increases to about $10 \%$ and about $75 \%$, respectively, for the 5-h and 24-h duration experiments. These maximum contributions occur in the temperature ranges 1700 to $1900 \mathrm{~K}$ and 1900 to $2100 \mathrm{~K}$ for $\mathrm{UC}_{2}$ and $\mathrm{ThO}_{2}$ particles, respectively. Of course, at the end of the temperature rise experiments, the contributions of the slow release fraction are the complement of those (given above) for the rapid release fraction.

\subsubsection{Profile Parameters in the Isothermal and Temperature Rise Experiments}

As stated in Sections 2.3 .2 and 5, the profile parameters were to be determined by analyzing the isothermal experiments and to be adjusted on the basis of the temperature rise experiments at temperatures not sampled in the isothermal experiments. The results of this procedure are now examined by comparing the values of the orofile parameters, $f_{\beta}$ and $s$, derived from the model parameters of Table 6-1 with the values measured in the isothermal experiments as given in Tables 4-3 through 4-6.

The relationships between the profile parameter $f_{B}$ calculated from the data of Table 6-1 and measured in the isothermal experiments are

$$
f_{\beta, \text { meas }}=0.95 f_{\beta, \text { calc }}^{1.01} \text { for Xe, }
$$




$$
f_{\beta, \text { meas }}=0.84 f_{\beta, \text { calc }}^{1.01} \text { for } \mathrm{Kr} \quad \text {. }
$$

These relationships are least-squares fits. The values of $f_{\beta, \text { meas }}$ derived from these equations differ from those derived from the equation $f_{\beta \text {, meas }}=$ $f_{\beta, \text { calc }}$ by less than $10 \%$ in the case of $\mathrm{Xe}$ and $20 \%$ in the case of $\mathrm{Kr}$ over the range of experimental values. The standard deviations in the measurement of $f_{\beta}$ in the isothermal experiments are $20 \%$ for xenon and $50 \%$ for krypton. Therefore, the model parameters may be regarded as representing the $\mathrm{f}_{\beta}$ values derived from the isothermal experiments with fidelity.

For the profile parameter $S$ examined in the form $S /\left(1-f_{\beta}\right)$, the relationships analogous to Eqs. 6-5 and 6-6 are

$$
\begin{aligned}
& {\left[\mathrm{S} /\left(1-\mathrm{f}_{\beta}\right)\right]_{\text {meas }}=1.46\left[\mathrm{~S} /\left(1-\mathrm{f}_{\beta}\right)\right]_{\text {calc }}^{1.05} \text { for } \mathrm{Xe},} \\
& {\left[\mathrm{S} /\left(1-\mathrm{f}_{\beta}\right)\right]_{\text {meas }}=0.63\left[\mathrm{~S} /\left(1-\mathrm{f}_{\beta}\right)\right]_{\text {calc }}^{0.978} \text { for } \mathrm{Kr}}
\end{aligned}
$$

These relationships are least-squares fits. The values of $S /\left(1-f_{B}\right)$ derived from these equations differ from those derived from the equation $\left[S /\left(1-f_{\beta}\right)\right]_{\text {meas }}=\left[S /\left(1-f_{\beta}\right)\right]_{c a l c}$ by less than $35 \%$ over the range of values between $2 \times 10^{-5}$ and $2 \times 10^{-1}$ for xenon and $2 \times 10^{-4}$ and $6 \times 10^{-1}$ for krypton. The standard deviations in the measurement of $s /\left(1-f_{\beta}\right)$ in the isotherma1 experiments are $20 \%$ for xenon and $80 \%$ for krypton. The model parameters adequately represent the $S /\left(1-f_{\beta}\right)$ values derived from the isothermal experiments.

\subsubsection{Uncertainty in the Model Parameters}

The uncertainties in the model parameters were estimated by performing a sensitivity calculation. In this calculation, the change in release was determined when each parameter was varied while all other parameters remained fixed at their mean values. The calculation was made for xenon release during the temperature rise experiment $7240-108$. 
The sensitivity of release, $R$, to change in model parameter $p$ is defined by the equation:

$$
S_{e}=\frac{\partial \ln \left(R / R_{m}\right)}{\partial \ln \left(p / p_{m}\right)}
$$

where the subscript $m$ refers to the mean values. At $R=R_{m}$ and $p=P_{m}$, $S_{e}=S_{e}^{0}$. The calculated values of $S_{e}^{o}$ are listed in Table 6-3. These values clearly indicate that release in the temperature rise experiments is very sensitive to the model parameters $\tau_{\beta 1},{ }^{\tau} \beta 2, \beta_{1}, \beta_{2}$, and $\alpha_{2}$ and only moderately sensitive or quite insensitive to $a_{1}, a_{2}, 1-C, s^{0}$, and $\sigma$ (except for $\sigma$ on the low side). The sensitivities given in Table 6-3 are for the conditions of time and temperature during the temperature rise experiment at which they are a maximum.

The percentage uncertainties in the model parameters can be determined approximately by using the following equation:

$$
U(p)=100\left(e^{ \pm \chi / S_{e}^{\circ}}-1\right)
$$

where $U(p)$ is the percentage uncertainty in parameter $p$ and

$$
x=\ln \left[1+\frac{U(R)}{100}\right]
$$

where $U(R)$ is the percentage uncertainty in release R. Equation 6-10 is based on a $\log$ normal distribution of errors. Its use is appropriate when the sensitivity is practically independent of the parameter values, i.e., when $s_{e}^{0} \approx s_{e}$.

The percentage uncertainties in the model parameters are given in Table 6-3. These uncertainties were calculated using Eq. 6-10 except for the parameter $\sigma$; for $\sigma$ the uncertainties were determined from the 
TABLE 6-3

SENSITIVITY OF RELEASE TO CHANGE IN MODEL PARAMETERS AND PERCENTAGE UNCERTAINTIES IN PARAMETERS CORRESPONDING TO 30\% UNCERTAINTY IN MEASURED RELEASE (ASSUMING A LOG NORMAL DISTRIBUTION OF ERRORS)

\begin{tabular}{c|c|c}
\hline & $\mathrm{S}_{\mathrm{e}}^{(\mathrm{a})}$ & $\begin{array}{c}\text { Percentage Uncertainties } \\
\text { in Parameters }\end{array}$ \\
\hline $1-\mathrm{C}$ & 1.0 & $+30 \% ;-23 \%$ \\
$\beta_{1}$ & -2.64 & $-9 \% ;+10 \%$ \\
$\tau_{\beta 1}$ & 5.19 & $+5 \% ;-5 \%$ \\
$\beta_{2}$ & -2.28 & $-11 \% ;+12 \%$ \\
$\tau_{B 2}$ & 36.0 & $+0.7 \% ;-0.7 \%$ \\
$\mathrm{a}_{1}$ & 0.345 & $+112 \% ;-53 \%$ \\
$\mathrm{a}_{2}$ & 0.381 & $+98 \% ;-49 \%$ \\
$\alpha_{2}$ & -3.99 & $-6 \% ;+7 \%$ \\
$\mathrm{~S}^{\circ}$ & 0.064 & $+5800 \% ;-98.3 \%$ \\
$\sigma$ & -0.97 & $-10 \% ;+\infty$ \\
\hline
\end{tabular}

(a)

$$
s_{e}^{\circ}=\left[\frac{\partial \ln \left(R / R_{m}\right)}{\partial \ln \left(p / p_{m}\right)}\right]_{p=p_{m}, R=R_{m}}
$$

where $R$ is release corresponding to changed value of parameter $\mathrm{p}$ and subscript $\mathrm{m}$ denotes mean value. 
curve of $\ln \left(R / R_{m}\right)$ versus $\ln \left(\sigma / \sigma_{m}\right)$ since $S_{e}^{\circ} \nVdash S_{e}$. For the calculations, $U(R)=30 \%$; the uncertainty in release is estimated to be about $30 \%$ for xenon and 50\% for krypton.

The model parameters $a_{1}, a_{2}, s^{\circ}$, and $\sigma$ can be evaluated more accurately in isothermal experiments than in temperature rise experiments. Consequently, the uncertainties in these model parameters can be reduced by analysis of the isothermal experiments. This is shown in Table 6-4. Further reduction in the uncertainties for $a_{1}, a_{2}, s^{0}$, and $\sigma$ can be obtained from performing additional isothermal experiments.

6.3. CHARACTERISTICS OF THE RELEASE MODEL

The fission product release model was described in terms of three characteristics in section 5.1. The first characteristic could be related to the results of the isothermal and temperature rise experiments. These were discussed in Section 5.2 and elaborated on in Sections 6.2.1 and 6.2 .2 .

The second and third characteristics of the fission product release model have been discussed in Section 5.3 and are elaborated on here. These characteristics describe the concept of subsystem for the rapid release fraction and the behavior of the subsystem with time and temperature.

The utility of the concept of subsystem for the rapid release fraction is demonstrated here. This is accomplished by determining the effect of reducing the number of subsystems on the accuracy of prediction of fission gas release. The ultimate reduction is to the level of one subsystem, which is equivalent to elimination of the concept of subsystem from the model. 
TABLE 6-4

COMPARISON OF UNCERTAINTIES IN MODEL PARAMETERS FROM ISOTHERMAL

AND TEMPERATURE RISE EXPERIMENTS CORRESPONDING TO A $30 \%$ UNCERTAINTY IN MEASURED RELEASE

\begin{tabular}{c|c|c}
\hline \multirow{2}{*}{ Parameter } & \multicolumn{2}{|c}{ Uncertainty from Experiments } \\
\cline { 2 - 3 } & Isotherma1 & $\begin{array}{c}\text { Temperature } \\
\text { Rise }\end{array}$ \\
\hline $\mathrm{a}_{1}$ & $+68 \% ;-41 \%$ & $+112 \% ;-53 \%$ \\
$\mathrm{a}_{2}$ & $+68 \% ;-41 \%$ & $+98 \% ;-49 \%$ \\
$\mathrm{~s}^{0}$ & $<+300 \% ;<-75 \%(\mathrm{a})$ & $+5800 \% ;-98.3 \%$ \\
$\sigma$ & $-;+40 \%$ & $-10 \% ;+\infty$ \\
\hline
\end{tabular}

(a) Includes $\mathrm{Xe}$ and $\mathrm{Kr}$ data; the error is larger for Kr data than for Xe data. 
The error in prediction of fission gas release is shown in Fig. 6-6 as a function of the number of subsystems. As the number of subsystems decreases, the error becomes increasingly larger. Therefore, the concept of subsystem is indispensable in the present release model.

The errors given in Fig. 6-6 are the relative errors and are always positive; thus, the predicted release is too large when using less than 200 subsystems for the calculation represented by Fig. 6-6.

The data of Fig. 6-6 were derived from a calculation of the release of xenon from $U_{2}$ particles with $74 \%$ FIMA. The errors apply to the calculations at $2 \mathrm{~h}(1850 \mathrm{~K})$ where the fractional release is on the order of 0.1 . For fractional release greater than 0.9 or less than 0.005 , the errors were always small.

With 200 subsystems for the calculations in Fig. 6-6, a subsystem was generated for every $2.6 \mathrm{~K}$ rise in temperature; with three subsystems, the temperature interval was $176 \mathrm{~K}$.

\section{REFERENCE}

6-1. York, D., "Least Squares Fitting of a Straight Line," Can. J. Phys. 44, 1079 (1966). 


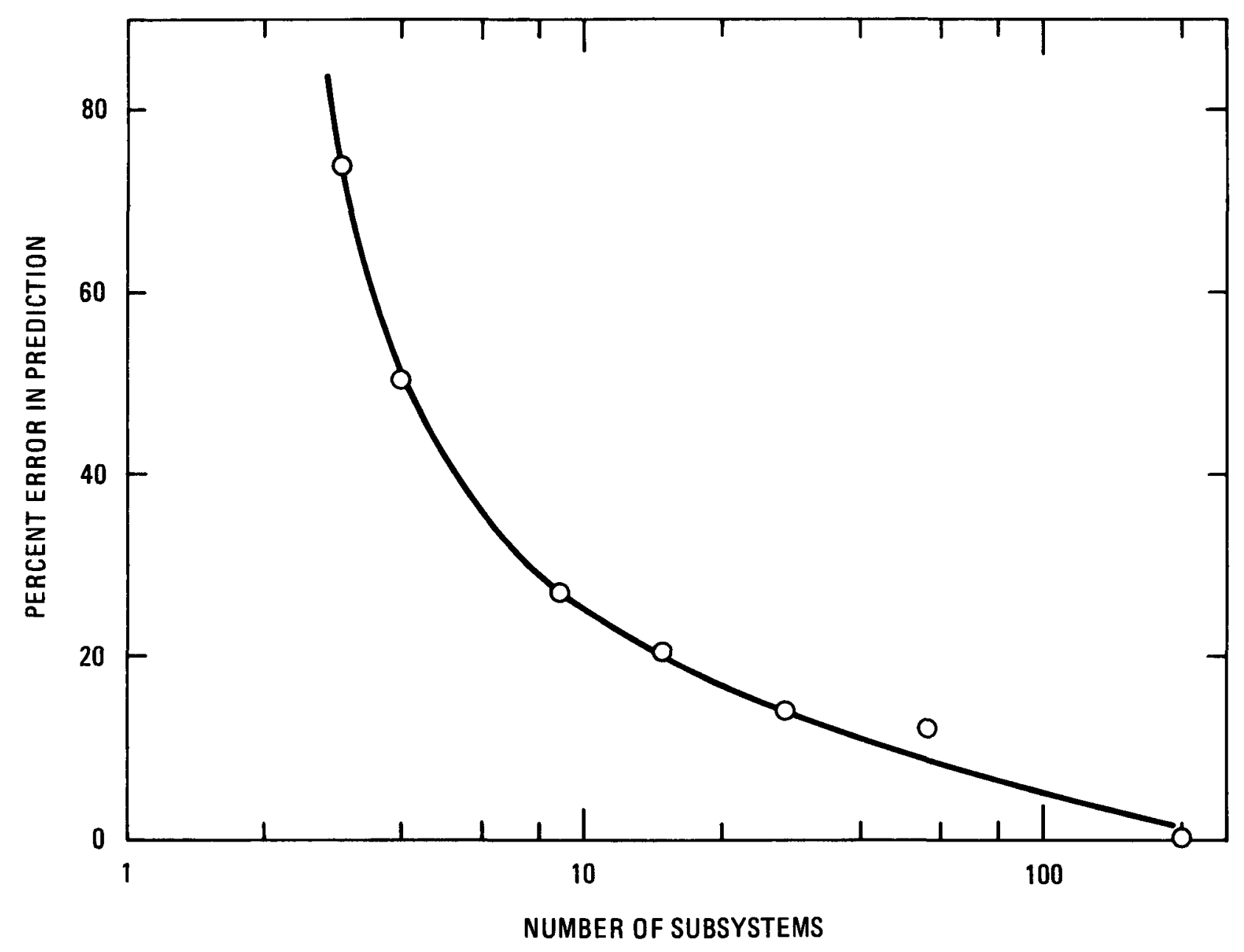

Fig. 6-6. Dependence of the accuracy in release model predictions of fission gas release on the number of subsystems 


\section{PHYSICAL INTERPRETATION OF THE RELEASE MODEL}

In this section, the physical interpretation of the release model is discussed. The basis for the physical interpretation is developed, to varyIng degrees, for each of two temperature regions with differing dominant fission product release mechanisms.

\subsection{AN INTERPRETATIVE FRAMEWORK FOR THE RELEASE MODEL}

The fractional release function can be approximated, at a fixed temperature $T$, by the equation

$$
f(t)=f_{\beta}+s \cdot t
$$

for times on the order of $1 \mathrm{~h}$ or larger since then the $f_{\alpha}$ function approaches one (see Eqs. 5-1 and 5-2). The parameter $f_{\beta}$ represents the rapid release of a constant fraction of the fission products and this implies the retention of the complementary fraction; however, the latter is subject to a slow but steady release according to the $s \cdot t$ term of Eq. $7-1$.

The foregoing situation can be interpreted in terms of sites in the fuel (kernels) which retain fission products with a binding energy exceeding the energy required for transport through unirradiated fuel. These sites are called traps. In the process of release, the fission products represented by the parameter $f_{\beta}$ either do not encounter traps or have energies (individually or collectively) great enough to avoid being trapped, whereas the other fission products, represented by the parameter $S$, are repeatedly trapped and are released from traps after acquiring the necessary activation energy through thermal motions. 
The parameter $f_{\beta}$ is the most important profile parameter in the temperature rise experiments (as stated previously in Section 6.2.1). As indicated by Eq. 5-2, it is independent of time. This leads to the suggestion that the values of $f_{\beta}$ are independent of the transport processes and are determined by the properties of the fuel material. Consequently, the fuel material properties will be most important for the release. This theme is developed in Sections 7.2 and 7.3.

The parameter $f_{\beta}$ and, consequently, the fractional release function are strongly dependent on temperature and burnup, in general. The dependence of $f_{\beta}$ on temperature and burnup is shown in Fig. 7-1 for release of xenon nuclides from laser-failed $\mathrm{ThO}_{2}$ particles. First consider the temperature dependence.

The temperature dependence of $f_{\beta}$ clearly defines two distinct temperature regions. The temperature $T^{*}$ at the common boundary of these regions is $1990 \mathrm{~K} ; \mathrm{T}^{*}$ is the intersection of the extrapolations of the $\mathrm{f}_{\beta}$ curves from lower and higher temperatures toward $T^{*}$. Also, for all xenon and krypton nuclides studied, $\mathrm{T}^{*}$ is $1990 \pm 20 \mathrm{~K}$ for $\mathrm{ThO}_{2}$ and has the same mean value for lodine and tellurium nuclides but with a larger uncertainty. Furthermore, $T^{*}$ is independent of burnup.

Entirely similar results are obtained from the temperature dependence of $\mathrm{f}_{B}$ for $\mathrm{UC}_{2}$ as for $\mathrm{ThO}_{2}$. In the case of $\mathrm{UC}_{2}$, $\mathrm{T}^{*}$ is $1690 \pm 20 \mathrm{~K}$.

The two distinct temperature regions indicate the existence of two different release mechanisms, each of which predominates in one of the temperature regions. The physical interpretation for the two temperature regions will be considered separately in Sections 7.2 and 7.3 .

The parameter $f_{\beta}$ is also strongly dependent on the burnup in $\mathrm{ThO}_{2}$ as shown in Fig. 7-1. However, as the temperature increases, the dependence becomes weaker. For $U_{2}$, the parameter $f_{\beta}$ is only weakly dependent on burnup at all temperatures as shown, for example, in Fig. 7-2 for the case of xenon release. Some insight into the burnup dependence of $f_{\beta}$ is developed 


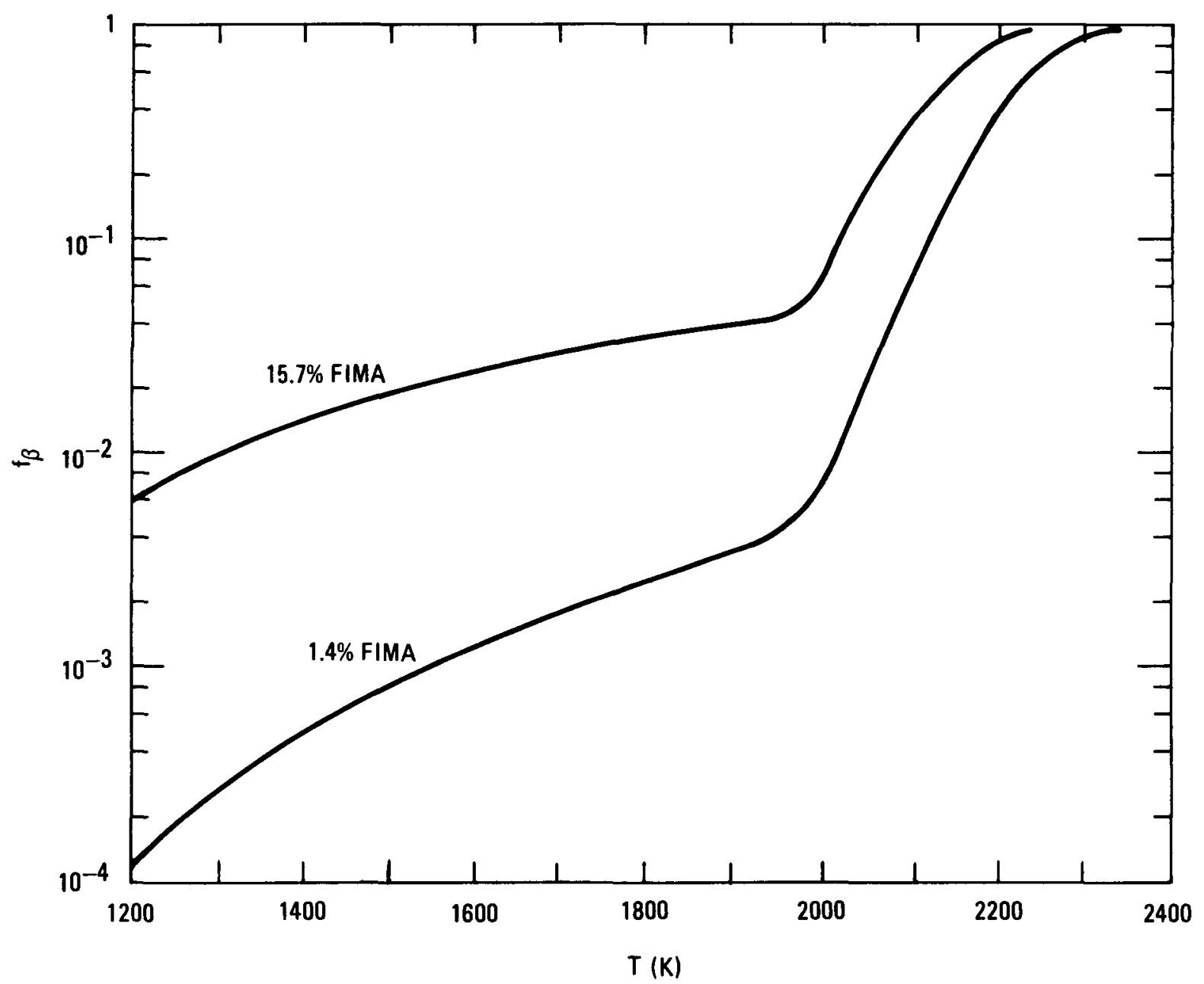

Fig. 7-1. Parameter $f_{\beta}(T)$ for release of xenon nuclides from laser-failed $\mathrm{ThO}_{2}$ particles at selected burnups 


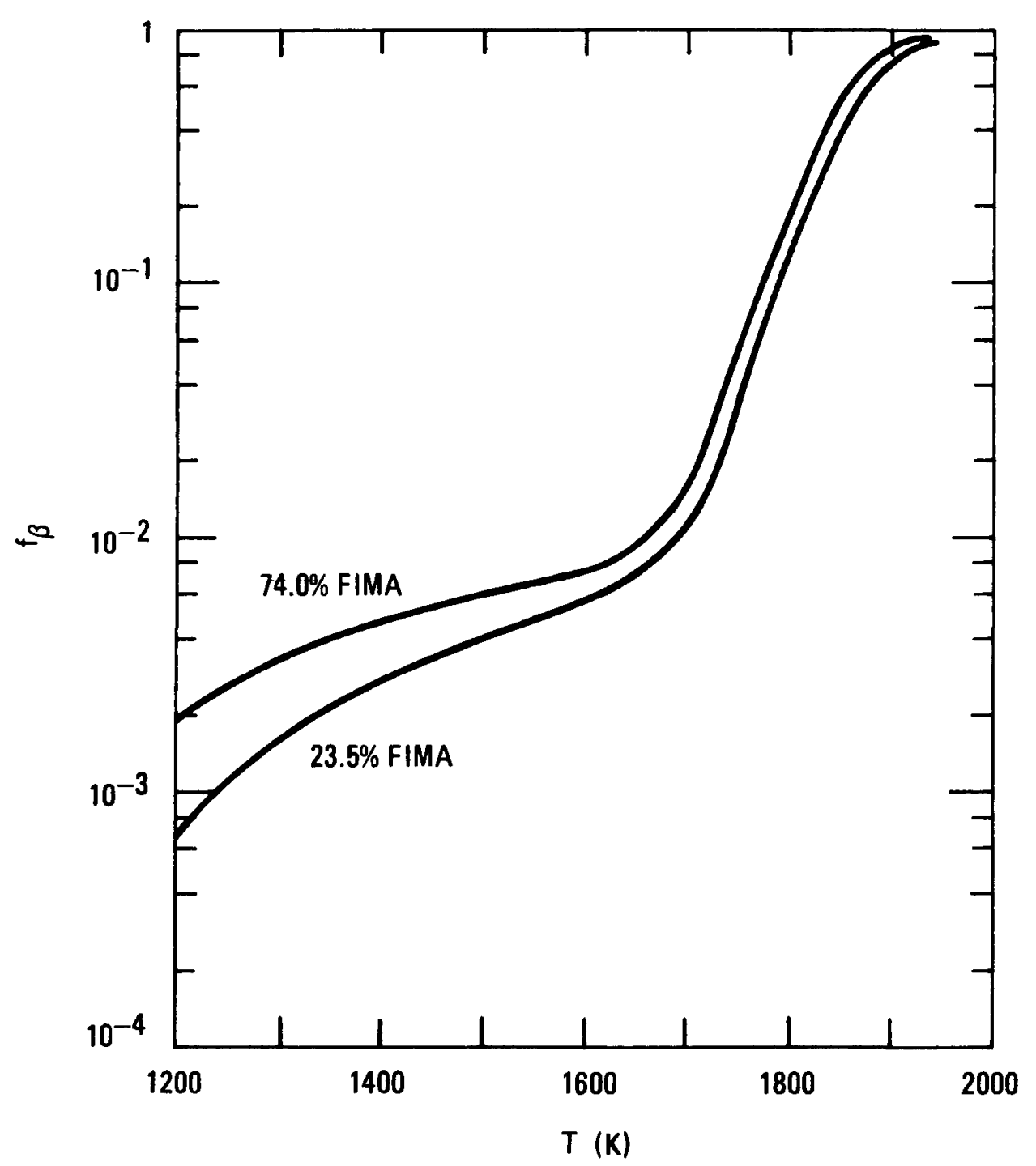

Fig. 7-2. Parameter $f_{\beta}(T)$ for release of xenon nuclides from laser-failed $\mathrm{UC}_{2}$ particles at selected burnups 
for $\mathrm{ThO}_{2}$ in Section 7.2 but for $\mathrm{UC}_{2}$, understanding is relatively restricted by the lack of any data at burnups below 23.5\% FIMA and of quantitative data characterizing the structure of $\mathrm{UC}_{2}$ kernels.

\subsection{RELEASE IN THE TEMPERATURE REGION BELOW T*}

The physical interpretation of the release model in the temperature region below $T^{*}$ is presented here. The interpretation involves a theoretically derived fractional release function, comparison of it with the fractional release function of the model introduced in Section 5, and a detailed analysis of the profile parameters $f_{\beta}, \alpha$, and $S$ based on the comparison.

\subsubsection{A Theoretical Fractional Release Function}

To derive a fractional release function, treatment of the diffusion of fission products in a fuel having homogeneously distributed traps is appropriate. This is in accord with the general interpretation of the release mode1 (as given in Section 7.1).

To treat diffusion, trapping, and release from traps, the following equations are used:

$$
\begin{aligned}
& \frac{\partial N}{\partial t}=D r^{-2} \frac{\partial}{\partial r}\left(r^{2} \frac{\partial N}{\partial r}\right)-g N+b N_{t}, \\
& \frac{\partial N_{t}}{\partial t}=g N-b N_{t},
\end{aligned}
$$

where

$$
\begin{aligned}
& \mathrm{N}=\text { density of free nuclides, } \\
& \mathrm{N}_{\mathrm{t}}=\text { density of trapped nuclides, } \\
& \mathrm{r}=\text { dimension variable, } \\
& \mathrm{g}=\text { probability per unit time or frequency of trapping, } \\
& \mathrm{b}=\text { probability per unit time or frequency of escape from traps, } \\
& D=\text { diffusion coefficient. }
\end{aligned}
$$


In Eqs. 7-2 and 7-3, single trapping and release frequencies represent all traps and these frequencies are independent of time and position. Thus, $g$ and $b$ represent the mean frequency per trap for capture by and release from traps, respectively. Also note that Eqs. 7-2 and 7-3 are, in effect, restricted to fixed temperature and burnup.

Similar equations were first solved numerically by Hurst (Ref. 7-1). An approximate analytical solution, appropriate for present purposes, has been obtained by 01 ander (Ref, 7-2). The fractional release expression which 0lander derived using his solution, slightly modified, is as follows.

$$
f=\frac{3 L}{a}\left\{\operatorname{erf}(g t)^{1 / 2}+\frac{b}{2 g}\left[(g t) \operatorname{erf}(g t)^{1 / 2}-m\right]\right\},
$$

where $\quad L=$ diffusion trapping length (the mean square distance an atom migrates to reach a trap is $\mathrm{L}^{2}$ ),

$a=$ radius of equivalent sphere from which release occurs,

$$
\begin{aligned}
\operatorname{erf}(g t)^{1 / 2} & =\text { error function of }(g t)^{1 / 2}, \\
m & \leq 0.5 \text { (see Appendix } C) .
\end{aligned}
$$

The diffusion trapping length is given by the relation

$$
L=\sqrt{\mathrm{D} / \mathrm{g}},
$$

and the dimension a is more suitably defined by the relation

$$
a=3 / s_{a} \rho,
$$

where

$$
\begin{aligned}
& S_{a}=\text { specific surface area (area/mass), } \\
& \rho=\text { the fuel density (mass/volume). }
\end{aligned}
$$


Equation 7-4 applies under the following conditions: (1) no fission products are in the traps at the beginning of the heating experiment, (2) $\mathrm{Dt} / \mathrm{a}^{2}<0.001$, and, for the second term only, (3) $\mathrm{gt} \geq 2$, and (4) $\mathrm{b} / \mathrm{g} \ll 1$. In Section 7.2 .7 conditions (2), (3), and (4) will be shown to apply to the heating experiments; condition (1) is very likely to be satisfied. If condition (1) is not satisfied, then the first term of Eq. 7-4 would have to be multiplied by $1-y$ and the second and third terms by $1+y$, where $y$ is the fraction of the gas initially in the traps.

\subsubsection{Comparison of Theoretically Derived and Semiempirical Fractional Release Functions}

The theoretically derived fractional release function, Eq. 7-4, is compared with the semiempirical fractional release function of the release model in the following form (see Section 5):

$$
f=f_{B}\left(1-e^{-\alpha t}\right)^{1 / 2}+s t
$$

This form is appropriate since conditions of constant temperature and burnup are required for comparison with Eq. 7-4.

Consider the first terms of Eqs. 7-4 and 7-7. Two identifications can be made. First,

$$
f_{B} \leftrightarrow 3 \mathrm{~L} / \mathrm{a}
$$

Thus, the fraction of the fission products that are rapidly released is determined by the ratio of the diffusion trapping length to the characteristic diffusion length of the fuel kernel. The relation 7-8 may be viewed in the following way. The fission products that are rapidly released lie in a surface layer with equivalent depth $L$ in a particle of radius $a$. The fraction of the total number of fission products lying within this layer is 


$$
f_{B}=\frac{4 \pi a^{2} \cdot L}{(4 / 3) \pi a^{3}}=\frac{3 L}{a} \text {, }
$$

provided $L \ll$ a. From data presented below, $L / a$ is found to be on the order of $10^{-4}$.

Second, there is the identification

$$
\left(1-e^{-\alpha t}\right)^{1 / 2} \leftrightarrow \operatorname{erf}(g t)^{1 / 2},
$$

To examine this correspondence, the relation between $\alpha$ and g needs to be determined.

As $t \rightarrow 0$, the semiempirical fractional release function, Eq. 7-7, tends to

$$
f=\sqrt{\alpha t} \cdot f_{\beta}
$$

Also, as $t \rightarrow 0$, the fission product migration distance becomes much less than $L$ and the fractional release is then given by

$$
f=6 \sqrt{D t / a^{2} \pi}
$$

Equation 7-12 is the solution to the diffusion equation without trapping terms for small $t$ (i.e., small f). By combining Eqs. 7-9, 7-11, and 7-12, one obtains

$$
\alpha=(4 / \pi)\left(D / L^{2}\right)
$$

Combining Eq. 7-13 with Eq. 7-5 leads to the desired relation between $\alpha$ and $g$,

$$
\alpha=(4 / \pi) g
$$


The correspondence, relation 7-10, becomes

$$
\left[1-e^{-(4 / \pi) g t}\right]^{1 / 2} \leftrightarrow \operatorname{erf}(g t)^{1 / 2}
$$

by using Eq. 7-14. Numerical evaluation and comparison of the right and left sides of Eq. 7-15 demonstrates that

$$
\left[1-e^{-(4 / \pi) g t}\right]^{1 / 2}=\operatorname{erf}(g t)^{1 / 2}+\varepsilon(g t),
$$

where $\varepsilon \leqslant 0.006$; the latter error corresponds to a maximum relative error of $0.7 \%$ for all values of $g t$. Thus, the first terms of Eqs. 7-4 and 7-7 can be practically regarded as identical.

The comparison of the second term of Eq. 7-7 with the second and third terms of Eq. 7-4 is simplified by taking into account the following factors:

1. The contribution of the second term of Eq. 7-7 is small by comparison with the first term for $t \leq 2 \mathrm{~h}$ in the temperature region below $\mathrm{T}^{*}$.

2. The values of $g$ are greater then $2 \mathrm{~h}^{-1}$ for the heating experiments.

Thus, when the second term of Eq. 7-7 becomes significant, gt $>4$ and the quantity in brackets in Eq. 7-4 tends to gt with an error less than about $10 \%$. Then, comparison of terms leads to the following:

$$
S t \leftrightarrow \frac{3 L}{a} \frac{b t}{2}=f_{\beta} \frac{b t}{2} \text {. }
$$

There are two aspects to this correspondence.

First, the linear dependence of fractional release on time, found in the 1sothermal heating experiments (Section 4.2.1.1), is confirmed by the 
solution to the diffusion-trapping equation, Eq. 7-4, for the conditions of the experiments.

Secondly, $S$ is the kernel release rate of fission products which have been repeatedly trapped and released from traps. Since $L$ is the diffusion trapping length, on the average, half of the fission products released from traps within a distance $L$ of a surface escape. The other half are, on the average, retrapped as are the fission products released from traps at distances from a surface greater than $L$. The trap release frequency is $b$ and the kernel escape rate is $f_{B}(b / 2)$.

\subsubsection{Further Interpretation of $\mathrm{f}_{\beta}$}

The profile parameter $f_{\beta}$ is dependent on the structure of the fuel material, according to the analytical development of Section 7.2.2, through the relation

$$
f_{B}=L S_{a} \rho,
$$

where $L$ is the diffusion trapping length, $S_{a}$ is the surface area accessible through the open porosity, and $\rho$ is the density. Equation 7-18 has been obtained by combining Eqs. 7-6 and 7-9. According to the results of the heating experiments, $f_{\beta}$ is dependent on burnup and temperature, in general. The contributions of the factors in Eq. 7-18 to the burnup and temperature dependence are now examined.

From this point until the end of Section 7.3, the interpretations will apply to the gaseous fission products but not to metallic fission products.

7.2.3.1. Burnup Dependence. The data on burnup for $\mathrm{ThO}_{2}$ and $\mathrm{JC}_{2}$ will be considered separately. For an elevenfold increase in burnup for $\mathrm{ThO}_{2}$, the values of $f_{\beta}$ increase by factors ranging from 11 to 60 for temperatures below $\mathrm{T}^{*}$, as shown in Fig. 7-1. This reflects an increase in the product LS (of Eq. 7-18); the changes in $\rho$ are too small to account for such changes in $f_{\beta}$. 
The changes in $S_{a}$ accompanying changes in burnup have not been measured but can be estimated by an indirect procedure. The procedure consists of comparing the $f_{\beta}$ values obtained in the present experiments with $f_{\beta}$ values obtained in independent experiments (Refs. 7-3, 7-4) in which 1ightly irradiated $\mathrm{ThO}_{2}$ samples having a wide variation in surface area were used. For the same $f_{\beta}$ values in the two sets of experiments, the known surface area in the one is treated as an equivalent surface area in the other.

The equivalent surface area for $\mathrm{ThO}_{2}$ with $15.7 \%$ FIMA is determined as shown in Fig. 7-3. The values of $\mathrm{f}_{B}$ for $\mathrm{ThO}_{2}$ samples of varying surface area (Refs. 7-3, 7-4) are shown as a function of temperature in the upper figure along with $f_{\beta}$ values from the present experiments for $\mathrm{ThO}_{2}$ with 1.4 and $15.7 \%$ FIMA. For further analysis, the data at a common temperature of $1300 \mathrm{~K}$ are chosen. These data are plotted in the lower figure in terms of $f_{B}$ versus $s_{a}$ on logarithmic scales; interpolation of the data yields a value of $270 \mathrm{~m}^{2} / \mathrm{kg}$ for the equivalent surface area of $\mathrm{ThO}_{2}$ with $15.7 \%$ FIMA.

The surface area for an unirradiated $\mathrm{ThO}_{2}$ kernel is estimated to be between 1.5 and 2.5 times the geometric surface area (Ref. 7-5). The mean of the corresponding values for the estimated surface area, $2.5 \mathrm{~m}^{2} / \mathrm{kg}$, is taken to represent the accessible surface area for $\mathrm{ThO}_{2}$ with $1.4 \%$ FIMA.

The derfved data on surface area indicate that the surface area changes by a factor of 108 when the burnup changes from 1.4 to $15.7 \%$ FIMA.

The denstty change accompanying a change in burnup can also be estimated by using the data of Refs. 7-3 and 7-4. The density is estimated to change from 9.9 to $8.5 \mathrm{Mg} / \mathrm{m}^{3}$ as the burnup changes from 1.4 to $15.7 \%$ FIMA.

By using Eq. 7-18, the change in $L$ with burnup can be derived by combining the changes in surface area and density with the change in $f_{\beta}$ at $1300 \mathrm{~K}$ as read from Fig. 7-3; $f_{\beta}$ changes by a factor of 36 . In this way, $L$ is found to decrease by a factor of 2.6 when burnup increases from 1.4 to $15.7 \%$ FIMA. 


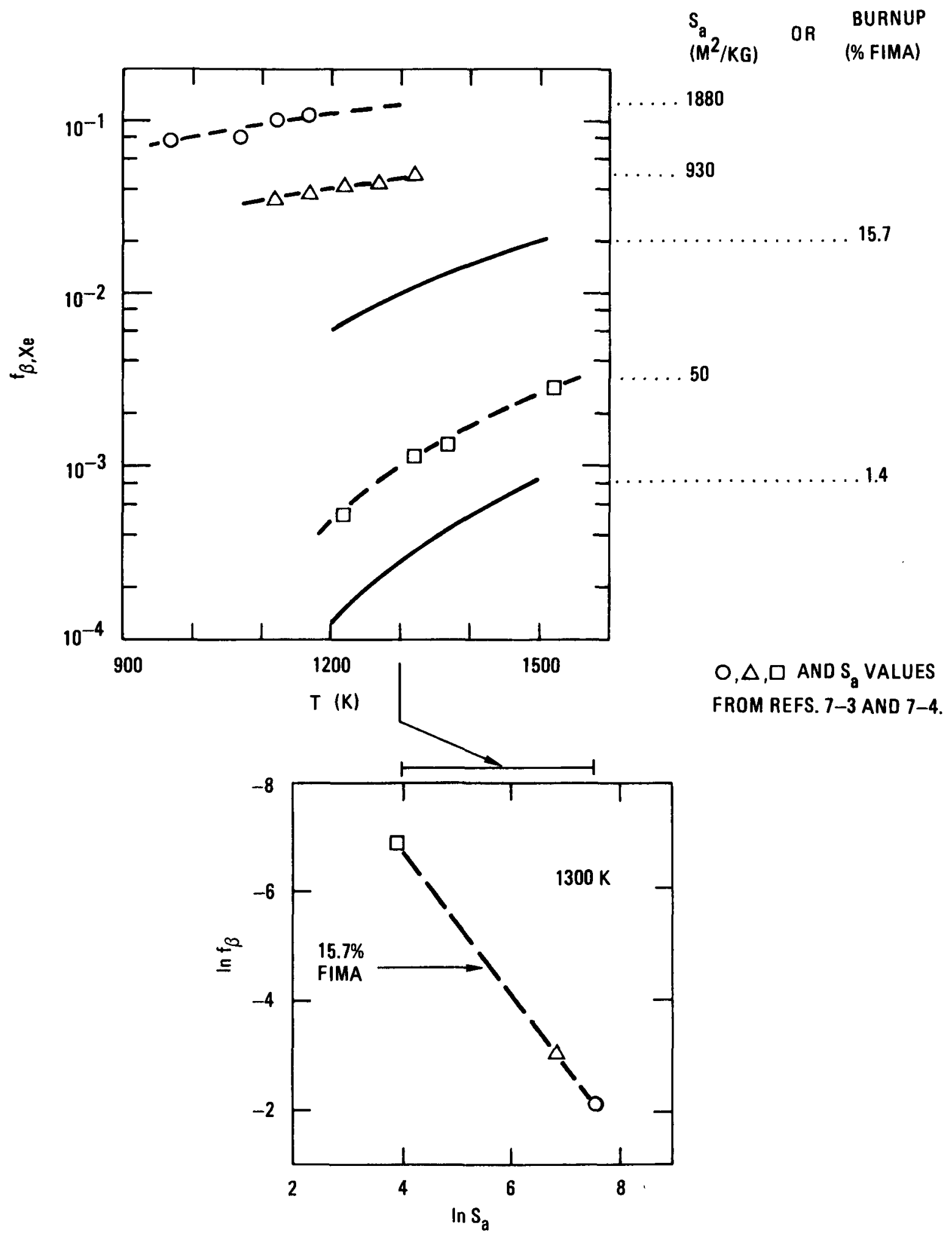

Fig. 7-3. Determination of equivalent surface area for $\mathrm{ThO}_{2}$ with $15.7 \%$ FIMA 
The decrease in $L$ can be predicted if the trap density is assumed to be proportional to the burnup. Since $\mathrm{L}^{2}$ is inversely proportional to the trap density (Ref. 7-2), L decreases by the factor $(15.7 / 1.4)^{1 / 2}=3.3$ when burnup increases from 1.4 to 15.7\% FIMA. This factor compares favorably with the value 2.6 deduced from changes in $f_{\beta}, s_{a}$, and $\rho$ with burnup.

The absolute values of $\mathrm{L}$, computed by using Eq. 7-18 and the values of $f_{B}, s_{a}$, and $\rho$ given above, are found to be 11.3 and $4.4 \mathrm{~nm}$ for the 1.4 and 15. $7 \%$ FIMA cases, respectively.

For a threefold increase in burnup in $\mathrm{UC}_{2}$, the values of $\mathrm{f}_{\beta}$ increase by factors ranging from 1.4 to 3 for temperatures below $T^{*}$, as shown in Fig. 7-2. As for $\mathrm{ThO}_{2}$, this reflects an increase in $\mathrm{S}_{\mathrm{a}}$ primarily; however, there are no independent data on surface area for $\mathrm{UC}_{2}$ on which to base a quantitative description of the increase in $f_{\beta}$. Further discussion of this matter will proceed by adopting an assumption which will be justified in Section 7.2.4.

The change in the surface area in $\mathrm{UC}_{2}$ at $1300 \mathrm{~K}$ accompanying a change in burnup from 23.5 to $74 \%$ FIMA is estimated as follows. By assuming the trap density to be proportional to the burnup, the factor by which the diffusion trapping length, $L$, decreases is calculated to be $(74 / 23.5)^{1 / 2}=1.8$. Since $f_{B}$ increases by the factor 2.1 at $1300 \mathrm{~K}$, the surface area must increase by a factor of 3.7. In drawing this conclusion, the probably small change in density, $\rho$, has been neglected.

At $1300 \mathrm{~K}$, the estimated change in surface area is nearly proportional to burnup for $\mathrm{UC}_{2}$ and nearly proportional to the square of burnup for $\mathrm{ThO}_{2}$. Apparently in $\mathrm{UC}_{2}$ the irradiation damage can be more readily annealed than in $\mathrm{ThO}_{2}$ or, at the higher burnups in $\mathrm{UC}_{2}$ as compared to $\mathrm{ThO}_{2}$, the dependence of surface area on burnup becomes weaker.

The surface areas of the $\mathrm{ThO}_{2}$ and $\mathrm{UC}_{2}$ in the as-selected test particles are dependent on the irradiation temperature and fission rate density experienced in the pretest capsule and reactor irradiations (see Section 3 ). 
Higher temperatures and fission rate densities accelerate sintering (thus decreasing the surface area) through the effects of a larger vacancy diffusion coefficient and a greater fission fragment flux through existing pores, respectively (Ref. 7-2).

For the $\mathrm{ThO}_{2}$ test particles, the irradiation temperatures and mean fission rate densities given in Table 3-1 are larger for $\mathrm{ThO}_{2}$ with $15.7 \%$ FIMA than with $1.4 \%$ FIMA. Consequently, the estimated change in surface area given above may be underestimated (see section 8 ). This conclusion is also reached for the $\mathrm{UC}_{2}$ test particles. In the latter case, the fission rate density was larger for $\mathrm{UC}_{2}$ with $74 \%$ FIMA than with $23.5 \%$ FIMA but the irradiation temperatures were not significantly different.

The data needed to make quantitative corrections for the effects of irradiation temperature and fission rate densities on surface area are not available. Note, however, that corrections would tend to improve the agreement between the calculated and predicted factors, presented above, by which the diffusion trapping length decreases with increasing burnup.

7.2.3.2. Temperature Dependence. The data on temperature dependence for $\mathrm{ThO}_{2}$ and $\mathrm{UC}_{2}$ will be treated together. The temperature dependence of $f_{B}$ is described by an empirical function, Eq. 5-4, with four model parameters. The component of $f_{\beta}$ which is dominant at temperatures below $T^{*}$ is given by

$$
f_{B 1}=\left\{1+\exp \left[\beta_{1}\left(\frac{10^{4}}{T}-\tau_{B 1}\right)\right]\right\}^{-1} .
$$

The model parameter $\beta_{1}$ can be expressed in terms of an activation energy, $Q_{B 1}$, according to Eq. 5-8; the model parameter $\tau_{B 1}$ can be expressed in terms of a characteristic temperature, $T_{1 / 2, \beta 1}=10^{4} / \tau_{\beta 1}$. The quantity $\mathrm{T}_{1 / 2, \beta 1}$ is the temperature at which $\mathrm{f}_{\beta 1}=1 / 2$. The activation energies and characteristic temperatures are given in Table $7-1$.

Comparison of the activation energies given in Table $7-1$ indicates that at the $67 \%$ confidence level the activation energies are independent of 
TABLE . 7-1

ACTIVATION ENERGIES AND CHARACTERISTIC TEMPERATURES ASSOCIATED WITH

$\mathrm{f}_{\beta}$ FOR XENON AND KRYPTON NUCLIDES IN $\mathrm{ThO}_{2}$ AND UC $\mathrm{UC}_{2}$ AT SELECTED BURNUPS AND FOR TEMPERATURES BELOW $\mathrm{T} *$

\begin{tabular}{c|c|c|c|c|c}
\hline \multirow{2}{*}{$\begin{array}{c}\text { Fue1 } \\
\text { Material }\end{array}$} & $\begin{array}{c}\text { Burnup } \\
(\% \text { F IMA })\end{array}$ & \multicolumn{2}{|c|}{ Xenon Nuclides } & \multicolumn{2}{c}{ Krypton Nuclides } \\
\cline { 3 - 6 } & 1.4 & 100 & 2092 & 125 & 1869 \\
\hline $\mathrm{ThO}_{2}$ & 15.7 & 75 & 1724 & 75 & 1724 \\
$\mathrm{ThO}_{2}$ & 23.5 & 108 & 1580 & 104 & 1330 \\
$\mathrm{UC}_{2}$ & 74.0 & 91 & 1420 & 67 & 1040 \\
UC $_{2}$ & \multicolumn{2}{|c|}{$7 \mathrm{Q}_{\beta 1}(\mathrm{~mJ} / \mathrm{mol})$} & $\mathrm{T}_{1 / 2}(\mathrm{~K})$ \\
\hline \\
$\begin{array}{c}\text { Uncertainty (\% standard } \\
\text { deviation) }\end{array}$
\end{tabular}


the fission gas element and are dependent on burnup (except for Xe in $\mathrm{UC}_{2}$ ). These results are in general accord with the suggestion of Section 7.1 that $f_{\beta}$ is determined by the properties of the fuel material.

Comparison of the characteristic temperatures of Table 7-1 leads to conflicting results about the dependence of $\mathrm{T}_{1 / 2, \beta 1}$ on the fission gas element and burnup. At the $67 \%$ confidence level, $\mathrm{T}_{1 / 2, \beta 1}$ is found to depend on the fission gas element for $\mathrm{UC}_{2}$ but not for $\mathrm{ThO}_{2}$ and to depend on burnup except for $\mathrm{ThO}_{2}$ in the case of krypton.

The activation energies of the quantities $L$ and $S_{a}$ on which $f_{\beta}$ depends through Eq. 7-18 can be roughly estimated as follows. By casting the temperature dependencies of the quantities in Eq. 7-13 into the Arrhenius form, the activation energy of $\mathrm{L}$ can be estimated to be

$$
Q_{L} \approx Q_{D} / 2
$$

where $Q_{D}$ is the activation energy for diffusion of fission gas in the absence of traps and where $Q_{\alpha}$ has been taken to be zero (see Section 5.3). Equation 7-20 implies that $\mathrm{L}$ increases with increasing temperature. This would be expected if more traps are annealed or coalesce at higher temperature. The activation energy $Q_{D}$ has not been measured for the fuel materials of interest here, but careful measurements of xenon diffusion in $\mathrm{UO}_{2}$ (Ref. 7-6) have yielded $Q_{D}=460 \mathrm{~kJ} / \mathrm{mol}$. Thus, $Q_{L}$ is probably near $230 \mathrm{~kJ} / \mathrm{mol}$ for xenon diffusion in $\mathrm{ThO}_{2}$.

By again using the Arrhenius form for the temperature dependence, the activation energy of $\mathrm{S}_{a}$ can be obtained from $\mathrm{Eq} \cdot 7-18$ as

$$
Q_{S a} \approx Q_{B 1}-Q_{L}
$$

The value of $\mathrm{Q}_{\mathrm{Sa}}$ is near $-140 \mathrm{~kJ} / \mathrm{mol}$. Thus, $\mathrm{S}_{\mathrm{a}}$ decreases with increasing temperature; this would be expected from sintering effects. According to Coble's model of sintering (Ref. 7-7), as elaborated by 0lander (Ref. 7-2), 
one expects $S_{a}$ to be proportional to $D_{s}^{-1 / 3}$, where $D_{s}$ is the volume selfdiffusion coefficient; thus $Q_{S a} \approx-Q_{D s} / 3$. The value of $Q_{D s}$, based on measurements of thorium in $\mathrm{ThO}_{2}$ (Ref. 7-8), leads to $\mathrm{Q}_{\mathrm{Sa}} \approx-150 \mathrm{~kJ} / \mathrm{mol}$, in reasonable agreement with the results of the heating experiments.

\subsubsection{Further Interpretation of $\alpha$}

The profile parameter $\alpha(\equiv 1 / t .8)$ is proportional to the diffusion coefficient, $D$, according to Eq. 7-13. This diffusion coefficient represents diffusion of fission gas in the absence of traps since Eq. 7-13 is valid only as $t$ approaches zero and the diffusion distance becomes much smaller than $\mathrm{L}$, the diffusion trapping length. D can be evaluated for xenon diffusion in $\mathrm{ThO}_{2}$ for the present experiments.

$$
\begin{aligned}
& \text { For temperatures below } T^{*}, \alpha=a_{1} \text { and Eq. } 7-13 \text { becomes } \\
& \qquad D=a_{1} L^{2} \pi / 4 \text {. }
\end{aligned}
$$

At $1300 \mathrm{~K}$, at which $\mathrm{L}$ has been evaluated from xenon release measurements (Section 7.2.3.1), $D\left(\mathrm{~m}^{2} / \mathrm{s}\right)=7.5$ and $3.6 \times 10^{-20}$ for burnups of 1.4 and 15.7\% FIMA, respectively. Based on the uncertainties given in Table 6-4, these values are not significantly different. This is to be expected for $D$.

The average value of $D, 5.5 \times 10^{-20} \mathrm{~m}^{2} / \mathrm{s}$, compares favorably with the value of the classical diffusion coefficient of $9.4 \times 10^{-20} \mathrm{~m}^{2} / \mathrm{s}$ at $1300 \mathrm{~K}$ derived from measurements of xenon diffusion in single crystal $\mathrm{UO}_{2}$ (Ref. $7-6)$.

The value of $\mathrm{D}$ for xenon diffusion in $\mathrm{ThO}_{2}$ is consistent with diffusion of single gas atoms for temperatures below $\mathrm{T}^{*}\left(\equiv 1990 \mathrm{~K}\right.$ for $\left.\mathrm{ThO}_{2}\right)$. This conclusion is based on a correlation of diffusion coefficients for gas bubbles as a function of bubble radius (Ref. 7-9); as the bubble radius decreases, the diffusion coefficient increases. This correlation indicates 
that single atoms have a diffusion coefficient on the order of $10^{-20} \mathrm{~m}^{2} / \mathrm{s}$ at $1300 \mathrm{~K}$. The conclusion of gas release by diffusion of single gas atoms has also been reached by Turnbull (Ref. 7-10) for temperatures up to $2070 \mathrm{~K}$ in $\mathrm{UO}_{2}$ and by Baker (Ref. 7-11) for temperatures up to $1770 \mathrm{~K}$ in $\mathrm{UO}_{2}$.

The values of $a_{1}$ can be used to test the assumption of proportionality between burnup and trap density at temperatures below $\mathrm{T}^{*}$. This assumption was used without confirmation in Section 7.2.3.1 to treat $\mathrm{UC}_{2}$ data. The assumption is represented by the relation

$$
\mathrm{F}=\mathrm{Ka}_{1},
$$

where $\mathrm{F}$ is the burnup in $\%$ FIMA, and $\mathrm{K}$ is a constant at fixed temperature. Equation 7-23 is based on the proportionality of $a_{1}$ with $L^{-2}$ and of trap density with $\mathrm{L}^{-2}$ and with $\mathrm{F}$ (assumed).

The $K$ values calculated from the $a_{1}$ and $F$ values for $U C_{2}$ given in Table 6-1 are consistent with the assumption tested. These values are independent of burnup for either fission gas element. The variation in $\mathrm{K}$ values is less than $25 \%$ and this is smaller than the errors of $+68 \%,-41 \%$ in $a_{1}$ given in Table $6-4$.

\subsubsection{Further Interpretation of $S$}

The profile parameter $S$ was determined in experiments at temperatures over a range including $T^{*}$; however, the parameter is most important near or below $T^{*}$ and a discussion of $S$ is therefore included here.

The profile parameter $S$ is represented by Eq. 5-5 with two model parameters, $S^{\circ}$ and $\sigma\left(\equiv Q_{\sigma} / R\right.$ according to $E q$. 5-9). The factor $1-f_{\beta}$ was empirically introduced into Eq. 5-5 to account for reduction in the release rate of the slow component (Section 5.2) as the kernel gas atom inventory is depleted. The values of the model parameters $S^{\circ}$ and $Q_{\sigma}$ are 1 isted in Table 7-2. 
TABLE 7-2

ACTIVATION ENERGIES AND PREEXPONENTIAL FACTORS ASSOCIATED WITH S FOR XENON AND KRYPTON NUCLIDES IN ThO 2 AND UC 2 AT SELECTED BURNUPS AND FOR TEMPERATURES BELOW T*

\begin{tabular}{|c|c|c|c|c|c|}
\hline \multirow{2}{*}{$\begin{array}{c}\text { Fuel } \\
\text { Materia1 }\end{array}$} & \multirow{2}{*}{$\begin{array}{l}\text { Burnup } \\
\text { (\% FIMA) }\end{array}$} & \multicolumn{2}{|c|}{ Xenon Nuclides } & \multicolumn{2}{|c|}{ Krypton Nuclides } \\
\hline & & $\mathrm{S}^{\circ}(1 / \mathrm{h})$ & $Q_{\sigma}(\mathrm{kJ} / \mathrm{mol})$ & $S^{0}(1 / h)$ & $\mathrm{Q}_{\sigma}(\mathrm{kJ} / \mathrm{mo} 1)$ \\
\hline $\mathrm{ThO}_{2}$ & 1.4 & $1.34(4)$ (a) & 285 & $4.22(6)$ & 340 \\
\hline $\mathrm{ThO}_{2}$ & 15.7 & $3.78(5)$ & 285 & $8.68(6)$ & 340 \\
\hline $\mathrm{UC}_{2}$ & 23.5 & $4.92(9)$ & 410 & $2.30(12)$ & 485 \\
\hline $\mathrm{UC}_{2}$ & $i 4.0$ & $1.32(10)$ & 410 & $6.18(12)$ & 485 \\
\hline \multicolumn{2}{|c|}{$\begin{array}{l}\text { Uncertainty }(\%) \\
\text { from Table } 6-4\end{array}$} & $\begin{array}{r}+300 \\
-75\end{array}$ & $\begin{array}{l}+40 \\
-10\end{array}$ & $\begin{array}{r}+300 \\
-75\end{array}$ & $\begin{array}{l}+40 \\
-10\end{array}$ \\
\hline
\end{tabular}

(a) $1.34(4)=1.34 \times 10^{4}$. 
The data of Table 7-2 demonstrate that the preexponential factor $\mathrm{S}^{\mathrm{O}}$ depends on the fission gas element, the fuel material, and burnup, whereas the activated energy, $Q_{\sigma}$, is independent of burnup. Within the uncertainty limits given in Table 7-2, the variations in $Q_{\sigma}$ with fission gas element and fuel material cannot be established as significant. Nevertheless, the trends indicate the activation energy is larger for krypton than for xenon and larger in $\mathrm{UC}_{2}$ than in $\mathrm{ThO}_{2}$.

The profile parameter $S$ has been related to $b$, the mean escape frequency of fission gas from traps, according to Eq. 7-17. Combining Eqs. $7-17,5-5$, and 5-9 yields

$$
b=\frac{2 S^{\circ} e^{-Q_{\sigma} / R T}\left(1-f_{\beta}\right)}{f_{\beta}}
$$

By evaluating the right side of Eq. $7-24$ in the temperature range (1700 to $2000 \mathrm{~K}$ ) of the isothermal experiments from which $\mathrm{S}$ values were derived, the mean escape frequency per trap, $b$, is found to be independent of burnup for both xenon and krypton in $\mathrm{ThO}_{2}$ and $\mathrm{UC}_{2}$, within the uncertainty associated with $b$. This would be expected if only the number but not the nature of the traps changed with burnup.

In the temperature range of 1700 to $2000 \mathrm{~K}$, the temperature dependence of $b$ is governed approximately by $Q_{\sigma}$. The values of $Q_{\sigma}$ for $\mathrm{ThO}_{2}$ (Table 7-2) are comparable to the estimated binding energy (240 to $290 \mathrm{~kJ} / \mathrm{mol})$ for rare gas atoms with vacancy clusters in the isostructural $\mathrm{CaF}_{2}$ (Ref. 7-12).

\subsubsection{Recoiled Fission Products}

During the pretest reirradiation to generate short-1ived nuclides (see Section 2.2), a small fraction of the nuclides recoiled from the kernel and most were embedded in the carbonaceous coatings surrounding the kernel. In the subsequent heating experiments (see Section 2.3), these embedded nuclides could be released. The interpretation of Sections 7.2.2 through 
TABLE 7-3

ACTIVATION ENERGIES AND CHARACTERISTIC TEMPERATURES ASSOCIATED WITH

$\mathrm{f}_{\beta}$ FOR XENON AND KRYPTON NUCLIDES IN ThO ${ }_{2}$ AND UC $\mathrm{UC}_{2} \mathrm{AT}$ SELECTED BURNUPS AND FOR TEMPERATURES ABOVE $\mathrm{T}^{*}$

\begin{tabular}{|c|c|c|c|c|c|c|c|}
\hline \multirow{2}{*}{$\begin{array}{c}\text { Fuel } \\
\text { Material }\end{array}$} & \multirow{2}{*}{$\begin{array}{l}\text { Burnup } \\
(\% \text { FIMA })\end{array}$} & \multicolumn{3}{|c|}{ Xenon Nuclides } & \multicolumn{3}{|c|}{ Krypton Nuclides } \\
\hline & & $Q_{B 2}$ & $(\mathrm{~kJ} / \mathrm{mol})$ & $\mathrm{T}_{1 / 2}(\mathrm{~K})$ & $\mathrm{Q}_{\beta 2}$ & $(\mathrm{~kJ} / \mathrm{mol})$ & $\mathrm{T}_{1 / 2}(\mathrm{~K})$ \\
\hline $\mathrm{ThO}_{2}$ & 1.4 & & 982 & 2217 & & 982 & 2179 \\
\hline $\mathrm{ThO}_{2}$ & 15.7 & & 982 & 2132 & & 982 & 2146 \\
\hline $\mathrm{UC}_{2}$ & 23.5 & & 856 & 1869 & & 856 & 1484 \\
\hline $\mathrm{UC}_{2}$ & 74.0 & & 856 & 1848 & & 856 & 1828 \\
\hline \multicolumn{2}{|c|}{$\begin{array}{l}\text { Uncertainty (\% } \\
\text { standard deviation) }\end{array}$} & & \pm 12 & \pm 0.7 & & \pm 19 & \pm 1.1 \\
\hline
\end{tabular}


7.2.5 is based on the implicit assumption that the contribution of these embedded nuclides to release in the heating experiments is negligible. This assumption is examined here.

of the nuclides directly recoiled from the kernel, about $99 \%$ are embedded in the coatings surrounding the kernel. This is demonstrated by steady-state fractional release measurements (Ref. 7-13) at $600^{\circ} \mathrm{C}$ on laserfailed $(8 \mathrm{Th}, \mathrm{U}) \mathrm{O}_{2}$ particles with dense $500-\mu \mathrm{m}$-diameter kernels at essentially zero burnup. At $600^{\circ} \mathrm{C}$, the fission products will not diffuse from their stopping sites. The measured steady-state fractional release for $\mathrm{Kr}-85 \mathrm{~m}$ is $3.6 \times 10^{-4}$ (Ref. 7-13) and since the recoil fraction is 0.027 , not more than about $1 \%$ of the recolled nuclides have escaped from the coatings.

The diffusive release of the recoiled nuclides from the coatings does not contribute significantly to values of the profile parameter $f_{\beta}$. This conclusion is based on the following considerations. With increase in burnup, $f_{\beta}$ increases significently as shown in Fig. 7-1 for $\mathrm{ThO}_{2}$ particles. However, for the buffer and pyrocarbon coatings surrounding the kernel, densification increases with fluence (Ref. 7-14) (and therefore with burnup) and fission gas release decreases with increasing densification (Ref. 7-15). Consequently, the increase in $f_{B}$ with burnup cannot result from diffusive release of recoiled nuclides embedded in the coatings. Further, the $f_{B}$ values for ThO $_{2}$ particles with $15.7 \%$ FIMA cannot have any significant contribution from diffusive release of recolls since any contribution of recoils would have to be less than corresponds to $\mathrm{f}_{\beta}$ values for the $1.4 \%$ FIMA case (see Fig. 7-1).

From the analyses of the profile parameter $\alpha$ in Section 7.2.4, the value of the diffusion coefficient associated with release of the fraction $\mathrm{f}_{\beta}$ of fission gas atoms has been shown to be independent of burnup. Therefore, for $\mathrm{ThO}_{2}$ particles with 1.4 and $15.7 \%$ FIMA, the dominant release mechanism can be regarded as identical and the recoil contribution to $f_{B}$ as negligible. 
Additional observations consistent with the preceding conclusion are: (1) the agreement of the diffusion coefficient derived from analysis of the profile parameter $\alpha$ with one derived from independent measurements of xenon diffusion in $\mathrm{UO}_{2}$ (see Section 7.2.4), and (2) the consistency of $\mathrm{f}_{B}$ values with those independently obtained from bare $\mathrm{ThO}_{2}$ Dellets (see Fig. 7-3).

On the basis of the above considerations, the conclusion has been reached that diffusive release of recoiled nuclides embedded in the coatings surrounding the kernel does not contribute significantly to values of $f_{z}$ for $\mathrm{ThO}_{2}$ particles with 1.4 and $15.7 \%$ FIMA. This conclusion a so applies to the data on $\mathrm{ThO}_{2}$ with $0.25 \%$ FIMA (see Section 4.1) and to the data on $\mathrm{UC}_{2}$ particles since (1) all test particles have essentially similar coatings surrounding the kernel, and (2) the $f_{B}$ values (or fractional release values at about $1 \mathrm{~h}$ ) for these particles are approximately equal to or larger than the $\mathrm{f}_{B}$ values for the $\mathrm{ThO}_{2}$ particles with 1.4 and $15.7 \%$ FIMA.

The diffusive release of recoiled nuclides from the coatings apparently does not contribute significantly to values of the profile parameter S; however, there are insufficient data to draw a firm conclusion. The values of $S$ increase with increasing burnup as indicated by the data of Table 7-2 and this implies, as argued above, that the increase cannot result from any contribution to release by diffusive release of recoil nuclides.

The activation energy associated with $S$ is independent of burnup. If the dominant contribution to values of $S$ were from diffusive release of recoiled nuclides, the activation energy would be expected to increase with increasing burnup as the coatings surrounding the kernel became more dense.

Finally, in many of the isothermal experiments, the contribution to release by diffusive release of recoiled nuclides is significantly smaller than that corresponding to the profile parameter $S$ since the latter contribution exceeds the recoil fraction. This is Indicated by some of the data in Tables 4-3 through 4-6. 


\subsubsection{Applicabllity of Theoretical Fractional Release Function}

The theoretical fractional release function, Eq. 7-4, introduced in Section 7.2.1 can be applied to the heating experiments provided conditions $1,2,3$, and 4 given in Section 7.2 .1 are satisfied. Condition (1) requires that no fission products are in traps at the beginning of the heating experiments; otherwise, the terms of Eq. 7-4 have to be differently weighted as described in Section 7.2.1. Condition (1) is probably satisfied for the heating experiments. Since the reirradiation of the particles was performed at temperatures below $100^{\circ} \mathrm{C}$, fission gases would not have migrated from their stopping sites after fission; these sites are regarded as part of the fuel matrix and not in themselves traps. The fraction of fuel material occupied by traps would be approximately $1 \%$ for traps of mean diameter $1 \mathrm{~nm}$ separated by a mean distance of $5 \mathrm{~nm}$ (see Section 7.2.3.1). Hence, only this fraction of the fission products would be held in traps inftially.

Condition (2) is satisfied by xenon and krypton in $\mathrm{UC}_{2}$ for temperatures below $1660 \mathrm{~K}$ and in $\mathrm{ThO}_{2}$ for temperatures below $1900 \mathrm{~K}$ at $1.4 \%$ FIMA and $1500 \mathrm{~K}$ at $15.7 \% \mathrm{FIMA}$. These results are based on the inequality $\pi \alpha \mathrm{f}_{\beta}^{2} / 36<$ 0.001 , which is equivalent to condition (2), Dt/ $\mathrm{a}^{2}<0.001$. The former Inequality is derived by combining the latter inequality with Eqs. 7-6, $7-13,7-18$, and $5-3$ for temperatures less than $T^{*}$.

Condition (3) is satisfied by xenon and krypton for $t>1.5 \mathrm{~h}$ independent of fuel material and burnup. This result is based on the inequality $\pi a t / 4 \geq 2$, which is equivalent to condition (3), gt $\geq 2$. The former is derived from the latter inequality by use of Eq. 7-4. Condition (3) applies to the second term of Eq. $7-4$ and this term only becomes important at times greater than 1 to $2 \mathrm{~h}$.

Condition (4) is satisfled by xenon and krypton independently of fuel material and burnup for temperatures below $1800 \mathrm{~K}$ in $\mathrm{ThO}_{2}$ and $1600 \mathrm{~K}$ in $\mathrm{UC}_{2}$. These results are based on the inequality $8 \mathrm{~S} / \pi \alpha \mathrm{f}_{\beta} \ll 1$, which is equivalent to condition ( 4$), \mathrm{b} / \mathrm{g} \ll 1$. The former can be derived from the latter 
inequality by use of Eqs. $7-14$ and $7-24$ and the approximation $1-f_{\beta} \approx 1$ valid for temperatures below $T^{*}$.

The application of the theoretical fractional release function, Eq. $7-4$, to the heating experiments shows that the method of determining $f_{\beta}$ (Section 4.2.1.1) is not precisely correct. The quantity $f_{\beta}$ was determined by extrapolating the linear portion of the fractional release profile of an isothermal experiment to $\Delta t=0$. According to $\mathrm{Eq} .7-4$, this procedure results in an underestimation of $f_{B}$ by the factor $\sim 0.65(3 \mathrm{Lb} / 2 \mathrm{ag})$. This factor, as a fraction of $\mathrm{f}_{\beta}$, becomes $0.325(\mathrm{~b} / \mathrm{g})$. The latter quantity is less than 0.02 for temperatures below $1800 \mathrm{~K}$ in $\mathrm{ThO}_{2}$ and $1600 \mathrm{~K}$ in $\mathrm{UC}_{2}$. Consequently, the error in determining $f_{\beta}$ by the method of Section 4.2.1.1 is negligible.

\subsection{RELEASE IN THE TEMPERATURE REGION ABOVE T*}

A limited physical interpretation of the release model in the temperature region above $T^{*}$ is presented here. The interpretation deals with qualitative aspects of release and the dependence of profile parameters on the fission gas element, the fuel material, temperature, and burnup.

\subsubsection{Qualltative Aspects of Release Above T*}

The temperature region above $T^{*}$ is distinguished by the relatively large fractional releases of fission products which closely approach one at temperatures of 2000 and $2300 \mathrm{~K}$ In $\mathrm{UC}_{2}$ and $\mathrm{ThO}_{2}$, respectively. The mechanisms by which single fission gas atoms are released at temperatures below $\mathrm{T}^{*}$ can only account for 1ess than $10 \%$ of the fission gas release above $\mathrm{T}^{*}$. This leads to the suggestion that the collective release of gas atoms in bubbles is the dominant mechanlsm of gas release at temperatures above $T^{*}$.

There is no readily available theoretical development which may be used to interpret the fractional release function of the release model (Section 5) at temperatures above $T^{*}$ as has been done in Section 7.2 for 
temperatures below $\mathrm{T}^{*}$. However, at temperatures above $\mathrm{T}^{*}$, the general nature of the profile parameters $f_{\beta}$ and $\alpha$ (as well as $S$ as discussed in Section 7.2.5) is preserved. The parameter $f_{\beta}$ is still primarily dependent on the properties of the fuel material and $\alpha$ is still a measure of the migration speed of fission gases. The changes occur in the particular properties on which $f_{\beta}$ depends and the particular mode of migration which $\alpha$ represents.

\subsubsection{Further Interpretation of $\mathrm{f}_{\beta}$}

The particular properties of the fuel material on which $f_{\beta}$ depends at temperatures above $T *$ remains to be established; however, the heating experiments give some guidance.

Since $f_{\beta}$ is constant at a fixed temperature, corresponding to the release of a fixed fraction of the gas, the behavior of $\mathrm{f}_{\beta}$ again indicates that the nature and number of traps are important. However, for temperatures above $\mathrm{T}^{*}$, the traps are probably those with which gas bubbles are associated.

The burnup dependence of $f_{\beta}$ is weaker at temperatures above $T *$ than below $T^{*}$. Perhaps this reflects the assembly of gas atoms into a relatively sma11 number of traps.

The temperature dependence of $f_{\beta}$ is very strong at temperatures above $T^{*}$. This dependence is given by

$$
f_{B 2}=\left\{1+\exp \left[\beta_{2}\left(\frac{10^{4}}{T}-\tau_{B 2}\right)\right]\right\}^{-1},
$$

where $\beta_{2}$ and $\tau_{\beta 2}$ are the model parameters. The parameter $\beta_{2}$ can be expressed in terms of the activation energy, $Q_{B 2}$, according to Eq. $5-8$; the model parameter $\tau_{\beta 2}$ can be expressed in terms of the characteristic temperature $\mathrm{T}_{1 / 2, \beta 2}=10^{4} / \tau_{\beta 2}$. The quantity $\mathrm{T}_{1 / 2, \beta 2}$ is the temperature at which $f_{B 2}=1 / 2$. The activation energies and characteristic temperatures are 1isted in Table 7-3. 
Comparison of the activation energies of Table 7-3 indicates that, within the listed uncertainties, the activation energies are independent of the fission gas element and burnup but are dependent on the fuel material. The same results are obtained by comparison of the characteristic temperatures of Table 7-3 except for the dependence of the characteristic temperature on burnup in the case of xenon in $\mathrm{ThO}_{2}$. These results are consistent with a dependence of $f_{B}$ on the properties of the fuel material and with migration of fission gas atoms in bubbles.

The magnitudes of the activation energies in Table 7-3 are relatively large. The large magnitudes probably represent a sum of activation energies corresponding to the temperature dependencies of several structural properties.

\subsubsection{Further Interpretation of $\alpha$}

The component of $\alpha$ which becomes dominant at temperatures above $\mathrm{T}^{*}$ is given by

$$
\alpha\left(T^{*}\right)=a_{2} e^{-Q \alpha 2 / R T}
$$

where $Q_{\alpha_{2}}$ is the activation energy defined by Eq. 5-10. Values of the preexponential factor, $a_{2}$, and activation energy, $Q_{\alpha 2}$, are listed in Table 7-4.

Comparison of the activation energies of Table 7-4 indicates that, within the listed uncertainties, the activation energy, $Q_{\alpha 2}$, is independent of the fission gas element and burnup except in $\mathrm{UC}_{2}$ where $\mathrm{Q}_{\alpha_{2}}$ for xenon varies with burnup; $Q_{\alpha 2}$ does depend on the fuel material. These results are generally in accord with migration of fission gas in bubbles.

The mechanism of bubble migration can be deduced from the activation energy in $\mathrm{ThO}_{2}$; for $\mathrm{UC}_{2}$, the data are inadequate and other complications enter as discussed in Section 7.4. 
TABLE 7-4

ACTIVATION ENERGIES AND PREEXPONENTIAL FACTORS ASSOCIATED WITH $\propto$ FOR

XENON AND KRYPTON NUCLIDES IN ThO 2 AND UC 2 AT SELECTED BURNUPS AND FOR TEMPERATURES ABOVE T*

\begin{tabular}{c|c|c|c|c|c}
\hline \multirow{2}{*}{$\begin{array}{c}\text { Fuel } \\
\text { Material }\end{array}$} & $\begin{array}{c}\text { Burnup } \\
(\% \text { FIMA })\end{array}$ & $\mathrm{a}_{2}(1 / \mathrm{h})$ & $\mathrm{Q}_{\alpha 2}(\mathrm{~kJ} / \mathrm{mol})$ & $\mathrm{a}_{2}(1 / \mathrm{h})$ & $Q_{\alpha 2}(\mathrm{~kJ} / \mathrm{mol})$ \\
\cline { 3 - 6 } & 1.4 & $6.03(5)(\mathrm{a})$ & 246 & $5.57(5)$ & 242 \\
$\mathrm{ThO}_{2}$ & 15.7 & $3.36(6)$ & 246 & $1.12(6)$ & 242 \\
$\mathrm{ThO}_{2}$ & 23.5 & $1.82(12)$ & 511 & $7.02(10)$ & 446 \\
$\mathrm{UC}_{2}$ & 74.0 & $1.0(11)$ & 418 & $3.09(11)$ & 446 \\
$\mathrm{UC}_{2}$ & $\begin{array}{l}\text { Unyyyyy} \\
\text { from Table 6-4 }\end{array}$ & -41 & \pm 7 & +68 & \pm 7 \\
\hline
\end{tabular}

$$
\text { (a) } 6.03(5)=6.03 \times 10^{5} \text {. }
$$


There are four mechantsms by which bubbles can migrate in fuel material. These mechanisms depend on one of the following: (1) surface diffusion (Ref. 7-2), (2) volume diffusion (Ref. 7-2), (3) vapor transport (Ref. 7-10), and (4) nucleation of atomic layers (Refs. 7-16, 7-17). The last process applies to faceted bubbles; however, at high temperatures, the bubbles become spherical (Ref. 7-11) and then the bubbles move by mechanisms (1), (2), or (3).

The temperature dependencies of the mechanisms relevant to the heating experiments for temperatures above $T^{*}$ are described by (1) the activation energy for surface self-diffusion of the fuel material, (2) the activation energy for the lattice self-diffusion of one of the atomic species of the fuel material, and (3) the heat of vaporization. By comparing the magnitude of the observed activation energy with the quantities associated with mechanisms (1), (2), and (3), the mechanisms of bubble migration may be deduced.

The activation energy for bubble migration in $\mathrm{ThO}_{2}, 244 \pm 17 \mathrm{~kJ} / \mathrm{mol}$, compares favorably with the activation energy of $234 \mathrm{~kJ} / \mathrm{mol}$ for anion diffusion in $\mathrm{ThO}_{2}$ (Ref. 7-8). This suggests that the mechanism governing bubble migration in $\mathrm{ThO}_{2}$ is volume diffusion in which anion vacancies enter and leave the bubble. This mechanism is consistent with the fact (Ref. 7-8) that the predominant defects in fluorite structures are anion vacancles (and anion interstitials). By contrast to the observed activation energy, the activation energy for cation diffusion in $\mathrm{ThO}_{2}$ is $468 \mathrm{~kJ} / \mathrm{mol}$ (Ref. 7-8), the heat of vaporization of $\mathrm{ThO}_{2}$ is $680 \mathrm{~kJ} / \mathrm{mol}$ (Ref. 7-18), and the activation energy for surface self-diffusion would be expected to be close to the value of the heat of vaporization (Ref. 7-2).

\subsubsection{Inventory of Short-lived Fission Gas Nuclides in Bubbles Above $T^{*}$}

The inventory of short-lived fission gas nuclides in bubbles had to be established within times on the order of $1 \mathrm{~h}$ after the start of the heating experiments if these nuclides were released as bubbles at temperatures above $T *$. During the pretest reirradiation, the temperature was too low to 
permit gas migration, and so no opportunity existed for short-lived nuclides to enter or form gas bubbles before the heating experiments. After heating for times on the order of $1 \mathrm{~h}$, the gas release was nearly complete. Therefore, the inventory of short-lived nuclides in bubbles had to develop within times significantly smaller than $1 \mathrm{~h}$.

Bubbles existed in the particles prior to reirradiation. These bubbles were formed during the capsule and reactor irradiations (see section 3 ) and consisted of $\mathrm{Kr}-85$ and stable gas nuclides. Most bubbles in the particle kernels during the heating experiment were of this origin.

The time required for a gas atom to move to a trap is a characteristic time for the short-lived nuclide inventory of gas bubbles to develop. This time is $L^{2} / 2 D$. If $L$ and $D$ are cast into an Arrhenius form and Eq. 7-20 is used, the characteristic time becomes $\mathrm{L}_{0}^{2} / 2 \mathrm{D}_{0}$, where the subscript denotes the preexponential term in an Arrhenius-type equation. This ratio can be evaluated at any temperature since it is independent of temperature. If at $1300 \mathrm{~K}, \mathrm{~L}$ is taken to be $5 \times 10^{-9} \mathrm{~m}$ (Section 7.2.3.1) and $\mathrm{D}$ to be $5.5 \mathrm{x}$ $10^{-20} \mathrm{~m}^{2} / \mathrm{s}$ (Section 7.2.4), then the characteristic time becomes $0.06 \mathrm{~h}$. Thus, the condition for establishing the inventory of short-lived fission gas nuclides in bubbles is met.

\subsection{FURTHER ASPECTS OF THE INTERPRETATION}

There are implications and limitations associated with the foregoing interpretation whose treatment is beyond the scope of this report. Nevertheless, their formulation is of general interest in connection with the data, model, and interpretation given above. Some of them will be briefly considered here.

\subsubsection{Structural Changes in The Fuel Material}

The increase in the profile parameter $f_{\beta}$ with temperature implies, according to the ideas of Section 7.1, that the structure of the fuel material is changing with temperature. The important temperature changes occur 
not only in the temperature rise experiments but also in the isothermal experiments; in the latter, the fuel particle must be brought to the temperature of the experiment from room temperature and this induces structural changes.

For the isothermal experiment, $f_{\beta}$ is constant at each temperature (and burnup) and since the fractional release corresponding to it is reached in times on the order of $1 \mathrm{~h}$, the structural changes affecting $f_{\beta}$ are required to occur within times on the order of $1 \mathrm{~h}$. While important structural changes may occur within $1 \mathrm{~h}$, there is no doubt that they continue to occur throughout the isothermal experiment. The effect of continuing changes may be small but, in any case, the application of the theoretical fractional release function, Eq. $7-4$, is, on this account, an approximation.

In the temperature rise experiments, the important structural changes occur throughout the experiments.

\subsubsection{Structure of Fuel Material Surfaces}

In treating the rapid release fraction at temperatures below $T^{*}$, the release was ascribed to fission products lying in a surface layer of equivalent depth $L$. Since $L$ is the diffusion trapping length, the essence of this interpretation is that fission products escape from the surface layer because they do not encounter traps in the process.

Another plausible interpretation (Ref. 7-19) ascribes the release to a surface layer with properties different from the bulk as a result of radiation damage other than trap formation. If the depth of this layer is small compared with $\mathrm{L}$ [as appears to be the case in some experiments (Refs. 7-4, $7-20,7-21,7-22)$, albeit on very 1ightly irradiated materialj, then the damaged surface layer can be neglected; if the depth is comparable to $\mathrm{L}$, it could govern $\mathfrak{f}_{\beta}$.

The mafor piece of evidence against the significance of a damaged surface layer (as defined above) under the conditions of the heating 
experiments is the agreement between the diffusion coefficient derived from the heating experiments for migration in the surface layer with one derived from independent experiments under conditions that made surface and trapping effects negligible (see Section 7.2.4).

\subsubsection{Composition Changes in the Kernel}

The chemical composition of the fuel kernel changes as the burnup increases; yet, in the description of the release behavior of the particles used in the heating experiments, there is little suggestion of these changes. In the case of $\mathrm{ThO}_{2}$ particles, with relatively small burnups, this might be expected; however, in the case of $\mathrm{UC}_{2}$, the absence of a strong effect on the release behavior of changes in chemical composition is remarkable in view of the fact than $74 \%$ of the uranium atoms have fissioned in the high burnup $\mathrm{UC}_{2}$ particle.

The burnup dependence of the parameters $Q_{\beta 1}, T_{1 / 2, \beta 1}, a_{1}, S, Q_{\beta 2}$, and $\mathrm{T}_{1 / 2, \beta 2}$ is not essentially different in $\mathrm{UC}_{2}$ than in $\mathrm{ThO}_{2}$; only in the case of $\alpha(\mathrm{T} *)$ (Eq. 7-26) is the burnup dependence much stronger in $\mathrm{UC}_{2}$ than in $\mathrm{ThO}_{2}$. Also, the insensitivity of $\mathrm{f}_{\beta}$ to burnup is illustrated in Fig. 7-2.

\section{REFERENCES}

7-1. Hurst, D. G., "Diffusion of Fission Gas. Calculated Diffusion from a Sphere Taking Into Account Trapping and Return From the Traps," Atomic Energy of Canada Report AECL-1550, November 1962.

7-2. Olander, D. L., "Fundamental Aspects of Nuclear Reactor Fuel Elements," ERDA Report TID-26711-P1, Apri1 1976.

7-3. Karkhanavala, M. D., M. C. Naik, K. N. G. Kaima1, and 0. P. Chawla, "Kinetics of Release of Xenon from Sintered $\left(\mathrm{ThO}_{2}-0.1 \% \mathrm{UO}_{2}\right)$ Pellets," Bhabha Atomic Research Centre Report BARC-513, Government. of India Atomic Energy Commission, Bombay, 1970. 
7-4. Naik, M. C., K. N. G. Kaimal, and M. D. Karkhanavala, "Release of Xenon from Low-Dose Irradiated Thoria Pellets," J. Nuc1. Mater. 67 239 (1977). (The work reported in this reference is partly that of 0. P. Chawla as shown in Ref. 7-3.)

7.5. Car1 Notz, Oak Ridge National Laboratory, private communication.

7.6. Carter, J. C., E. J. Driscoll, and T. S. Elleman, "Xenon-133 Diffusion and Trapping in Single Crystal Uranium Dioxide," phys. stat. sol. (a) 14, 673 (1972).

7-7. Coble, R. L., "Sintering Crystalline Solids. I. Intermediate and Final State Diffusion Models," J. Appl. Phys. 32, 787 (1961).

7-8. Matzke, Hj., "Lattice Disorder and Metal Self-Diffusion in NonStoichiometric $\mathrm{UO}_{2}$ and $(\mathrm{U}, \mathrm{Pu}) \mathrm{O}_{2}, " \mathrm{~J}$. Physique 34, C9-317 (1973).

7-9. Dollins, C. C., "On Fission Gas Swelling Below $\sim 1200^{\circ} \mathrm{C}$," J. Nucl. Mater. 60, 107 (1976).

7-10. Turnbul1, J. A., "The Mobility of Intragranular Bubbles in Uranium Dioxide During Irradiation," J. Nucl. Mater. 62, 325 (1976).

7-11. Baker, C., "The Migration of Intragranular Fission Gas Bubbles in Irradiated Uranium Dioxide," J. Nuc1. Mater. 71, 117 (1977).

7-12. Felix, F. W., and S. Y. T. Lagerwell, "Diffusion of $\mathrm{Ar}, \mathrm{Kr}$ and $\mathrm{Xe}$ in $\mathrm{CaF}_{2}$ Investigated in U-Doped Single Crystals of $\mathrm{CaF}_{2}$ After Neutron Irradiation," phys. stat. so1. (a) 4, 73 (1971).

7-13. Pointud, M.-L., and P. Chenebault, "Emission of Fission Gases by Failed Coated Oxide Fuel Particles," Nucl. Techno1. 35, 494 (1977).

7-14. Scott, C. B., D. P. Harmon, and J. F. Holzgraf, "Postirradiation Examination of Capsules P13R and P13S," ERDA Report GA-A13827, General Atomic Company, October 8, 1976.

7-15. Myers, B. F., et al., "The Behavior of Fission Product Gases in HTGR Fuel Material," DOE Report GA-A13723, General Atomic Company, October 1977.

7-16. Willertz, L. E., and P. G. Shewmon, "Diffusion of Helium Gas Bubbles In Gold and Copper Foils," Met. Trans. 1, 2217 (1970).

7-17. Beeré, W., "Transport Kinetics in Faceted Bubbles," J. Nucl. Mater. 45, 91 (1972/73). 
7-18. Ackermann, R. J., and E. G. Rauh, "High Temperature Properties of the Thorium-oxygen System: A Revision of The Thermodynamic Properties of Tho $(\mathrm{g})$ and $\mathrm{ThO}_{2}(\mathrm{~g})$," High Temp. Sci. ․, 463 (1973).

7-19. Fel1x, F., et al., "Rare Gas Release from Solids with Special Attention to Nuclear Fuel Materials," Proc. UN Itern. Conf. Peaceful Uses At. Energy, 3rd, Geneva, 1964, 11, 363 (1965).

7-20. Kelley, R., "The Diffusion of 'Attached' Inert-Gas Activity," Can. J. Chem. 39, 2411 (1961).

7-21. Auskern, A., "Release of Xenon from Uranium Carbide at Low Temperatures," J. Am. Ceram. Soc. 47, 390 (1964).

7-22. Taketan1, K., and K. Ikawa, "Release of Xenon from Sintered $\mathrm{UO}_{2}$ at Low Temperatures," J. Nucl. Sci. Technol. 4, 589 (1967). 
8. APPLICATION OF THE EXPERIMENTAL DATA AND RELEASE MODEL TO CORE HEATUP EVENTS

Procedures for applying the experimental data and release model tc core heatup events are presented.

The calculation of fission product release is performed according to the procedure given in Section 5.4. This procedure requires the fractional release function, $f$, which is fully presented in section 5.3. The parameters needed to evaluate the fractional release function at the burnups of the test particles are given in Table 6-1 for xenon and krypton nuclides and in Table 6-2 for cesium nuclides. For lodine and tellurium nuclides, the parameters for xenon given in Table 6-1 are recommended with the following exception: for tellurium, the model parameters $a_{1}$, $a_{2}$, and $\alpha_{2}$ are taken to be 10,10 , and 0 , respectively. In addition to the fractional release function, $f$, the procedure of Section 5.4 requires a relationship between temperature and time; Eq. 4-14 is adequate although other arrangements are possible.

The experimental data and the release model are in excellent accord as demonstrated in Sections 6 and 7 . In applying the data and model to core heatup events, however, there are three aspects which need to be considered. These concern (1) decreases in temperature with time, (2) burnup, and (3) irradiation temperature and fission rate density.

The release model of Section 5.4 in its present state is applicable to temperature rises only. If applied during temperature declines, then the model and data will overestimate the release of fission products. Although there are no serious obstacles to removing this conservatism from the model, this has not been done in the present study. 
The time constraints on the present work limited the selection of $\mathrm{ThO}_{2}$ and $\mathrm{UC}_{2}$ test particles to two burnups. In applying the data and model to a core heatup event, it is therefore necessary to interpolate and, to a lesser extent, extrapolate (downward in burnup) the values of the model parameters. This can be done with the model parameters for xenon and krypton nuclides and thus also for lodine and tellurium nuclides. However, cesium represents a special case.

Release of cesium from the kernels of failed particles could be unambiguously evaluated only for $\mathrm{ThO}_{2}$ with $1.4 \%$ FIMA; in all other cases, release of cesium initially in the buffer obscured measurement of release from the kernel. Consequently, use of the cesium release data from $\mathrm{UC}_{2}$ and $\mathrm{ThC}_{2}$ (at high burnup) would result in a large overestimate of release at early times in a core heatup event. Thus, additional data must be obtained from other release data (see, for example, Refs. 8-1 and 8-2) by applying (1) the procedure of Appendix B to select data from those particles with negligible cesium in the coatings before testing, and (2) the model developed and confirmed by the present study.

To determine the values of the model parameters for xenon (and iodine and tellurium) and krypton at any burnup in the range of interest for HTGR systems, the following is suggested. The model parameters which vary with burnup are treated as linear in burnup if they occur in exponentials or are nearly constant and otherwise as nonlinear in burnup. This is in line with the dependence of release on a power of the burnup as reported for fission gases (Ref. 8-2) and for fission product metals (Ref. 8-3).

For the model parameters that are linear in burnup, the value of the model parameter $\mathrm{p}$ at burnup $\mathrm{F}$ is determined from the relations

$$
\begin{aligned}
\mathrm{p} & =\mathrm{c}+\mathrm{dF}, \\
\text { with } \quad \mathrm{c} & =\mathrm{p}_{\ell}-\mathrm{bF},
\end{aligned}
$$


and

$$
\mathrm{d}=\left(\mathrm{p}_{\mathrm{u}}-\mathrm{p}_{\ell}\right) /\left(\mathrm{F}_{\mathrm{u}}-\mathrm{F}_{\ell}\right)
$$

where

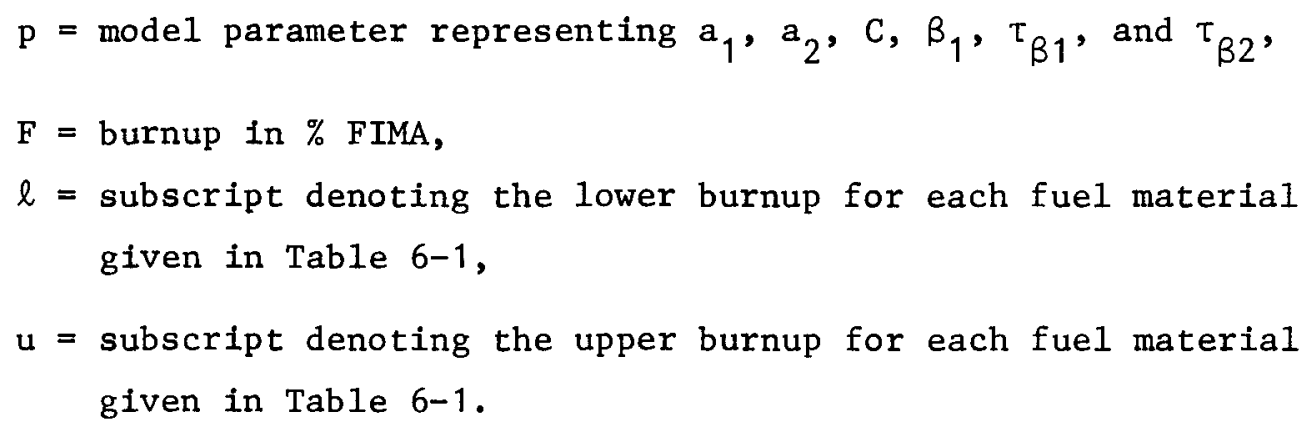

For the model parameter $s^{\circ}$, which is treated as nonlinear in burnup, the value of $\mathrm{s}^{0}$ is determined from the following relation:

$$
s^{o}=s_{0}^{o} F^{n}
$$

where $\quad S_{0}^{0}$ and $n$ are constants.

The data needed to determine the values of the model parameters at any burnup between 0 and $15.7 \%$ FIMA in $\mathrm{ThO}_{2}$ and between 0 and $74 \%$ FIMA in $\mathrm{UC}_{2}$ are given in Table 8-1. Data are given for the model parameters that are independent of burnup and linearly and nonlinearly dependent on burnup. For iodine and tellurium, the data given in Table 8-1 for xenon may be used with the exception that, for tellurium, the values $a_{1}=10, a_{2}=10$, and $\alpha_{2}=0$ should be used at all burnups in both $\mathrm{ThO}_{2}$ and $\mathrm{UC}_{2}$ (see Section 6.1.2).

The effect on fission product release of the pretest irradiation temperatures and fission rate densities to which the test particles were subjected could not be systematically examined with the limited number of experiments in this study. In the pretest irradiation (see Section 3), the test particles had generally experienced higher temperatures and fission rate densities than they would have experienced under normal operating conditions of the HTGR, with the exceptions that the mean irradiation temperatures for the $\mathrm{ThO}_{2}$ particles with $1.4 \%$ FIMA 
TABLE 8-1

RECOMMENDED VALUES OF THE MODEL PARAMETERS FOR APPLICATION TO CORE HEATUP EVENTS

\begin{tabular}{|c|c|c|c|c|}
\hline \multirow[b]{2}{*}{ Parameters (p) } & \multicolumn{2}{|c|}{$\mathrm{ThO}_{2}$} & \multicolumn{2}{|c|}{$\mathrm{UC}_{2}$} \\
\hline & $\mathrm{Xe}$ & $\mathrm{Kr}$ & $\mathrm{Xe}$ & $\mathrm{Kr}$ \\
\hline \multicolumn{3}{|c|}{ Independent of burnup } & \multicolumn{2}{|c|}{$\mathrm{p}=$ constant } \\
\hline $\begin{array}{l}\alpha_{2} \\
\beta_{2}^{2} \\
\sigma^{2}\end{array}$ & $\begin{array}{l}2.96(4)(a) \\
11.81 \\
3.44(4)\end{array}$ & $\begin{array}{l}2.91(4) \\
11.81 \\
4.08(4)\end{array}$ & $\begin{array}{l}5.59(4)(b) \\
10.3 \\
4.92(4)\end{array}$ & $\begin{array}{l}5.37(4) \\
10.3 \\
5.84(4)\end{array}$ \\
\hline
\end{tabular}

Linearly dependent on burnup

$\mathrm{p}=\mathrm{c}+\mathrm{dF}$

$\stackrel{\infty}{1}$

\begin{tabular}{|c|c|c|c|c|c|c|c|c|}
\hline & $c$ & $d$ & $c$ & $\mathrm{~d}$ & $\mathrm{c}$ & $\mathrm{d}$ & c & $\mathrm{d}$ \\
\hline $\begin{array}{l}a_{1} \\
a_{2} \\
c^{2} \\
\beta_{1} \\
\tau_{\beta 1} \\
\tau_{\beta 2}\end{array}$ & $\begin{array}{l}2.13 \\
3.33(5) \\
0.9968 \\
1.23 \\
4.68 \\
4.49\end{array}$ & $\begin{array}{l}0.403 \\
1.93(5) \\
-3.62(-3) \\
-2.10(-2) \\
7.13(-2) \\
1.26(-2)\end{array}$ & $\begin{array}{l}1.31 \\
5.02(5) \\
0.980 \\
1.56 \\
5.31 \\
4.58\end{array}$ & $\begin{array}{l}0.169 \\
3.94(4) \\
-2.52(-3) \\
-4.20(-2) \\
3.15(-2) \\
4.90(-3)\end{array}$ & $\begin{array}{l}0.403 \\
0.0 \\
0.99 \\
1.39 \\
6.00 \\
5.32\end{array}$ & $\begin{array}{l}5.56(-2) \\
1.84(10)^{(c)} \\
0.0 \\
-3.96(-3) \\
1.41(2) \\
1.19(-3)\end{array}$ & $\begin{array}{l}0.402 \\
6.15(10) \\
0.987 \\
1.46 \\
6.54 \\
5.38\end{array}$ & $\begin{array}{l}4.97(-2) \\
3.34(9)(c) \\
-1.0(-4) \\
-8.91(-3) \\
4.16(-2) \\
1.19(-3)\end{array}$ \\
\hline
\end{tabular}

Non-linearly dependent on burnup $\mathrm{s}^{\mathrm{o}}=\mathrm{s}_{\mathrm{o}}^{\mathrm{o}} \mathrm{F}^{\mathrm{n}}$

\begin{tabular}{c|c|c|c|c|c|c|c|c}
\hline \multirow{2}{*}{$\mathrm{s}^{\circ}$} & $\mathrm{s}_{\mathrm{o}}^{\mathrm{o}}$ & $\mathrm{n}$ & $\mathrm{s}_{\mathrm{o}}^{\mathrm{o}}$ & $\mathrm{n}$ & $\mathrm{s}_{\mathrm{o}}^{\mathrm{o}}$ & $\mathrm{n}$ & $\mathrm{s}_{\mathrm{o}}^{\mathrm{o}}$ & $\mathrm{n}$ \\
\cline { 2 - 8 } & $8.42(3)$ & 1.38 & $3.82(6)$ & 0.298 & $3.26(8)$ & 0.860 & $1.51(11)$ & 0.862 \\
\hline
\end{tabular}

(a) $2.96(4)=2.96 \times 10^{4}$.

(b) Average of values given in Table 6-1.

(c) The value of $a_{2}$ at $23.5 \%$ FIMA has been increased to avoid obtaining negative numbers with the recommended function for $\mathrm{p}$ (i.e., $\mathrm{a}_{2}$ ). 
and the $\mathrm{UC}_{2}$ particles with 23.5 and $74 \%$ FIMA were in the range of fuel temperatures found under normal operating conditions. As mentioned in Section 7.2.3.1, the effect of higher irradiation temperatures and fission rate densities is to reduce the surface area of the fuel material; this, in turn, would reduce the release of fission products as indicated by Eq. $7-18$.

Even though in the pretest irradiation the test particles experienced higher temperatures and fission rate densities than expected under normal operating conditions, the data and analysis of this study can be regarded as valid for application to core heatup events. This conclusion is based on the following considerations.

During the heating experiments in the present study, the test particles were subjected to high temperatures (higher than the pretest irradiation temperatures). This induced structura ${ }_{\perp}$ changes including reduction in surface area via sintering. As deduced in Section 7.4.1, these changes occur mainly within $1 \mathrm{~h}$. Consequently the structural changes induced in the heating experiments of the present study practically override the differences in structure, i.e., surface area, which the fuel material in the particles might have had at the beginning of the heating experiments as a result of pretest irradiation conditions different from those encountered under normal operating conditions of the HTGR for the same burnup.

The analysis presented in Section 7.2.3.2 on the activation energy associated with changes in surface area is also consistent with the absence of any persistent effect on surface area during the heating experiments attributable to pretest irradiation conditions. Thus, an independently derived value of the activation energy is in agreement with the activation energy deduced from the data of this study without any correction for the effects of pretest irradiation temperature or fission rate density. 


\section{REFERENCES}

8-1. "HTGR Fuels and Core Development Program, Quarterly Progress Report for the Period Ending February 28, 1977," ERDA Report GA-A14298, General Atomic Company, March 1977.

8-2. "HTGR Fuels and Core Development Program, Quarterly Progress Report for the Period Ending February 28, 1978," DOE Report GA-A14863, General Atomic Company, March 1978.

8-3. "HTGR Generic Technology Program: Fuels and Core Design and Development, Quarterly Progress Report for the Period Ending May 31, 1978," DOE Report GA-A14953, Genera1 Atomic Company, June 1978 . 


\section{SUMMARY}

A study was made to provide a description of the release of fission products from falled fuel particles during a core heatup event in an HTGR. The need for this study was established in the Accident Initiation and Progression Analysis program (Refs. 1-1, 1-2); the largest uncertainty in the core heatup event was found in the release rates of fission products from failed fuel particles.

The release of fission products was measured from laser-failed BISO $\mathrm{ThO}_{2}$, TRISO $\mathrm{UC}_{2}$, and WAR particles for a range of burnups. The burnups were $0.25,1.4$, and $15.7 \%$ FIMA for the $\mathrm{ThO}_{2}$ particles; 23.5 and $74 \%$ FIMA for $\mathrm{UC}_{2}$ particles; and 60\% FIMA for WAR particles.

Two types of experiments were performed: isothermal and temperature rise experiments. The range of the temperatures was from $1200^{\circ}$ to $2300^{\circ} \mathrm{C}$. In the temperature rise experiments, the gradients were between 50 and $450^{\circ} \mathrm{C} / \mathrm{h}$.

Release was monitored for the fission products important in the core heatup event; these included xenon, iodine, krypton, tellurium, and cesium nuclides. The particle inventory of the short-lived isotopes of the first four elements was generated by reirradiating the test particles.

The relative release behavior of xenon and fodine was determined in preliminary experiments. The fractional releases of xenon and iodine nuclides were found to be the same over the temperature range $1220^{\circ}$ to $2270^{\circ} \mathrm{C}$ for fractional release values from $5 \times 10^{-4}$ to near 1 
The time dependence of the fractional release in isothermal experiments was characteristic. The fractional release increased rapidly for the first hour of heating and then more slowly until the end of the experiment 3.5 to $7 \mathrm{~h}$ later. After about $1 \mathrm{~h}$, the fractional release was linear in time. The fractional release time profiles were characterized by three profile parameters representing (1) the magnitude of the initial rise, $f_{\beta}$, (2) the time to reach $80 \%$ of this magnitude, $\alpha^{-1}$, and (3) the slope of the linear portion, $S$.

The profile parameters had a strong temperature dependence: $f_{\beta}$ increased monotonically with temperature and $\alpha^{-1}$ and $S$ increased to maximum values at intermediate temperatures and declined at higher temperatures.

A characteristic profile was also observed in temperature rise experiments. At temperatures below $\mathrm{T}^{*}=1720^{\circ} \mathrm{C}$ in $\mathrm{ThO}_{2}$ and $\mathrm{T} *=1420^{\circ} \mathrm{C}$ In $\mathrm{UC}_{2}$, the rate of increase of the fractional release was small, whereas above $T^{*}$ it was large.

The isothermal experiments provided the basis for developing a release model and the temperature rise experiments provided a test for the model in describing the release in a core heatup event. The temperature rise experiments also enabled the model parameters to be determined at temperatures not sampled in the isothermal experiments.

The central feature of the release model developed here is the fractional release function which describes the release as a function of time and temperature. This function was formulated semiempirically but, for specific conditions, is practically identical to the fractional release function derivable from a diffusion equation with trapping terms.

The release model has three major features: (1) the fission product atom population for each nuclide is divided into a subpopulation which is rapidly released and one which is slowly but steadily released, 
(2) the rapidly released subpopulation is further divided into a large number of independent subsystems, and (3) as the temperature rises, the subsystems of (2) sequentially begin to migrate from their initial location in the fuel and the fractional release profile for each subsystem is unfolded in time. The profile parameters $f_{\beta}$ and $\alpha$ are associated with the rapidly released subpopulation and the parameter $S$ with the slowly released subpopulation.

Comparison of the predictions of the release model with the observed releases of fission products in the temperature rise experiments showed very good agreement. In the case of xenon and krypton nuclides, the predicted and observed releases differed by less than $18 \%$, which is less than the associated uncertainties. This agreement includes experiments of $5-$ and $24-\mathrm{h}$ duration.

In the case of lodine and tellurium, the predictions based on xenon profile parameters were not significantly different from observed releases except in two instances. For iodine, the release mechanism changes and becomes different from that for xenon at high burnup and temperature in $\mathrm{UC}_{2}$. For tellurium, the rate of transport of the rapid1y released subpopulation is apparently greater than that of xenon, at least in $\mathrm{ThO}_{2}$.

In the case of cesium, the predicted and observed releases differ by 1 ess than $15 \%$ for release from $\mathrm{ThO}_{2}$ with $1.4 \% \mathrm{FIMA}$; in all other cases, the release of cesium initially in the buffer obscured measurement of release from the kernel.

In the temperature rise experiments, the most important profile parameter was $f_{\beta}$. The contribution to the total release by the rapidly released subpopulation was greater than $90 \%$ at the end of the temperature rise experiments. 
A physical interpretation of the release model was made. This permitted an understanding of the dominant mechanisms governing release in a core heatup event. It also strengthened the credibility of the model by relating the parameters of the release model to physical events and to literature values of physical quantities commensurate with the parameter values.

The release of fission gas occurs predominately by migration of single gas atoms below $\mathrm{T}^{*}$ and most likely by migration of bubbles above $\mathrm{T}^{*}$.

The magnitude of $f_{B}$, the most important profile parameter, is a function of the properties of the fuel material and is independent of transport behavior. At temperatures below $T^{*}$, the important fuel properties were the density, the accessible surface area of the fuel, and the diffusion trapping length; the latter quantity squared is the mean square distance an atom migrates to reach a trap. At temperatures above $T^{*}$, the important fuel properties were not established, but traps remained important.

The profile parameter $\alpha$ is related to the speed of transport of fission product atoms in trap-free regions of the fuel and of bubbles.

The profile parameter $\mathrm{S}$ is related to the transport of fission products which are repeatedly trapped and released from traps.

Procedures for applying the experimental data and model to the calculation of fission product release during a core heatup event were presented. 


\section{ACKNOWLEDGMENTS}

The authors thank Anne Bagierek and D. W. Hill who measured the sample activities and were generous in their help with related problems, J. S. Greenwood and R. W. Tomlin who performed the test particle irradiations, D. J. Wakefleld who provided guidance in computer programming and contributed to the scrutiny of the early release models, W. E. Bell for his encouragement and continued interest and last, but not least, A. W. Barsell whose support and patience were vital to the achievements of this study. 
APPENDIX A

LIST OF SYMBOLS*

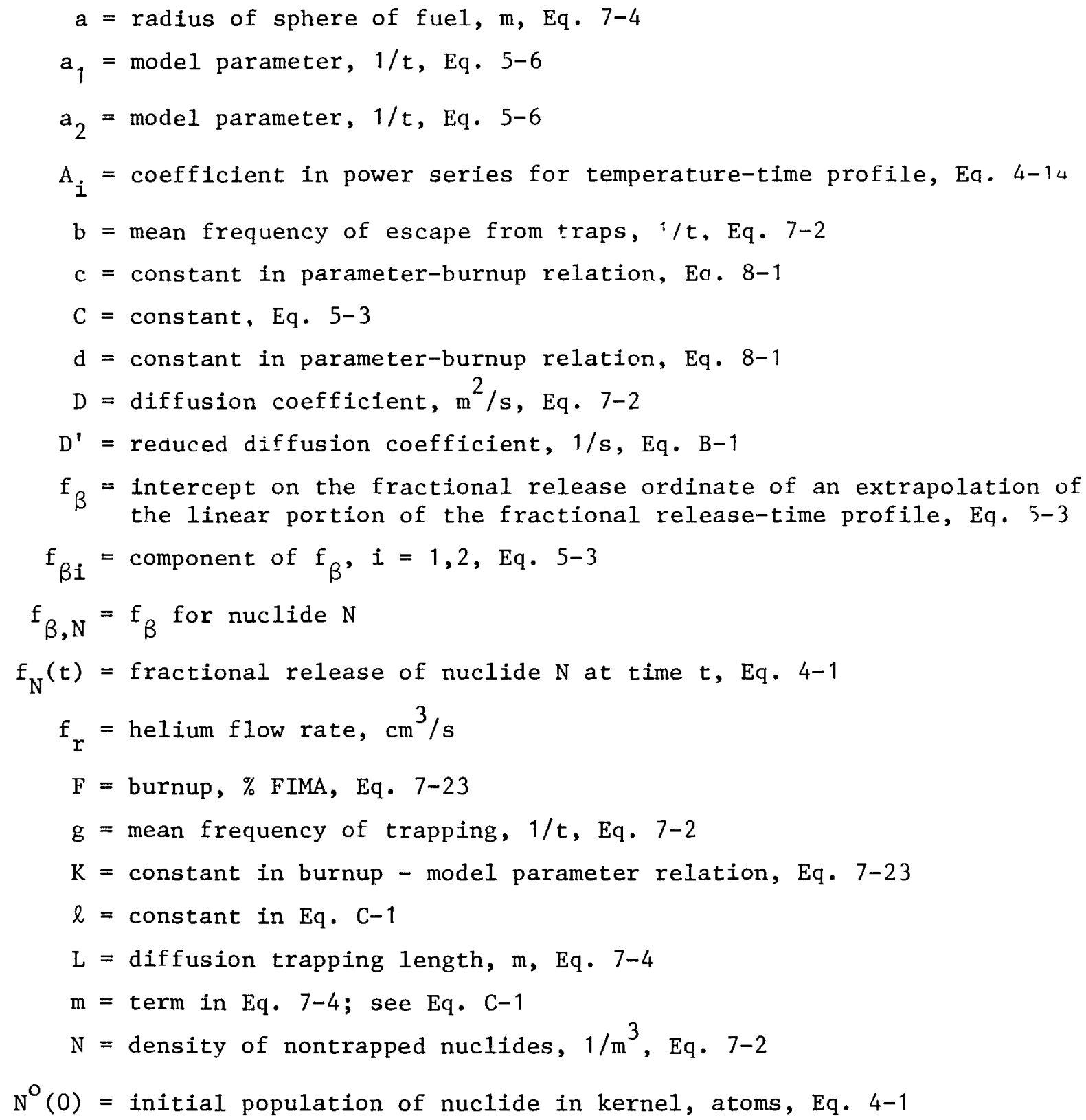

* Note that all units shown in figures are capitalized. 


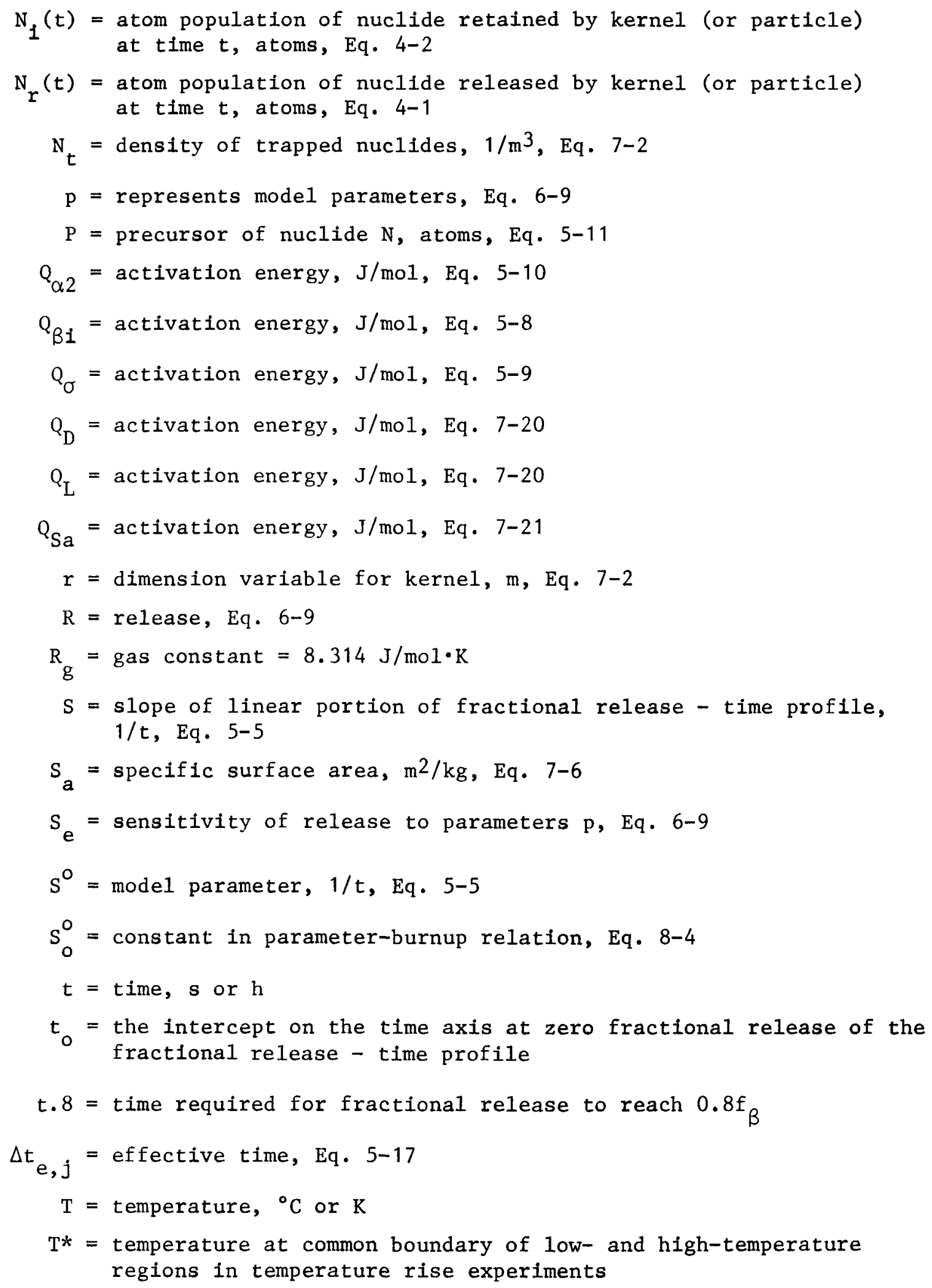




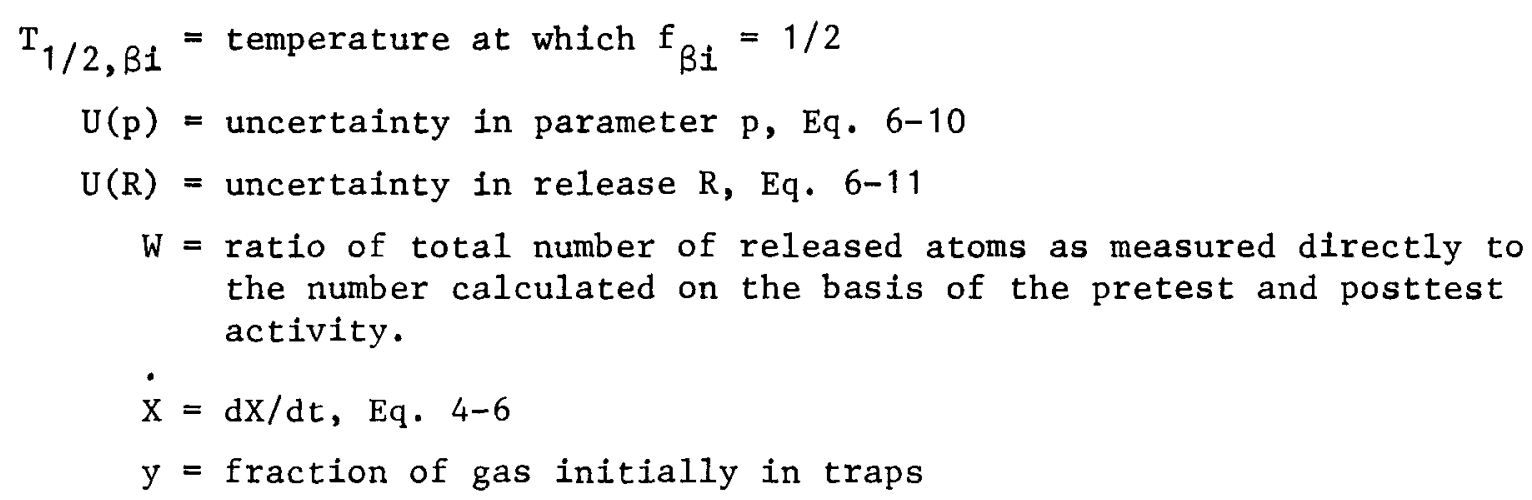
the number calculated on the basis of the pretest and posttest activity.

Greek leters

$$
\begin{aligned}
\alpha & =\text { reciprocal of profile parameter } t .8,1 / \mathrm{t}, \mathrm{Eq} \cdot 5-1 \\
\alpha\left(\mathrm{T}^{*}\right) & =\text { component of } \alpha \text { dominant above } \mathrm{T}^{*}, 1 / \mathrm{t}, \mathrm{Eq} \cdot 7-26 \\
\alpha_{2} & =\text { model parameter, } \mathrm{T}, \mathrm{Eq} \cdot 5-6 \\
\beta_{i} & =\text { model parameter, } \mathrm{T}, \mathrm{Eq} \cdot 5-4 \\
\delta_{i j} & =\text { Kronecker delta, Eq. } 4-4 \\
\lambda_{\mathrm{N}} & =\text { decay constant for nuclide } \mathrm{N}, 1 / \mathrm{t}, \mathrm{Eq} \cdot 4-1 \\
\rho & =\text { density of fuel material, } \mathrm{kg} / \mathrm{m}^{3}, \mathrm{Eq} \cdot 7-6 \\
\sigma & =\text { model parameter, } \mathrm{T}, \mathrm{Eq} \cdot 5-5 \\
\tau_{B i} & =\text { model parameter, } 104 / \mathrm{T}, \mathrm{Eq} \cdot 5-4
\end{aligned}
$$

Subscripts and superscripts

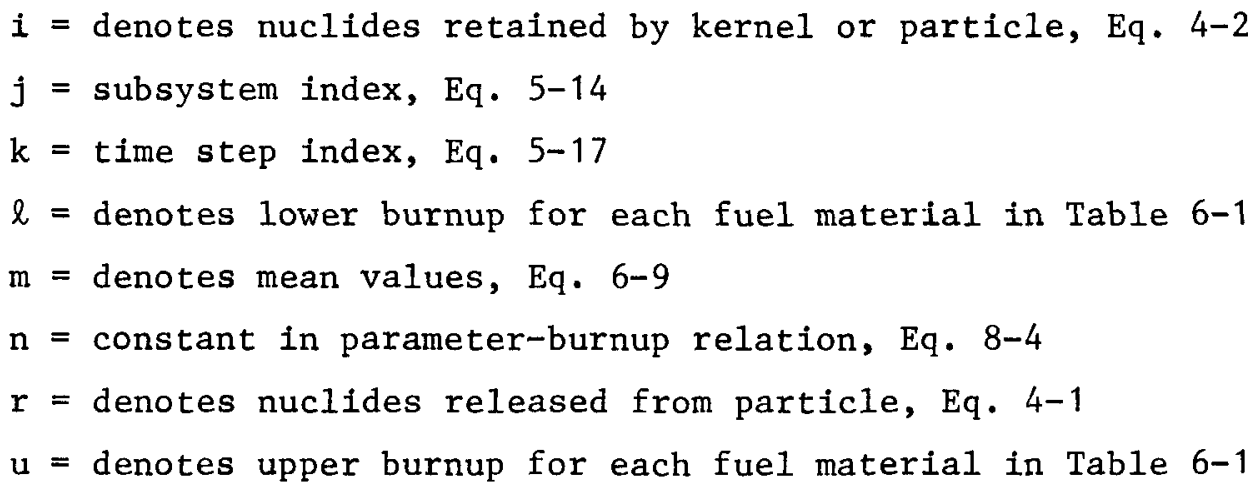




\section{APPENDIX B}

ESTIMATION OF THE FRACTIONAL RELEASE OF CESIUM FROM FUEL KERNELS DURING IRRADIATION UNDER REACTOR AND CAPSULE CONDITIONS

To interpret the cesium release data given in Tables 4-9 and 4-14, the Initial distribution of cesium between kernel and coatings must be known for the test particles. The distribution is a consequence of the irradiation history of the test particles and the long half-1ife of Cs-134 and Cs-137.

To determine the distribution, the reduced diffusion coefficient for cesium in the fuel materials must be known as a function of burnup and temperature. This diffusion coefficient is used to calculate the fractional transfer of ceslum from the fuel kernels into the coatings during irradiation.

B. 1. REDUCED DIFFUSION COEFFICIENT FOR CESIUM IN CARBIDE KERNELS

The available data on cesium diffusion in carbide kernels are given in Ref. B-1. The reduced diffusion coefficient derived from these data is given by

$$
D^{\prime}(1 / \mathrm{s}) \approx 5.4 \times 10^{-7} \mathrm{~F}^{6} \mathrm{e}^{-36200 / \mathrm{T}} \mathrm{e}^{ \pm(450 / \mathrm{T}+2.71)}, \quad \text { (B-1) }
$$

where $\mathrm{F}$ is \% FIMA and the exponential at the right gives the uncertainty limits.

To use Eq. B-1, an average value of $D^{\prime}$ is computed for the burnup profile appropriate to the Irradiation history of the test particles. These profiles are shown in Figs. $\mathrm{B}-1 \mathrm{a}$ and $\mathrm{B}-1 \mathrm{~b}$ for the $\mathrm{UC}_{2}$ particle 


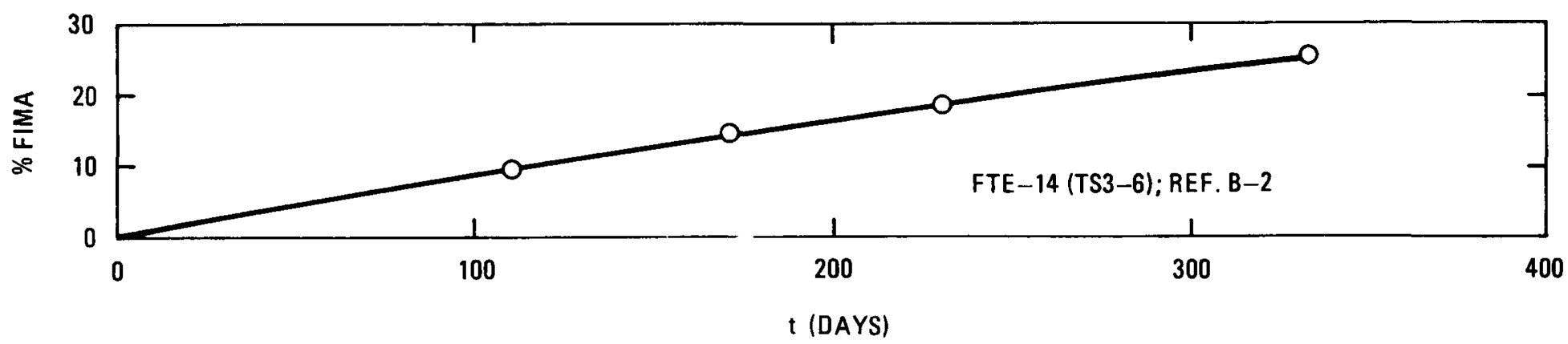

(a)

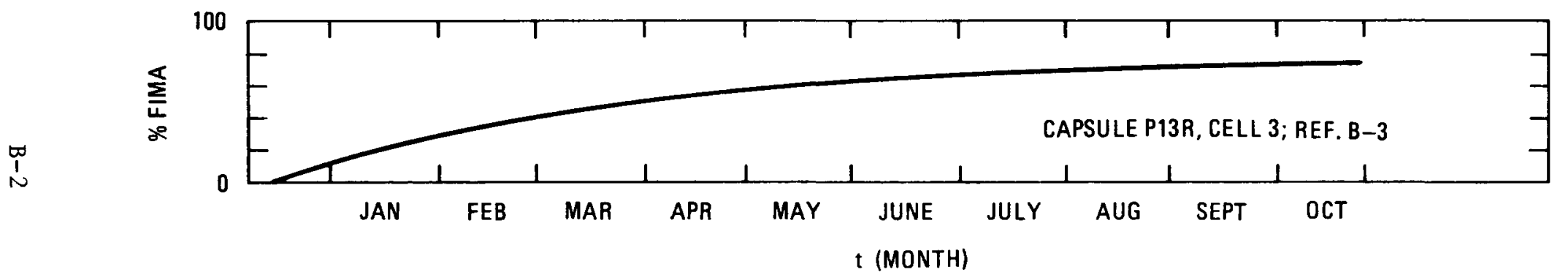

(b)

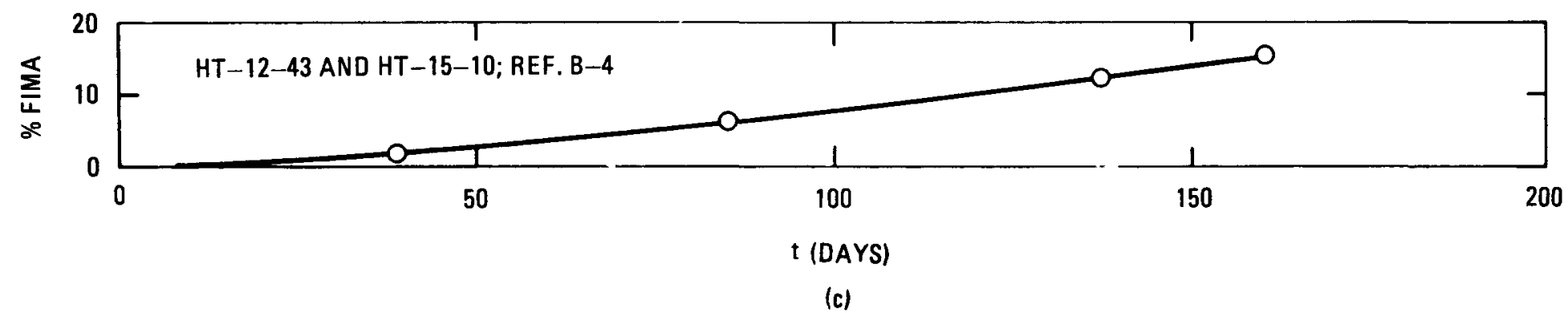

Fig. B-1. Time dependence of burnup in Peach Bottom (FTE-14) and capsules P13R, HT-12, and HT-15 
Irradiated in Peach Bottom (FTE-14) and in capsule P13R (see Table 3-1). The profile in Fig. B-1a can be treated as linear in time, while that in Fig. B-1b cannot. For a linear burnup profile, the average value of the reduced diffusion coefficient of Eq. B-1 is equal to $\mathrm{D}^{\prime / 7}$. For the P13R capsule burnup profile, the average value of the reduced diffusion coefficient will be greater than $D^{\prime} / 7$; however, as shown below, the actual value does not need to be known.

\section{B.2. REDUCED DIFFUSION COEFFICIENT FOR CESIUM IN OXIDE KERNELS}

There are three sources of data on cesium release from oxide kernels (Refs. B-1, B-4, B-5); unfortunately, these sources are not in agreement, generally. Therefore, in assessing cesium release from oxide kernels, the largest of the reduced diffusion coefficients derivable from these sources is used so as to be conservative in predicting the release.

The largest reduced diffusion coefficients were obtained from Ref. B-5 and are as follows:

$$
D^{\prime}(1 / s)=7.6 \times 10^{-7} \mathrm{e}^{-9360 / \mathrm{T}},
$$

which applies for burnups greater than 5\% FIMA and

$$
D^{\prime}(1 / s)=2.5 \times 10^{-11},
$$

at $1400^{\circ} \mathrm{C}$ for $2.5 \%$ FIMA. Equation $B-2$ was derived by dividing the reported (Ref. B-5) diffusion coefficient expression by $\mathrm{a}^{2}$, where $\mathrm{a}=2.5 \times 10^{-4} \mathrm{~m}$. Equation B-2 is used here without averaging for the burnup profile. Equation $\mathrm{B}-3$ was derived using $\mathrm{a}=2 \times 10^{-4} \mathrm{~m}$. In applying Eq. $\mathrm{B}-3$ to the temperatures and burnups of interest here, it was multiplied by $(1.4 / 2.5)^{4}$ $\exp [-9360(-1 / 1673+1 / T)](1 / 5)$. This factor (1) accounts for a burnup dependence of $\mathrm{F}^{4}$, which can be derived from the data of Ref. B-4, (2) assumes the same temperature dependence as given by Eq. B-2, and (3) treats the burnup profile, Fig. B-1c, as linear for the purpose of computing an average value of $D^{\prime}$. 
B.3. FRACTIONAL TRANSFER OF CESIUM FROM KERNEL TO COATING AS A RESULT OF REACTOR AND CAPSULE IRRADIATION

The fractional release of a fission product from the fuel kernel under Irradiation conditions is given (Ref. B-6) by

$$
f=4 \sqrt{D^{1} t / \pi},
$$

where $f$ is the fractional release. To account for the overall effect of burnup on release, $D^{\prime}$ in Eq. B-4 is replaced by the average values of $D^{\prime}$, as discussed in Sections B. 1 , and B. 2 .

The calculated values of the fractional release for the test particles are presented in Table B-1 along with the input data. These fractional releases represent the fraction of the cesium inventory transferred to the coating during irradiation in the reactor and capsules.

Only in the case of $\mathrm{ThO}_{2}$ at $1.4 \% \mathrm{FIMA}$ is the release of cesium from the kernel negligible during the irradiation in the capsule. For all other cases, the release is substantial. These data are used in Section 6 in interpreting the cesium release data of Tables 4-9 and 4-14 in terms of the release model developed in Section 5 .

The results in Table $B-1$ for capsule P13R show that the use of a larger, average reduced diffusion coefficient would have no effect as $f=1.0$ for the particles irradiated.

\section{REFERENCES}

B-1. Myers, B. F., and W. E. Bel1, "Cesium Transport Data in HTGR Systems," DOE Report GA-A13990, General Atomic Company, to be published.

B-2. Holzgraf, J. F., General Atomic Company, private communication. B-3. Scott, C. B., D. P. Harmon, and J. F. Holzgraf, "Postirradiation Examination of Capsules P13R and P13S," ERDA Report GA-A13827, General Atomic Company, October 8, 1976. 
TABLE B-1

CALCULATED FRACTIONAL RELEASE, $\mathrm{f}$, OF CESIUM FROM KERNELS DURING IRRADIATION OF PARTICLES IN REACTOR AND CAPSULES

\begin{tabular}{|c|c|c|c|c|c|c|}
\hline Test Particle & $\begin{array}{c}\text { Burnup } \\
\text { (\% FIMA) }\end{array}$ & $\begin{array}{l}\text { Irrad. } \\
\text { Time } \\
\text { (d) }\end{array}$ & $\begin{array}{l}\text { Irrad. } \\
\text { Temp } \\
\left({ }^{\circ} \mathrm{C}\right)\end{array}$ & $\begin{array}{c}\bar{D}^{\prime} \\
(1 / s)\end{array}$ & Eq. & $f$ \\
\hline HT- $12-43$ & 1.4 & 38.6 & $<1240$ & $2.7(-13)(a)$ & (b) & $<0.003$ \\
\hline HT- $15-10$ & 15.7 & 160 & $<1440$ & $3.2(-9)$ & B-2 & $<0.5$ \\
\hline $\begin{array}{l}\text { FTE-14 } \\
4161-01-030\end{array}$ & 23.5 & 316 & $\begin{array}{l}1095 \\
1208(c)\end{array}$ & $\begin{array}{l}5.2(-10) \\
3.0(-9)\end{array}$ & $\begin{array}{l}B-1 \\
B-1\end{array}$ & $\begin{array}{l}0.20 \\
0.54\end{array}$ \\
\hline $\begin{array}{l}P 13 R-3-4 \\
6151-00-035\end{array}$ & 74.0 & 285 & $\begin{array}{l}1015 \\
1075\end{array}$ & $\begin{array}{l}5.3(-8) \\
1.9(-7)\end{array}$ & $\begin{array}{l}\text { B-1 } \\
\text { B-1 }\end{array}$ & $\begin{array}{l}1.0^{(\mathrm{d})} \\
1.0^{(\mathrm{e})}\end{array}$ \\
\hline \multicolumn{7}{|c|}{$\begin{array}{l}\text { (a) } 2.7(-13)=2.7 \times 10^{-13} \text {. } \\
\text { (b) See text, Section } \mathrm{B} .2 .2 . \\
\text { (c) The mean temperature is } 1095^{\circ} \mathrm{C} \text { with an uncertainty of } 113^{\circ} \mathrm{C} \text {; the upper limit to the }\end{array}$} \\
\hline
\end{tabular}


B-4. Kania, M. J., et a1., "Irradiation Performance of HTGR Fertile Fuel in HFIR Target Capsules HT-12 Through HT-15: Part 1 Experiment Description and Fission Product Behavior," ERDA Report ORNL TM-5305, Oak Ridge National Laboratory, February 1977.

B-5. Stöver, D., and R. Hecker, "Cesium Release Data for BISO Coated Particles," Nucl. Technol. 35, 465 (1977).

B-6. Olander, D. R., "Fundamental Aspects of Nuclear Reactor Fuel Elements," ERDA Report TID-26711-P1, Apri1 1976, p. 206. 
APPENDIX C

MODIFICATION TO OLANDER'S SOLUTION OF THE DIFFUSION-TRAPPING EQUATION

Olander has obtained (Ref, C-1) an approximate solution to the diffusion-trapping equation, Eq. 7-4. This solution is appropriate for the heating experiments discussed in this report.

In obtaining his solution, Olander replaced the finite, upper limit to an integral (see Ref. C-1, footnote on $\mathrm{p} .309$ ) by infinity in order to evaluate the integral. This led to a value of $1 / 2$ for the factor $m$ in Eq. 7-4. The value $1 / 2$ overestimates the term generally and has the unfortunate consequence that as $t \rightarrow 0$, the fractional release, $f$, remains greater than zero (albeit sma11). A better approximation is made by replacing the $1 / 2$ term by

$$
\mathrm{m}=\frac{1}{2 \ell}\left(\frac{\ell+1}{1+\ell e^{-3.67 \sqrt{g t}}}-1\right),
$$

where $\ell=54.6$. This term has the limit 0 and $1 / 2$ as $t \rightarrow 0$ and $t \rightarrow \infty$, respectively, and for $g t>0.36$ gives the value of the integral in question (Ref. C-1, p. 309) with an error of less than $5 \%$.

REFERENCE

C-1. Olander, D. R., "Fundamental Aspects of Nuclear Reactor Fuel Elements," ERDA Report TID-26711-P1, April 1976, p. 206. 